\title{
El ordenamiento de precios y salarios de Juan II en 1442. Estudio histórico-diplomático
}

\author{
TOMÁS PUÑAL FERNÁNDEZ \\ Universidad de Extremadura
}

\section{RESUMEN}

El ordenamiento de precios y salarios promulgado por Juan II de Castilla en

1442 como consecuencia de una

petición de Cortes, supone un documento de primera mano para conocer con precisión la vida política y económica de la mitad del siglo XV.

Surgido a raíz de los avatares económicos, producidos por las sucesivas reformas monetarias encaminadas a contener la inflación de los precios, el análisis diplomático

e histórico de este documento nos proporciona, a veces indirectamente, datos tan valiosos como el ejercicio

del poder real en Castilla y el concepto de soberanía, junto al funcionamiento de las Cortes castellanas y su relación con la Corona. Del mismo modo gracias a este documento conocemos con precisión el modo de legislar en la Castilla bajomedieval, la aplicación de las leyes y de qué forma eran promulgadas. Junto a todo ello los aspectos económicos de la producción y la industria, el coste de la vida y los tipos de mercancías usuales en el comercio de la época.

Por tanto al hecho de haber sido,
ABSTRACT

The legislation about prices and wages promulgated by John /I of Castile in 1442, as a consequence of Parliament request, supposes a first - hand document to know accurately the economics and politics during the mid $x v$ century. This arose as a result of the economic effects caused by the successive monetary reforms implemented to control inflation; the historic and diplomatic analysis of this document gives, sometimes in an indirect way, valuable data about the exertion of the political power in Castile and the concept of sovereignty, as well as the functioning of the Castilian Parliament and its relationship with the Crown. At the same time and thanks to this document, we know accurately the legislative process during the late Middle-Ages in Castile, the entry into force of the law and the way it was enacted. It also includes the economic features of the production and the industry, the cost of living, and the most popular goods traded by that time. Therefore, in addition to the fact that this document has been practically unknown, the importance of 
hasta la fecha, un documento prácticamente desconocido, se une la importancia de su valor como fuente de historia política y económica, lo que supone una aportación más al conocimiento de la realidad castellana del siglo XV. En este caso el estudio paleográfico y diplomático aporta, al mismo tiempo, datos que pueden

ayudar a enriquecer los estudios sobre documentación real existentes,

al tiempo que ha permitido conocer con precisión la génesis del documento, tan compleja por habernos llegado el documento en forma de segunda copia, lo mismo que todo lo concerniente a la tradición diplomática por existir hasta tres versiones diferentes del mismo ordenamiento. its value has to be considered as a source of the politic and economic history, which implies an additional contribution to the Castilian situation during the xv century. In this case, the paleographic and diplomatic report provides, at the same time, data that could help to enrich the surveys about the existing actual documentation, as well as the obtention of a more precise knowledge about the document's origin, so complex to find, as it has arrived to us as a secund copy. The same situation happens about everything concerning the diplomatic tradition due to the existence of three different versions of the same legislation.

\section{INTRODUCCIÓN}

El presente estudio pretende dar a conocer uno de los documentos más importantes para la historia económica y hasta política, del reinado de Juan II de Castilla (1409-1452) ', en cuanto señala y reglamenta los precios y costes de determinados productos habituales en la mitad del siglo XV, cuya carestía provocada por una fuerte inflación, fruto de las reformas monetarias emprendidas, obligó a la intervención real, proporcionándonos de este modo una fuente, a la par histórica y diplomática, de primer orden.

El documento que analizamos es una segunda copia o traslado notarial, como se señala en el propio texto, de uno de los ordenamientos surgidos a raíz de la celebración de Cortes convocadas por Juan II en Valladolid en 1442. Sabemos que este reinado las sesiones de Cortes fueron bastante prolijas, en muchas de las cuales se trataron diversos asuntos de naturale-

\footnotetext{
1 La producción bibliográfica sobre el rey Juan Il de Castilla es bastante numerosa y de desigual interés, con todo se puede consultar a modo de sintesis la monografía de Porras Arboledas contenida en la colección "Reyes de Castilla y León» dedicada al estudio de los principales monarcas castellanos de la Edad Media; P. A. Porras Arboledas, Juan I/ (1406-1454), Corona de España, 10... I, Reyes de Castilla y León, Palencia, 1995.
} 
za económica, lo que indica la pujanza y dinamismo de dichas actividades en Castilla. En las de 1442, entre otros asuntos, aparecen algunos ordenamientos con este carácter, como el referido a la prohibición a los mercaderes extranjeros de comerciar exclusivamente con moneda de oro, ni sacarla de Castilla, debido a la desproporción entre el alto valor real, por los elevados precios de este metal, y el bajo valor nominal de la misma y su repercusión sobre el coste de la vida, así como sobre la necesidad de impulsar el comercio castellano potenciando las exportaciones frente a las importaciones $^{2}$, todo lo cual guarda alguna relación con la tasa de precios y salarios que comentamos ${ }^{3}$.

Es el Archivo de Villa de Madrid quien en la actualidad custodia este documento, que aparece sin signatura en la sección de Secretaría y al que se ha identificado como "cuaderno de las Cortes de Valladolid de 1442" en el catálogo sobre la documentación medieval de este archivo ${ }^{4}$. Con todo y para su más fácil localización, dicho documento aparece microfilmado junto a otros ordenamientos de Cortes y demás documentos reales del mismo periodo cronológico correspondiente a los reinados de Juan II y Enrique IV, entre 1403 y $1473^{5}$. Este hecho es lo que ha podido motivar, a nuestro entender , y justifica que haya permanecido inédito hasta hoy.

La importancia de este documento estriba en que, al parecer, es una de las pocas copias existentes de este ordenamiento. El texto de las Cortes de Valladolid de 1442 fue publicado por la Real Academia de la Historia, junto con el resto de las Cortes celebradas a lo largo de la Edad Media en un inmenso trabajo recopilatorio de varios años que dio lugar a la colección de las Cortes de León y Castilla publicadas en cuatro tomos ${ }^{6}$.

2 «... e aun acreçentar se han vuestros pechos e derechos por el comprar quelos dichos mercaderes estrangeros fizieren delas dichas mercadurias de vuestros rengos para llevar fuera dellos, e las penas que sobre ello vuestra alteza pusiere se derigan tanbien contra los vuestros subditos e naturales vezinos e moradores en vuestros regnos que compraren delos dichos mercaderes estrangeros commo contra los dichos estrangeros que troxieren las dichas mercadurias a vuestros rengos e las vendieren contra el tenor e forma de la dicha vuestra ordenança e ley..."; Cortes de Valladolid de 1442, petición n. ${ }^{9} 43$, "Cortes de los antiguos Reinos de León y Castilla", R.A.H., tomo III, Madrid, $1866,392-451,440$ y ss.

3 Sobre estudios referidos a ordenamientos de Cortes medievales se puede ver el trabajo de M. I. OSTOLAZA ELIZONDO, Teoría y práctica a través de los ordenamientos de Cortes castellano-leonesas; "Congreso sobre historia de las Cortes de Castilla y León", Valladolid, 1990, 301-312.

4 De este modo dicho documento se registra con el número 278 del catálogo y se dice erróneamente estar editado en las Cortes de Castilla y León, tomo III, que publica la Real Academia de la Historia. M. C. Cayetano Martín, La documentación medieval en el Archivo de Villa (1152-1474), Ayuntamiento de Madrid, Madrid, 1991, 119.

5 Archivo de Villa de Madrid, en adelante A.V., Secretaria, Documentos Reales (1403-1474), roIlo $777 / 90$, sin numeración.

6 Cortes de los antiguos Reinos de León y Castilla, Real Academia de la Historia, Madrid, 1863 1882 
Para realizar la edición de las de Valladolid de 1442 se utilizó el códice existente en la Biblioteca Nacional ${ }^{7}$ que es una copia moderna de alguno de los cuadernos que se expidieron de estas Cortes, cotejado con otros dos, uno el del Archivo de Simancas y otro el que se conservaba en la biblioteca de la colección Salazar y Castro, actualmente en la Academia de la Historia. Estos dos últimos se utilizaron para anotar las posibles variantes con respecto al códice de la Biblioteca Nacional. En ninguno de ellos se incluye el ordenamiento de precios y salarios, existiendo, hasta la fecha, tres versiones distintas del mismo documento debidas a una serie de modificaciones parciales: La primera sería el supuesto original que Liciniano Sáez reproduce en el apéndice documental $n .{ }^{\circ} X$ de su obra publicada en 1786 y cuya única edición hemos podido localizar en el Fondo Histórico de la biblioteca de la Universidad Complutense de Madrid 8 , y cuya localización no señala, faltando el protocolo, la notificación y parte del expositivo. Una segunda que es la copia de Madrid del siglo xv que analizamos, y una tercera modificación que aparece muy poco tiempo después de haberse producido la segunda, la cual nos ha llegado en forma de copia simple del siglo XVIII y se conserva en uno de los manuscritos de la Biblioteca Nacional, donde se dice estar sacada del archivo de la catedral de Córdoba, sin duda del documento que en su día fuera expedido a este concejo andaluz ${ }^{9}$.

Sabemos que tras finalizar la reunión de Cortes se entregaban de forma gratuita copias de los ordenamientos o actas llamadas cuadernos a los procuradores asistentes ${ }^{10}$ que éstos llevaban a sus respectivos municipios para ser presentadas en el concejo ante el que eran leidas públicamente en sesión extraordinaria para proceder a su cumplimiento, máxime tratándose de ordenamientos con fuerza de ley. Y no sólo dichas copias, sino que, a su vez, determinadas partes implicadas podian solicitar cuantos traslados estimasen conveniente. Todo ello justificaría la existencia en muchas villas y ciudades castellanas, como Madrid, de copias de estos ordenamientos de ámbito general y de obligado cumplimiento, que debían ser conocidos por

7 Se trata de tres manuscritos del siglo xvill cuyo título genérico es: "Ordenamientos y Cortes de los reyes Alfonso X y sucesores hasta Juan II, 1252-1447". Las Cortes de 1442 aparecen en el volumen 3. B.N. Manuscritos, Mss. 9912, v. 3, h. 57-101.

- Liciniano SÁEZ, Apéndice a la crónica nuevamente impresa del señor rey Don Juan el Il en que se da noticia de todas las monedas, de sus valores y del precio que tuvieron varios géneros en su reinado, Madrid, 1786, doc. X, 107-116.

9 Con el título de "Ordenamientos en tiempo de don Juan II, rey de Castilla", B.N., Manuscritos, Mss. 13.107, 180-192.

10 Así lo dice Piskorski, señalando que los procuradores de las ciudades se cuidaban de que 10 contenido en dichos cuadernos reprodujese exactamente lo que habian pedido; V. PISKORSKI, Las Cortes de Castilla en el periodo de tránsito de la Edad Media a la Moderna (1188-1520), traducción de C. Sánchez-Albornoz, ediciones El Albir, Barcelona, 1977, 97 y ss. 
todos y no sólo por los fieles concejiles encargados, en este caso, de aplicar las tasas que se recogen en el texto y velar por su cumplimiento. Este es uno de los motivos de la existencia de la copia madrileña, y posiblemente de otras aún inéditas en otros archivos municipales. Hasta la fecha lo más aproximado que conocemos es la que en su día publicara Torres Fontes referida al concejo de Murcia, con la salvedad de que este documento no es una copia del ordenamiento de 1442, sino una elaboración municipal de precios y salarios a raíz de lo contemplado en el mismo ordenamiento, en que el rey señala que los fieles de cada concejo podrán determinar los precios más convenibles para determinados productos ${ }^{11}$. La tasa de Murcia es, pues, una tasa local que deriva del propio ordenamiento de 1442, mientras que la de Madrid es la que con carácter general se aplicó a algunos artículos y mercancías concretos con fuerza y vigor de ley en toda la Corona de Castilla.

El ordenamiento de precios y salarios de 1442, representa un ejemplo diplomático e histórico importante que justifica plenamente su presente estudio y edición. Para la ciencia diplomática en cuanto indirectamente nos permite llevar a cabo el análisis pormenorizado de una tipología concreta de la diplomática real que son los ordenamientos de Cortes, de los que existen algunos, aunque escasos, estudios parciales, y que nos introducirá en muchos de los aspectos de la diplomática cancilleresca bajomedieval como preludio del surgimiento y afianzamiento de nuevas tipologías documentales de gran predicamento a lo largo de la Edad Moderna, pero que, sin embargo, hunden sus raíces en el medievo diplomático.

Por otro lado dicho ordenamiento constituye un documento histórico de primera categoria, al poner de manifiesto la dinámica económica de un periodo tan importante de la historia castellana de la mitad del siglo XV, tan complejo como convulso, pero al mismo tiempo tan lleno de matices y realidades económicas que son las que se manifiestan a través del presente documento. Desde los aspectos monetarios hasta los relacionados con la vida cotidiana, como los tipos de mercancías que se comercializaban y que nos informan de cómo vestían, calzaban, comían o se defendían los castellanos del momento, pasando por el coste de la vida y otros asuntos de carácter político, social e institucional derivados del mismo discurso diplomático. De este modo, una vez más, la diplomática justifica más que nunca su categoría de ciencia historiográfica y se pone al servicio del historiador como instrumento de análisis y conocimiento de la historia.

11 J. TORRES FONTES, "La vida en la ciudad de Murcia en 1442-1444. Precios y salarios", Anuario de historia económica y social 1 (1968), 691-714. 
En el presente trabajo comenzaremos estudiando los caracteres externos del documento resaltando aquellas novedades paleográficas más importantes en cuanto a la forma y manera en que dicho documento fue redactado y escrito. Este capítulo nos parece de capital importancia tanto por las similitudes como por las diferencias que pueda presentar con otros escritos contemporáneos, prestando particular atención a la morfología gráfica, en cuanto creemos que las letras, como signos dotados de significado, constituyen una manifestación más dentro de la plástica artística del lugar y el momento en que fueron ejecutados, amén de ser un claro exponente del sentimiento cultural de una época.

Especial atención dedicaremos a la génesis documental, bastante interesante por cuanto se trata de un traslado que referencia e inserta otras copias y documentos anteriores que también serán objeto de un cuidadoso análisis en cuanto a sus caracteres internos. El mismo interés reviste la tradición diplomática, por cuanto de las tres versiones que conservamos del ordenamiento, debemos establecer cuál pudo ser la primera y cuáles las modificaciones posteriores. Concluiremos la parte expositiva con una breve referencia histórica a este ordenamiento de 1442 y un estudio comparativo de precios de las tres versiones conservadas. Junto a ello un pequeño glosario de términos y definiciones muy útiles para comprender parte de lo contenido en el texto. Al final, y por el interés que ofrece, se insertará el apéndice documental con el contenido del ordenamiento de 1442, así como su modificación con el segundo ordenamiento que se produjo poco después, señalando las correspondientes normas de trascripción.

\section{CARACTERES EXTERNOS}

\subsection{Soporte y tintas}

Tanto la copia madrileña como el original y el primer traslado del ordenamiento de precios y salarios de 1442 se escribieron sobre papel, como se señala en el mismo texto en la fórmula de validación: "el qual va escripto en dies fojas de papel...". Aparte se dice que el primer traslado iba escrito en 8 hojas de papel del tamaño de medio pliego cada una, escritas por ambas caras y aunque no se señale, la copia madrileña está también escrita por ambas partes.

Se observa foliación original, bastante imperceptible, en caracteres romanos en el folio $2 \mathrm{v}$. en la parte inferior central, debajo de la rúbrica del escribano que cierra el texto, así como en los folios 3 v., 4 v. y 5 v., sin que aparezca en el resto. Todos los folios han sido numerados a mano y con lápiz 
con numeración arábiga actual en el borde superior derecho, sin que existan en el documento signos evidentes de otra numeración anterior, lo que indica que una parte de los folios estaba sin numerar y, que de los señalados con número, se numeraron originariamente sólo las vueltas. También se indica en el propio texto que cada hoja aparece rubricada con el correspondiente "signum" escribanil en la parte de abajo de cada plana, lo mismo que en el primer traslado se dice que los folios iban rayados con dicho signo en la parte superior y posterior.

El recurso al papel en este tipo de documentos privados bajomedievales, y aún en los de carácter público, fue frecuente en detrimento del pergamino que, a pesar de todo no deja de utilizarse en los documentos de mayor solemnidad. Aunque se trata de una copia notarial, como el primer traslado, el papel se utilizó también en el original, ya que sabemos que los propios cuadernos de Cortes se escribian sobre papel, a pesar de tratarse, en muchos casos, de leyes que, en principio, exigían una materia escriptoria digna. El papel tenía dicha consideración y como tal era comúnmente aceptado en toda la baja Edad Media para casi todos los documentos, tanto en su tradición original como en copia.

El papel que analizamos es de una gran calidad. De buena textura y resistente, algo áspero al tacto y nada amarillento, a pesar del paso del tiempo, denota su fabricación textil en molinos traperos, en consonancia con lo que conocemos sobre la artesanía del papel en este periodo ${ }^{12}$. Todavía son visibles las marcas de su fabricación o verjurado en el primitivo molde o cedazo en el que se realizaban las hojas de papel formado por un fino enrejado de alambre de latón sujeto a un marco de madera rectangular, dando lugar a los puntizones y corondeles que recorren los folios en forma longitudinal y transversal respectivamente, señal clara de la tela metálica del molde en que se dejaba secar la pasta de trapos que le daba origen ${ }^{13}$. Como en todo el papel de esta época, y según hemos podido comprobar en otros documentos contemporáneos, aparecen 6 puntizones longitudinales de los que el tercero, en la mitad del folio, se aprovecha para formar el eje de la filigrana o marca de agua, estando, por tanto, situada «in cuarto» dato importante para conocer la procedencia del papel, sin que existan contramarcas ${ }^{14}$.

12 Sobre este asunto y con un planteamiento bastante didáctico se puede consultar el trabajo de C. Crespo Nogueira, “El papel soporte grático desde la Edad Media a la época actual", El papel y las tintas en la transmisión de la información. Primeras Jornadas Archivísticas del 12 al 16 de mayo de 1992 en Palos de la Frontera, Huelva, 1994, 39-53, 42 y ss.

13 G. Gayoso Carreira, Historia del papel en España, tomo I, Lugo, 1994, 30.

14 P. L. LORENZO CADARSO, "Caracteres extrinsecos e intrinsecos del documento", Introducción a la paleografía y a la diplomática general, A. RIESCO, ed., Madrid, 1999, 257-284, 260 y ss. 
Al examinar las marcas de agua 15 observamos que a partir del folio 3 r. y en todos los folios impares, el 5 r., el 7 r. y el 9 r., aparecen, más visibles en unos que en otros por efecto de la escritura, dos círculos con un aspa en su interior unidos entre sí y perpendiculares a una línea longitudinal que, como hemos señalado, coincide con el tercer corondel. Se trata de la conocida marca del carro en un tipo de papel muy utilizado por la cancillería de Juan II, según hemos observado en documentos públicos y cuadernos de Cortes de la época. Esta marca fue identificada por Briquet en su repertorio de filigranas con el número $3.544^{16}$. Según este autor dicha marca generó una familia del mismo tema con ligeras variantes y fue muy utilizada en factorías italianas, estando su origen, según el mismo, en las papelerias de Fabbriano en un periodo cronológico amplio que abarca desde 1424 a $1470{ }^{17}$. Efectivamente hemos podido comprobar dicho dato en algunos estudios sobre filigranas de diversos archivos españoles tanto castellanos y catalanes como también europeos ${ }^{18}$. Oriol Valls asegura que el papel del carro procedente de Fabbriano, en la Marca Anconiana, compitió con el papel español debido a una mejora y perfeccionamiento de las técnicas de fabricación con respecto al papel que desde época musulmana se había hecho en Valencia, Cataluña o Al-andalus ${ }^{19}$. A este respecto el propio ordenamiento que analizamos, en el capítulo dedicado al papel, señala al papel del carro como el de mejor calidad y el más caro, estableciéndose su precio de venta en 125 maravedís la resma. Frente a ello los precios de otro tipo de papel, incluidos los de pro-

15 Se señala que hacia finales del siglo xilı tiene lugar la aparición de las filigranas del papel debido a un dibujo hecho en grueso hilo de latón soldado con plata que se sujetaba al molde de fabricación mediante un fino hilo de latón, generando de este modo diversas formas de animales, órganos humanos, objetos, círculos o cruces, entre otros; Ver GaYoso CARREIRA, op. cit, 30 y ss.

16 C. M. BRIQUET, Les filigranes. Dictionnaire historique de marques du papier (s. XII-XVIII), 4 vols., Leipzig, 1923 (Niseva York, 1960).

17 Cita S. Llonens ORouño, «Las filigranas en el Liber Testamentorum de Jaume Piles», Actas del II Congreso nacional de historia del papel en España, Cuenca, 1997, 301-305, 302.

18 Son varios los autores que han podido comprobar la existencia de la marca del carro en distintos documentos del siglo Xv. Ver LloREns ORDuño para Cataluña, op. cit., 302. También M. D. DiAZ DE MiRANDA y A. M. HERRERo, «Registro de filigranas anteriores a 1500 en los archivos y bibliotecas asturianos", Actas del // Congreso nacional de historia del papel en España, 171-231, 183. De las mismas autoras, “Papeles medievales del archivo municipal de Avilés", Actas del III Congreso nacional..., 57-79, donde además se señala como dicha filigrana aparece también en archivos europeos italianos, Iranceses, holandeses y belgas, lo que indica su amplia difusión desde Italia, siendo una marca utilizada por distíntos molinos papeleros de una misa zona cuyo papel luego se distribuía en un tipo de venta ambulante. Del mismo modo A. CHACON, "Papel filigranado en el archivo de la catedral de Cuenca", Actas del I/ Congreso Nacional..., 187-231, 199. Según este autor aparecen dos variantes de esta marca, el carro de dos y cuatro ruedas, encontrándose dicha filigrana también en Perpiñán, aparte de en otros archivos españoles como Vic, Villareal, Játiva, Murcia, Castellón, Tuy, Orense, La Coruña, Alcira, Sueca, Montalbán y Valencia, entre otros. Sobre el mismo tema ver, M. P. Cruz PASCAL, "Las filigranas del archivo de la catedral de Murcia», Actas del III Congreso nacional de historia del papel en España, Valencia, 1999, 185-194, 190.

19 O. VALLS I SUBIRÁ, La historia del papel en España (ss. XV-XVI), Madrid, 1980. 
ducción hispana como el llamado toledano y el de barbadillo 20 ofrecen precios más bajos, lo que indica las respectivas calidades ${ }^{21}$ y justifica el empleo del papel de importación por la canciliería real ${ }^{22}$.

Un aspecto a destacar es que el ordenamiento habla de papel ceutí del carro y extiende esta denominación al resto del papel de importación. Esta noticia es importante ya que demuestra la fabricación de dicho papel en Ceuta ${ }^{23}$, que en este periodo era colonia portuguesa tras su conquista por el rey Joao I. El enclave norteafricano era la vía de penetración de muchas mercancías en España, y también del papel, ya que en Ceuta se daban cita, aparte de los portugueses, mercaderes musulmanes, castellanos, aragoneses e italianos que comercializaban diversos productos que penetraban en Castilla desde los puertos del sur y se distribuían a través de las ferias, como la de Medina del Campo, a donde acudían dichos mercaderes ${ }^{24}$. Además en las descripciones de la Ceuta medieval se cita la existencia de 103 molinos, entre ellos batanes, aunque no se diga que podían ser también papeleros ni se mencione la elaboración ni venta de papel ${ }^{25}$.

Es posible que la Corona adquiriese partidas importantes de papel para la cancillería, así como algunos escribanos, aunque a este respecto hemos

20 Sobre el papel toledano de tradición musulmana aparecen las primeras referencias en torno a 1141. Un manuscrito del siglo xIX, recientemente publicado, considerado por sus editores como el primer manual español de diplomática, señala que el papel de Toledo era un papel grueso, moreno y mal molido, lustroso y muy cargado de cola, hasta el punto de verse en él los pedazos de lienzo y las hilachas sin triturar procedentes de su fabricación; J. C. GALENDE y M. L. PALACIO, «Apuntes de paleografía crítica (1860 a 1861)", Espacio, Tiempo y Forma, Historia Medieval, 11 (1998), 85-185, 112. En cuanto al papel de Barbadillo se señala que se pudiera tratar de una de las tres localidades próximas a Santo Domingo de Silos, Barbadillo del Mercado, Barbadillo del Pez o Barbadillo de Herreros donde habia molinos de papel; Gayoso CarreIra, op. cit., 20.

21 Ver apéndice documental $n .^{2} 1$.

22 Sobre la cancillería castellana en el siglo XV, ver M. S. MARTin Postigo, La cancillería castellana de los Reyes Católicos, Valladolid, 1959.

23 Se afirma en escritos del siglo XIX que el papel ceutí o cepti se fabricaba en Ceuta, o lo más en África, y que era muy terso, estaba muy bien molido y superaba en bondad al mejor papel de $\mathrm{Ho}$ landa; GaLende y PALACIO, op. cit., 112.

24 Se puede consultar la obra editada por S. CAVACIOCCHI, «Produzione e commercio della carta e del libro (SS. XIII-XVIII)", Istituto internazionale di storia economica F. Datini de Prato, serie II. Atti delle settimane di studi e altri convegui, 23, Firenze, 1992. Además ver el trabajo de B. CAUNEDO DEL POTRo, "Reflexiones en torno al comercio exterior castellano en las postrimerias de la Edad Media", La Península lbérica en la era de los descubrimientos (1391-1492). Actas de las III Jornadas hispanoportuguesas de historia medieval, tomo I, 393-420, 396.

25 En la Ceuta del siglo xv existían ciento tres molinos y el más importante de ellos era el que se encontraba en Masamiriyin, que era una vasta construcción con amplios patios y numerosos corredores con almacenes, naves y cámaras. Esta descripción junto con otras referidas a molinos batanes, alhóndigas, mercados y tiendas se puede ver en Al-Ansari, ljtisar al-Ajbar, traducción de $J$. VALLVÉ BERMEJO en "Descripción de Ceuta musulmana en el siglo XV», Al-Andalus, XXVII (1962), 398$442,428$. 
comprobado, y en lo que respecta a la documentación notarial madrileña representativa de la diplomática privada, que la filigrana del carro no aparece, estando sólo presente en los documentos de carácter público, lo que avala la idea de nuevo de un papel de buena calidad para uso básicamente oficial o de documentos de cierta relevancia o importancia, siempre y según el deseo de las partes o parte implicada.

El documento presentan en su conjunto una buena hechura y un aceptable estado de conservación ${ }^{26}$, siendo legible en casi toda su totalidad. No obstante presenta cierto desgaste en el borde superior derecho del primer y segundo folios, que señalan un uso continuado propio de un documento de estas características. Asi mismo los signos de pliegues que se observan indican que el documento estuvo doblado en cuatro partes. No existen signos de friabilidad, lo que ratifica de nuevo la buena calidad del papel, y aunque existen algunos elementos externos de deterioro, no dañan de manera considerable al documento. Lo más apreciable, en este sentido, sería el agujero de tamaño mediano que ocupa la parte central iriferior del último folio, lo cual afecta, aunque no demasiado, a la lectura de una parte de los renglones, concretamente el 17, 18 y 19 del folio recto y el 16, 17 y 18 del vuelto. En el primer caso parte de la data crónica referida al día de la semana, la mención al sistema de datación en la palabra "Ihesucristo", así como la expresión "mil", apareciendo perfectamente legibles el siglo, la década y el año, lo cual no ha impedido la datación genérica del cuaderno original de Cortes, aunque sí del dia, dato importante para establecer la tradición diplomática, como más tarde veremos. De igual forma sucede en el renglón 19 en lo referido al primer apellido del escribano, el cual hemos podido deducir por comparación con el cuaderno de Cortes editado por la Academia de la Historia, en el que aparece el mismo rogatario. En lo referente al folio vuelto falta alguna mención específica al cuaderno de ordenanzas originales del que se saca el traslado y la palabra "presencia» cuando se refiere a que los testigos asistieron a la génesis documental, pero que resulta perfectamente deducible por el contexto.

El resto de los deterioros se deben en su mayor parte a agentes biológicos. Pequeñas manchas oscuras en la parte superior del folio 2 v., una mancha mediana en la parte inferior del $4 \mathrm{r}$. y diversas manchas de reducido tamaño en el todo el conjunto del folio 10 , todas ellas provocadas por

26 Existe una abundante bibliogratía sobre causas y técnicas de degradación y conservación del papel, con todo se puede consultar el trabajo de Rabal i Merola con un planteamiento bastante didáctico; V. RABAL I MEROLA, "El papel artesanal: Historia, actualidad y características", Actas del II Congreso nacional..., 47-53, 52 y ss. 
hongos favorecidos por la humedad y la propia composición del papel. Se trata, en todo caso, de señales bastante habituales en este tipo de documentos medievales, más o menos visibles según haya sido su estado de conservación.

Más evidentes son los daños debidos a insectos, por lo menos en cuanto afectan de manera importante no sólo a la materia escriptoria, sino a la escritura. Aparecen algunas taladraduras y agujeros pequeños en los márgenes derecho e izquierdo del primer folio que afectan a parte de las letras de ambas caras. Del mismo modo sucede en el folio 2, así como en el 3 en su margen izquierdo. Se deduce que la taladradura del primer folio ha afectado a los siguientes, es decir el 2 y el 3 , debido a la acción continuada del insecto. Por último el folio 10 , que es uno de los más afectados, presenta, como se dijo, un gran agujero en el centro, que por sus características no se debe a ataque de insectos, así como otro más pequeño en su parte inferior.

En cuanto a posibles deterioros provocados por el papel y la tinta, se observan pequeñas manchas en forma de quemaduras diseminadas por casi todos los folios, sobretodo a partir del folio $6 \mathrm{r}$. y en todo el folio 10 , aunque la tinta está en buen estado, no produciendo demasiados traspasos, y como ya hemos señalado, no se observa friabilidad del papel.

Con respecto al elemento escriptorio, el documento nos informa que los signos del escribano que iban en cada hoja del primer traslado habian sido realizados con tinta: "van sennaladas de mi sennal de nonbre de partes de ayuso e de arriba rrayadas con tinta...", lo que nos hace pensar que sucedía con el resto del documento. En la copia madrileña, sin embargo, no se señala nada, pero es evidente el empleo igualmente de la tinta, la llamada metalo-gálica, habitual en este tipo de documentos bajomedievales. Esta tinta cuya composición y características han sido perfectamente estudiadas y puestas de manifiesto, se compone básicamente de un ácido, el llamado gálico y un óxido de metal, sulfato de hierro o cobre. Él ácido gálico se extraía de las agallas, ricas en tanino, galotanino, o bien del zumaque, sustancia curtiente habitualmente empleada por los curtidores para la elaboración de los cueros y por lo tanto muy comercializada 27. El sulfato de metal se mezclaba con el ácido gálico y por efecto de la oxidación se generaba una sustancia de color negro u oscuro a la que luego se añadía un aglutinante para espesar, la goma arábiga, y un disolvente como agua o vino que se encargaban de provocar los procesos y reaccio-

27 Un desarrollo más específico sobre esta cuestión se puede ver en mi trabajo; T. PUÑaL FERnÁndez, Los artesanos de Madrid en la Edad Media (1200-1474), Estudios de la UNED, Madrid, 2000. 
nes pertinentes que daban lugar a la tinta propiamente dicha, lista para su utilización ${ }^{28}$.

\subsection{Formato $y$ estructura}

El documento se presenta en forma de cuadernillo cosido con hilo trenzado de lino, a través de una solapa plegada a lo largo del borde izquierdo que consta de dos costuras en el anverso y tres en el reverso. Esta forma, según hemos podido comprobar, suele ser la usual en los cuadernos de Cortes del siglo xv. El formato es tipo folio, "fojas" dice el texto, con unas medidas de $240 \times 330 \mathrm{mms}$, escrito por ambas caras, como se ha señalado, y con los márgenes justificados, siendo las medidas de la caja de escritura bastante irregulares debido a la propia disposición del texto. La media rondaría entre $190-200 \times 260 \mathrm{mms}$. del primer folio y los $130 \times 260 \mathrm{mms}$. del segundo. Como en el margen derecho aparecen los números romanos que señalan los precios de los productos contenidos en el ordenamiento, las medidas abarcan casi todo el ancho del folio, por tanto entre 180 y 200 mms. El texto en sí oscila entre los 130 y los $140 \mathrm{mms}$., excepto algunos asientos más largos de entre 190 y $200 \mathrm{mms}$.

La media de renglones por folio es de unos 30 , siendo el máximo los 37 renglones del tolio 9 vuelto que se corresponde con la prolija relación de las cláusulas que acompañan al dispositivo textual, siendo uno de los más densos en escritura. Señalar a este respecto que no se observan a lo largo del documento señales de que los renglones hayan sido rayados mediante pautas.

El primer folio donde se hace la presentación del documento y se copia integramente el primer traslado sacado del cuaderno de Cortes presenta tres párrafos claramente diferenciados. A partir del segundo folio comienza la relación propiamente dicha de los precios de cada producto o mercancía con su correspondiente encabezamiento. Dicha relación está estructurada en pequeños párrafos o asientos generalmente de entre 3 y 4 renglones, siendo los más cortos de tan sólo un renglón y los más largos de no más de 8 , ofreciendo el documento un aspecto claro y nítido, con palabras y renglones bien separados. Cada párrafo se inicia con un calderón ortográfico en forma de «p», que en la mayoría de los casos, presenta un largo caido ver-

28 Todo el proceso de su elaboración basado en algunas fórmulas del siglo xv se puede seguir en Mut Calafell, quien transcribe una fórmula de preparación de la tinta hallada entre la documentación del notario valenciano Andreu Juliá en 1415 y que reproduce en el apéndice documental $n .^{\circ} 3$; A. Mut CALAFELL, “Fórmulas españolas de la tinta caligráfica negra de los siglos Xill a XIX y otras relacionadas con la tinta», Actas del II Congreso nacional..., 103-183. 
tical y cuyo último trazo, a veces, voltea hacia la izquierda el propio calderón para formar la letra inicial de la primera palabra, caso de la «l» y la «p». A su vez, cada asiento termina con una línea de justificación, aunque muchas veces, no en los casos de aquellos asientos de tan sólo un renglón, y el correspondiente calderón de cierre que delimita por la parte derecha cada asiento en forma de una especie de corchete o paréntesis.

Debido a este esquema textual, sólo el primer y los dos últimos folios presentan un aspecto más compacto debido a que no hay separación de párrafos. Cada relación o asiento de precios o de salarios lleva su mención expresa en números romanos que ocupan, como se dijo, la mayor parte del margen derecho. La relación se extiende hasta el folio 8 , comenzando entonces la parte final del documento que es la copia del primer traslado con sus correspondiente dispositivo, cláusulas y data para terminar con la mención a los escribanos que realizaron las dos copias y las consiguientes fórmulas de validación de las mismas. Cada folio se cierra, en cuanto a la caja de escritura, con un trazo o raya horizontal de la medida de la misma caja, de cuyo «ductus» forman parte la correspondiente rúbrica, que generalmente aparece situada en la parte central, otras veces a la derecha, y la señal del nombre del escribano. A este respecto se observa, aunque no siempre, una alternancia en la forma de las rúbricas, más simples en los folios rectos y más desarrolladas en los vueltos, lo que puede indicar una señal de validación final por folio y cuyo objetivo no era otro que evitar posibles falsificaciones.

Señalar que a lo largo de los folios aparecen unas anotaciones aclaratorias o glosas, a veces, simplemente titulativas, en el margen izquierdo en letra humanística-cortesana del siglo XVI ${ }^{29}$. Esto es bastante usual en los cuadernos de Cortes, sólo que en la mayoría de los que hemos examinado dichas glosas forman parte del mismo documento, sin haber sido añadidas más tarde. Generalmente hay una glosa por encabezamiento, aunque algunos párrafos tienen la suya. En el folio final , y dentro del margen inferior derecho, aparece una breve relación del documento con el mismo tipo de letra que las glosas y el número 112, pero escritos al revés, que se debe al registro que del documento se hiciera a posteriori.

En cuanto a su aspecto externo el documento presenta una factura muy simple y sencilla, en relación con la mayoría de los cuadernos de Cortes, no observándose signos especiales como letras capitales decoradas

29 Sobre la evolución de la letra humanistica con respecto al periodo bajomedieval es interesante el artículo de M. L. MandigorRa Llavata, "La escritura humanística en la Corona de Aragón. Sus orígenes y difusión social en el siglo XV", XIV Congresso di Storia della Corona d'Aragona, tomo IV, Sassari-Algüero, 1990, 222-237. También el artículo de J. C. GALENDE DíaZ, "La escritura humanística en la Europa del Renacimiento", Espacio, Tiempo y Forma. Historia Medieval, 11 (1998), 187. 
ni otros ornamentos. Sólo destacar como signo especial la aparición regular de llamadas en forma de manos que a lo largo del margen izquierdo señalan sólo aquellos asientos donde no se pone precio a los productos. Se trata de manos dibujadas con el mismo tipo de tinta que el resto del documento, y que en forma de puño destacan un largo dedo que apunta directamente al calderón ortográfico con que comienza el asiento. Aparecen 10 manos o llamadas a lo largo del texto de la siguiente forma: una en el folio $2 \mathrm{v}$., otra en el $3 \mathrm{r}$., tres en el folio $5 \mathrm{v}$., una en el $6 \mathrm{v}$., otra en el $7 \mathrm{v}$. y tres en el folio $8 \mathrm{v}$., las cuales hemos podido comprobar que están formadas, en su mayoría, por cuatro dedos, excepto la primera que tiene tres. De todos los dedos, el que apunta al asiento es el superior, cuya disposición nos indica que se trata de la mano derecha, la utilizada habitualmente para escribir. Hay que señalar que este recurso suele ser habitual en los cuadernos de Cortes.

\subsection{Morfología de la escritura}

El traslado madrileño de precios y salarios de 1442 fue elaborado por el escribano real y notario público Juan Sánchez de Sigüenza. La letra del documento es, pues, la letra de este escribano, quien literalmente dice: "saque e escrivi e lo conçerte...". Se trata, por tanto, de la letra de un profesional de la escritura que domina su ejecución, rápida y cursiva, asi como los elementos escrituarios de la época, nexos, enlaces y abreviaturas, junto a un perfecto dominio de las estructuras gramaticales y la ortografía. Esto significa que el modo de escribir no se aparta sustancialmente del de otros documentos contemporáneos tanto públicos como privados, por lo que el análisis paleográfico de este documento no aporta grandes novedades al conjunto de lo que sabemos y conocemos sobre la escritura castellana de los documentos del siglo XV. Por consiguiente no nos detendremos en un pormenorizado y exhaustivo análisis, salvo en lo concerniente a los ejemplos más significativos con el fin de marcar las similitudes o diferencias respecto a lo que sabemos en líneas generales sobre este tipo de escritura.

Se trata de una letra minúscula, reservándose sólo las mayúsculas para el comienzo del documento, en el encabezamiento e intitulación, sin que vuelvan a aparecer. Predomina la abundancia de astiles y caídos, con un alto grado de cursividad, de trazado rápido y muy angulosa y curvada en relación a los caracteres comunes de las escrituras góticas aparecidas en la península a comienzos del siglo xiI por evolución de la letra carolina. Con contrastes en el trazado, que afectan básicamente a astiles y caídos, así como a los trazos envolventes de algunas ligaduras, se puede hablar de es- 
critura con fuerte peso, con predominio de largos astiles inclinados hacia la izquierda de la caja de escritura.

Es también evidente la abundancia de ligaduras que unen letras y palabras por arriba, por abajo y volteando la letra de derecha a izquierda por encima de la caja de escritura, caso de "Dios". En cuanto a palabras ligadas son típicas la de artículo y nombre: «el+rey»: liga por arriba «l» y "r» y, sobre todo, las de preposición + artículo: «en+la», con el sistema de volteo superior de derecha a izquierda o «de+los» que liga simplemente por la parte superior. Al igual sucede con las preposiciones "que+por". También hemos encontrado casos de adjetivo y nombre: "exçelente+rey", ligadas al nivel de la misma caja de escritura. Los nexos se resumen en los habituales en esta escritura: "de+e» 0 «m+e».

Por la nomenclatura estamos ante la llamada y conocida comúnmente en los ámbitos paleográficos como letra cortesana (letra de la Corte) que en definitiva define una forma de escribir a partir de un determinado modelo de documentos reales ampliamente difundido en esta época tanto para documentos públicos como privados ${ }^{30}$. La cursividad y el propio ductus señalan que se trata de una cortesana muy cercana a la procesal. Predominan, pues, la plasticidad y el bello trazado, que hacen de este tipo de letra una auténtica manifestación de arte gráfico, pues las letras, sus nexos, ligaduras y abreviaturas en sí mismas constituyen un auténtico ornamento. El ductus gráfico responde, pues, a dicho modelo y presenta ligeras variantes que son las que comentaremos.

\section{VOCALES:}

A: En el documento aparecen los tres tipos más comunes de «a» cortesana: La "a" cóncava formada por dos curvas que se unen en la parte superior, la «a» llamada recta o triangular parecida a la actual y la de lineta. A ellas se añaden la "a» sobrepuesta como abreviatura en forma de sigma o la que en forma de bucle puede enlazar con la letra siguiente, caso de "qual»" o no, caso de «quaderno». Señalar que cualquiera de los tipos citados con anterioridad pueden aparecer en una misma palabra: «alguasiles» (prime-

30 Con relación a este tipo de letra se han planteado varias denominaciones, la de gótica cursiva redonda, y la comúnmente de cortesana, haciendo hincapié en el módulo cuadrangular, anguloso y quebrado de esta letra frente al módulo circular y menos anguloso de la llamada redonda que, al mismo tiempo, es de trazado más rápido. Sobre la primera ver M. J. SANZ FUENTES, "Paleografía en la Baja Edad Media castellana", Anuario de Estudios Medievales, 21 (1991), 528. En relación a la segunda, B. CASAdo QuintanizLA, Corona de Castilla: Documentos de la orden de Calatrava expedidos durante los tres últimos maestrazgos (1445-1489). Estudio diplomático, Madrid, 1997, 46 y ss. 
ra cóncava y segunda sigmática como abreviatura), «adelantados» (primera triangular y segunda de lineta) o «alcaydes» (primera cóncava y segunda de lineta), reservándose siempre la cóncava como letra inicial.

E: La «e» casi siempre se abrevia tanto a mitad como a final de algunas palabras. Aparece en todas las variantes de la cortesana, como un simple trazo vertical, a veces, casi imperceptible que une con la letra siguiente mediante trazo horizontal. En la conjunción «en» se escribe como trazo vertical aislado. También como trazo oblicuo enlazando con la letra posterior, caso de «es», o como una «a» mayúscula cóncava cuando es palabra inicial. Cuando actúa como simple conjunción "y» se utiliza la de tipo uncial.

I: Se escribe en sus dos formas más usuales. Como «i» latina uncial ejecutada mediante un pequeño trazo oblicuo o, a veces, vertical o frecuentemente con largo caído hacia la izquierda, casi paralelo a la caja de escritura en forma de doble trazo. En ocasiones, la misma «i» uncial hace también este trazo a la izquierda semejando una "y». Otra variante es la «i» que prolonga su último trazo hacia la izquierda envolviendo la palabra, pero sin unir con la palabra siguiente, caso de «mi».

O: Esta letra presenta una morfología muy sencilla y un trazado anguloso, pudiéndose escribir cerrada o ligeramente abierta por la parte superior, bien recta o inclinada a la derecha.

U: La «u» presenta una morfología simple, bien como uncial, bien como si fuese una " $\mathrm{V}$ ", unas veces abierta, otras cerrada, con largo ástil hacia la izquierda confundiéndose con la "V». Es la forma más abundante, sobre todo en palabras como «uno" o «un».

\section{CONSONANTES:}

B: Esta es una de las letras que presenta mayores variantes. Generalmente está formada por dos ojos o bucles y se curva hacia la derecha de forma que el ojo superior es el resultado del trazo precedente, pudiendo unirse con la letra siguiente bien por arriba o por abajo. Este ojo puede aparecer abierto o cerrado y, a veces, inclinado hacia la izquierda, incluso en una misma palabra, caso de "çebri». Cuando el ojo se cierra en muchos casos es para enlazar con la letra precedente, como en "çibdades", aunque no siempre se utiliza este nexo, apareciendo en ocasiones sin él. También el ojo inferior de la letra puede aparecer abierto o cerrado. Otra variante es la "b» con astil recto o vertical y ojo abierto o cerrado, generalmente usada con vocal "a» o "e" a las que puede o no unirse, caso de "Algarbe". En otros casos el ojo superior se cierra para enlazar con la vocal precedente, caso de la «a» de lineta o servir de signo de abreviatura. 
Cuando une con la letra siguiente por la parte inferior, lo hace, casi siempre, con «l», caso de "blancas", aunque no siempre, o con «r», caso de «brujas». También con las vocales como la "a» triangular, la "e" o la «i" como en "resçebida". Caso singular es el de "Cibdad Real» donde la "ç» puede unirse a la "b» por la parte superior o inferior, mientras que en otras ocasiones la «b» aparece con ojo superior cerrado y abierto abajo pero sin unirse con la "ç» por la parte superior sino atravesándola o cortándola formando, a veces, la «d».

Otra variante es la que no cierra ninguno de los dos ojos y no se une con la vocal siguiente. También la que une sus dos ojos para formar uno solo. En todos los casos hay que señalar que estas distintas variantes de la "b" pueden aparecer indistintamente en una misma palabra.

C: Presenta la forma habitual con trazado de abajo hacia arriba y siempre ligada a la letra siguiente por la parte superior. Cuando va con cedilla, ésta se representa o como un trazo corto aislado en la parte inferior de la caja de escritura o envolviendo de derecha a izquierda parte de la palabra por arriba.

D: Su trazado responde a una evolución de la uncial con ojo en la parte superior que prolonga para unir con la letra siguiente. Puede quedar abierta cuando el trazo inicial sirve de abreviación o enlazar desde el trazo anterior. Una «d" muy caracteristica y numerosa del documento que analizamos es la que presenta un largo astil inclinado hacia la izquierda que, en ocasiones, se usa como signo de abreviación. Aparece una «d" muy especial en la palabra "Medinaçeli» cuyo ojo se prolonga en un largo caído hacia la izquierda dibujando un doble trazo en forma de vientre. En este caso pensamos que se debe más a una peculiaridad del escribano que al propio ductus común de esta letra.

F: Presenta distintas formas de ejecución. Con trazo inicial vertical que termina en oblicuo y trazo horizontal que atraviesa la barra para unir con la letra siguiente o bien trazada de abajo a arriba en forma de doble bucle para unirse por la parte inferior a la letra siguiente. Una variante es la que presenta barra o trazo vertical atravesado por una especie de alfa, de modo que la letra queda abierta por arriba.

G: Esta letra presenta siempre un caído curvado hacia la izquierda, pudiéndose trazar con bucle abierto o cerrado, sobre todo cuando une con la vocal o palabra siguiente, aunque no siempre.

H: Se trata de una letra poco habitual, que aparece en palabras como «lohan", "lahen", "lhesucristo" o "dicho" y "dichas" y en todas ellas se traza de diferente manera. Siempre se traza de arriba abajo. Casi siempre duplicando el primer trazo como un astil que, en algunos casos, puede tener forma de vientre, y en otros no, ya que se prolonga el segundo trazo hacia la izquierda, pero envolviendo la palabra por arriba y 
cortando dicho astil a la altura de su curva. De las dos formas aparece en la palabra "lohan". Significativa es la "ch» del nombre "Machin" con primer trazo duplicado e inclinado hacia la derecha y segundo trazo también duplicado que se proionga en forma de vientre hacia la izquierda casi paralelo a la caja de escritura.

$\mathrm{J}$ : Es una letra que aparece poco y cuando lo hace en palabras como «Brujas", "juanes" o "ventaja" se realiza como largo trazo vertical que da lugar a un astil y un caído ligeramente inclinado a la izquierda o levemente arqueado en la parte superior, pudiendo o no ligar con la letra siguiente.

L: Puede enlazar tanto por arriba como por abajo. Cuando liga por arriba con la palabra anterior el bucle se cierra, cuando no, queda abierto. Se ejecuta con astil vertical, pudiendo éste ser más alargado y estrecho o más panzudo e inclinado hacia la derecha, actuando de signo abreviativo. A veces el bucle se prolonga en trazo horizontal hacia la izquierda.

M: Formada por tres pequeños trazos rectos en forma de vientre. Rara vez liga con la vocal siguiente. Una forma es la que los trazos no se unen por arriba, apareciendo como si se tratase de tres trazos verticales aislados o unidos los dos primeros y abierto el tercero o viceversa.

$\mathbf{N}$ : Con dos trazos en forma de vientre, se presenta cerrada por arriba, es decir con los trazos unidos, o abierta, sin unir o unidos por la parte inferior como si se tratase de una "u».

P: Su trazado obedece a dos bucles en forma de un 8 incinado. El inferior se traza hacia la izquierda, mientras el superior puede aparecer abierto o cerrado. Se traza de arriba a abajo, pudiendo ligar con el lazo envolvente de la "ç» precedente en que el mismo trazo sirve para ejecutar el bucle inferior, caso de "çapateros".

Q: Es una letra que casi siempre aparece con un bucle envolvente hacia la izquierda que la voltea para unirse, en algunos casos, por el mismo trazo a la siguiente, formando la abreviatura de "a" como en "quarenta". Con el resto de las vocales la letra también se prolonga en un trazo envolvente como en «que» o «qui».

R: Aparecen varias formas de esta letra. La más simple es la formada por un primer trazo vertical y un segundo horizontal que une con la letra siguiente. Al final de palabra se abre en forma de vientre y alarga el trazo horizontalmente hacia la derecha. También aparece la ur» formada por un trazo inicial duplicado en forma de vientre invertido y final oblicuo que se une a la letra siguiente mediante travesaño vertical, casi siempre en posición inicial y con sonido de doble «r». Un último tipo es la que aparece como simple apéndice de vocal curvado al final. En abreviatura se traza como un bucle sobrepuesto inclinado hacia la izquierda, caso de "doctor" o «corte".

S: Esta letra se traza siempre y sin excepción a lo largo de todo el documento en su forma sigmática. 
T: Aparece la de astil inclinado hacia la derecha y pequeño bucle a la izquierda que, a veces, queda reducido a un simple trazo apenas perceptible.

V: Esta letra es semejante a una "u" y como ella se escribe, caso de "cordovan». Una variante bastante utilizada es la de largo astil hacia la izquierda como en "vadana" o "valdres", confundiéndose con aquella "u» que se traza de la misma manera.

\subsection{Las abreviaturas y sus signos}

La letra gótico-cortesana presenta una gran variedad de abreviaturas ${ }^{31}$, básicamente en lo que respecta a determinadas letras entre las que destacan las consonantes "n" y "r" y casi todas las vocales, básicamente la "e», tanto a mitad como al final de determinadas palabras. En el documento sobre el que trabajamos son numerosos los ejemplos, apareciendo los dos tipos de abreviaturas más comunes, por contracción y suspensión, a las que se añaden las de sigla, letras sobrepuestas y lo que Casado Quintanilla denomina sistema abreviativo clásico o heredado, formado por palabras que han pasado al castellano directamente del latín y que abrevia con letra sobrepuesta la « $r »$ con el resto de las vocales, o bien cortan el astil inferior de la letra " $p$ " 32 . Conviene señalar que este tipo de abreviaturas del sistema clásico suelen ser abundantes .

Recordemos que las abreviaturas permitían al escribano o amanuense un ductus más rápido en las escrituras cursivas a lo que se podia añadir una cuestión de pura economía con el fin de ahorrar espacio y, por tanto, papel. La mayor parte de las abreviaturas se usaban como estereotipos que se repetían de manera casi mecánica, otro factor que también ayuda a explicar su repetición sistemática, sobre todo en textos largos. De gran utilidad puede ser el pequeño manual de Francisco Sevillano, que a pesar de su antigüedad, resulta enormemente didáctico para las abreviaturas más frecuentes y sus signos, así como siglas y nexos de la escritura del siglo $\mathrm{xV}^{33}$. En este sentido dicho autor recoge algunas de las abreviaturas que encontramos en el texto, tanto las referidas a nombres propios como comunes, muchas de las cuales proceden del latín ${ }^{34}$, lo que viene a indicar, de nuevo, un uso continuado de dichas abreviaturas desde época romana y, por tanto, una evolución continuada de la escritura a partir de algunos esquemas fijos.

31 Sobre abreviaturas se puede consultar, entre otros, el trabajo de J. LOPEZ DE TORO, Abreviaturas hispánicas, Madrid, 1957.

32 CASADO QUINTANILLA, op. cit., 59 y ss

33 F. SeVILlano Colom, Ensayo de un elenco de abreviaturas paleográficas medievales, Valencia, 1943.

34 Ver R. Álvarez de LA BRAÑa, Siglas y abreviaturas latinas con su significado por orden alfabético de un catálogo de las abreviaturas, León, 1884. 
Señalaremos a continuación qué palabras se abrevian y cuál es el tipo de abreviatura que se utiliza, de manera que pretendemos establecer una especie de somera relación de palabras abreviadas y sus características que puede ser muy útil en trabajos posteriores ${ }^{35}$.

\section{ABREVIATURAS POR CONTRACCIÓN:}

Nombres propios:

Burgos: Abrevia la «r».

Valladolid: Abrevia «adoli»

Gonçales: Abrevia la «n» y la vocal final

Pedro: Una " $p$ » con «o" sobrepuesta

Ihesucristo: $« i+h+x+p+0 »$

Nombres comunes:

Abreviatura de « $"$ » y de «r» precedida o seguida de vocal

Herradura: Abrevia en ocasiones la «r» final

Merçed: Abrevia «er» y la vocal final

Manera: Abrevia «er»

Presçio: Abrevia «re»

Marco: Abrevia «r»

Servillas: Abrevia "er"

Corte: Abrevia la «r»

Carta: Aparece la «C»+»t» con una «a» sobrepuesta en forma de sigma Pregonero: Abrevia "er"

Persona: Abrevia "er»

Partes: Abrevia la «r» y la vocal final

Terçias: Abrevia la "r»"

Parte: Abrevia la «r»

Mercadores: Abrevia «er» y la «e» final

Criado: Abrevia "ri"

Traslado: Abrevia «ra»

Cuaderno: Abrevia la «r»

\section{Otras abreviaturas}

Obispado: abrevia «is»

Florines: Abrevia la «e»

35 Sobre abreviaturas de sustantivos, verbos, adjetivos, adverbios y demás, se puede ver el trabajo de J. MATEu IBAAS, Braquigrafía de sumas, Barcelona, 1984. 
Sennorios: Abrevia una de las «enes» y la «i»

Pennas: Abrevia la «a»

Derecho: Abrevia la «e" y la «ec»

Dia: Abrevia la «i»

Tierras: Abrevia «ie»

Moneda: Abrevia "ed»

Jurisdiçion: Abrevia «is»

Testimonio: Abrevia «moni»

Nombre: Abrevia la «m»

Escribano: Abrevia casi toda la palabra, apareciendo $u e+s+c+v »$ con una "O» sobrepuesta

Alcaldes: Aparecen las siguientes letras, " $a+1+1+d+s »$

Notario: Se señalan " $n+0+t »$ con una «o» sobrepuesta

Maravedis: Están « $m+r+s$ ", o simplemente un punto con trazo horizontal encima

Verbos:

Sangrar: Abrevia la «n»

Meresçe: Abrevia la «e»

Consientan: Abrevia las dos «enes" $y$ "en»

Nombren: Abrevia la «m» y la «n»

Preposiciones:

Contra: Abrevia la «n» y la «r»

Para: abrevia «ar»

Adjetivos:

Ningunas: Abrevia "una"

Algunas: Abrevia "una"

Quinto: Abrevia «uin» y la vocal final

Primera: Abrevia «ri» y «er»

Buenas: Abrevia «en»

Pronombres:

Vuestros: Abrevia «uest»

Nuestro/a: Aparecen $« n+r+o / a »$

Adverbios:

Donde: Aparece simplemente con una "0" precedida de este signo ( Acostumbrada: Abrevia la «m»

Mostrada: Abrevia "ra" 
ABREVIATURAS POR SUSPENSIÓN:

Nombres propios:

Alfonso: Abrevia la «o» final

Machin: Abrevia la «n», aunque en otra ocasión no lo hace.

Cordova: Abrevia la vocal final

Nombres comunes:

Badana: Abrevia la "a» final

Cordovan: Abrevia la "n"

Plateros: Abrevia «eros"

Corte: Abrevia la «e»

Camara: Abrevia «ra»

Verbos:

Sangrar: Abrevia la «r» final

Fuere: Abrevia "ere»

Façer: abrevia "er»

Leer: Abrevia "er»

Saque: Abrevia "ue"

Escribi: Abrevia «cribi»

Conjunciones:

Non: Abrevia la «n» final

Nin: Abrevia la «n» final

Adjetivos:

Açemilar: Abrevia «ilar»

Preposiciones:

Contra: Abrevia «ra»

Adverbios:

Dentro: Abrevia «ro»

En cuanto a los signos de abreviación son también los comunes en este tipo de escritura, distinguiéndose entre generales y especiales. Entre los primeros suele ser frecuente que sean los mismos trazos de las letras como astiles cuando se inclinan hacia la izquierda de la caja de escritura o se prolongan en el trazo final hacia la izquierda, aunque no sean astiles. También el bucle sobre la palabra o el simple trazo horizontal u oblicuo son abundantes. Junto a todos ellos los especiales como la letra sobrepuesta que adop- 
ta diversas variantes, como tal se coloca sobre la palabra la vocal final de la misma. Otra manera es en forma de bucle que puede voltear la letra o palabra caso de la "r" con vocal o la "a" que es la letra que adopta más variedad de abreviaturas, sobrepuesta a la izquierda de la palabra en forma de bucle que puede aparecer, en ocasiones, aislado o en forma de sigma.

\section{LOS CUADERNOS DE CORTES EN EL SIGLOXV}

Esta tipología documental que debe su nombre al propio formato en el que se presenta, es especialmente abundante en el periodo a que nos referimos, pues las sesiones de Cortes ${ }^{36}$ fueron casi sistemáticas, especialmente a lo largo del reinado de Juan II, el cual prácticamente inaugura el siglo XV. Sólo en la década de los años cuarenta se celebran diversas reuniones, como las Cortes de Valladolid de 1440, de nuevo en Valladolid en 1442, vinculadas con el ordenamiento que estudiamos, las Cortes en el Real sobre Olmedo en 1445, etc.

La política convulsa y de constantes enfrentamientos, en una guerra casi endémica motivada por el enfrentamiento con los primos del rey, los infantes de Aragón ${ }^{37}$, que se disputaban el trono de Castilla y la toma de partido por parte de la nobleza hacia uno u otro bando, con la controvertida figura del condestable don Álvaro de Luna ${ }^{38}$ y el primogénito don Enrique, cuya postura basculó hacia un lado $u$ otro, según los intereses políticos, produjeron un clima de inestabilidad, que en muchas ocasiones se resolvía por vía de Cortes a las que Juan II recurria como forma de asegurarse el apoyo y la ayuda de las ciudades y villas castellanas. Un apoyo que no era ni mucho menos incondicional, en la medida en que los procuradores aprovecharon la débil situación política del monarca para sus reivindicaciones. Ambas partes salieron, pues, beneficiadas y ello generó en forma de cuadernos de Cortes una de las legislaciones más amplias de los reinados trastámaras.

El esquema de cada una de las peticiones que conforman los cuadernos es muy sencilla. Los procuradores solicitan del rey la resolución de algún asunto que puede ser de diversa índole y naturaleza y que puede

36 Se señala que la etimología de la palabra Cortes se debe a que estas sesiones o asambleas se reunian donde se hallaba el rey y su corte, que durante la Edad Media fue itinerante; E. DE TAPIA Ozcariz, Las Cortes de Castilla (1188-1833), Madrid, 1964, 10.

37 Ver la obra de E. Benito RuANo, Los infantes de Aragón, Pamplona, 1952.

38 Sobre este importante personaje político clave para entender el reinado de Juan Il se puede ver, I. PASTOR BODMER, Grandeza y tragedia de un valido. La muerte de don Álvaro de Luna, colección Marqués de Pontejos, 2, Caja Madrid, Madrid, 1992. También J. M. Calderón Ortega, Álvaro de Luna: Riqueza y poder en la Castilla del siglo xv, Madrid, 1998. 
afectar a los intereses generales del Reino o, en ocasiones, a los de la ciudad o villa que representan 39: "Me fueron dadas çiertas petiçiones por los dichos procuradores...". Estas peticiones podian de ser de varios tipos en cuanto a su contenido y aplicación. Las de carácter general para todo el ámbito de la Corona de Castilla y cuya aplicación era también general, las de contenido también general pero cuya aplicación era de ámbito local o territorial, y por último las de contenido y aplicación sólo local o personal referidas a municipios concretos o personas que se resolvian en forma de privilegios ${ }^{40}$. Las dos primeras cuando tenían fuerza de ley se manifestaban en forma de ordenamientos recogidos en el cuaderno original de Cortes cuya manifestación diplomática se hacía en forma de Provisión Real, y además en virtud de su ámbito de aplicación, se prestaban a sucesivos traslados o copias, tantos como el documento en cuestión y las circunstancias territoriales exigiesen ${ }^{41}$, en la medida en que se redactaba un cuaderno con el conjunto de los ordenamientos para cada una de las ciudades y villas castellanas con representación en Cortes, que no eran todas las de la Corona, sino sólo aquéllas de realengo ${ }^{42}$. A su vez dichas provisiones se tramitaban a través del Consejo Real: "con acuerdo de los de su Consejo...", por cuanto, como señala Salustiano de Dios, las Cortes se convirtieron en un apéndice del Consejo, a pesar de que la importancia de dicho organismo disminuía en función del aumento de influencia de las Cortes 43 . Parece evidente, sin embargo, que el Consejo Real se convirtió en esta época en un poderoso instrumento de la centralización regia, en vías a la construcción de lo que sería el Estado moderno ${ }^{44}$.

39 Sobre la representación de las ciudades castellanas en Cortes se puede consultar el trabajo de, C. Olivera Serrano, Las Cortes de Castilla y León y la crisis del Reino (1445-1474). El registro de Cortes, Burgos, 1986. También en cuanto al orden de intervención de los procuradores de las ciudades en las mismas y lo que ello significaba en cuanto a funciones de representación, la monografía de E. Benito RuANo, La prelación ciudadana. Las disputas por la precedencia entre las ciudades de la Corona de Castilla, Toledo, 1972.

40 Piskorski establece dos tipos de peticiones: generales y particulares, asi como las que atañian a los intereses de un determinado estamento social; PISKORSKI, op. cit., 98.

41 Resulta errónea la afirmación de que las respuestas eran dadas por los procuradores a las peticiones formuladas por el rey y que los cuadernos de Cortes se insertaban en una real cédula que servia de sanción de aquéllas; DE TAPIA OzCARIZ, op. cit., 22.

42 Se señalan 17 ciudades de realengo en el siglo $\mathrm{XV}$, debido a la política de enajenación de ciudades y territorios a favor de la nobleza, tanto laica como eclesiástica, practicada por los trastámaras desde Enrique II. Estas ciudades de señorío jurisdiccional eran representadas en Cortes por sus propios señores; PISKORSKI, op. cit., 41 y ss. También se puede consultar el trabajo de M. A. LADERO QUESADA, "Monarquía y ciudades de realengo en Castilla. Siglos XII a XV", Anuario de Estudios Medievales, 29 (1994), 719-774.

43 S. DE DIOs, El Consejo real de Castilla (1385-1522), Centro de estudios constitucionales, Madrid, 1982, 119 y ss. El mismo planteamiento en PISKORSKI, op. cit., 184.

44 J. M. MONSALVO ANTÓN, "Crisis del feudalismo y centralización monárquica castellana", Transiciones en la Antigüedad y feudalismo, Madrid, 1998, 139-167. 
Las peticiones podían presentarse desde el punto de vista diplomático con un encabezamiento que responde a una fórmula de cortesia o tratamiento regios que presenta, casi siempre, las mismas características, aunque con ligeras variantes. En el traslado que estudiamos, y por tanto en el cuaderno original del que es copia autentificada, se emplea la siguiente: "Muy alto e esclareçido prinçipe e muy poderoso rey e sennor». En la edición de las Cortes de Valladolid de 1442 aparecen fórmulas similares: "Muy alto e exçelente rrey e sennor". A estos adjetivos se añaden otros como "virtuoso" que no hacen sino indicar la definición que del poder regio se tenía en el siglo XV45. El monarca es "alto" porque se sitúa en la cúspide de la pirámide social, es "esclarecido" porque se le suponen una serie de virtudes que le distinguen del resto de la sociedad y por tanto es "virtuoso" y al mismo tiempo «excelente". Todo ello es la manifestación de la "virtus" que a fines de la Edad Media anuncia una de las características más importantes del humanismo.

A la fórmula de cortesía le sigue otra fórmula de reverencia y encomendación, expresada con un tono de cierta humildad, en que los procuradores simbólicamente besan las manos del rey y se encomiendan a su merced real: "Vuestros servidores los procuradores de las çibdades e villas de los vuestros regnos, besamos vuestras manos y nos encomendamos en vuestra merçed". Hay que decir que dicha fórmula aparece, aunque no siempre, al comienzo de la primera petición, continuando el resto con la simple expresión de "señor", “item" u "otrosy" El besamanos es la reminiscencia feudal del «ósculo» y manifiesta no sólo el sometimiento de los súbditos a su rey, sino el carácter paternalista del monarca como dispensador de auxilio y bienes a su pueblo. La merced regia que es sinónimo de gracia regia supone reconocimiento de soberanía y por tanto de poderío real.

Después de estas fórmulas tan significativas en cuanto a la definición real, le sigue una "expositio» que puede ser mas o menos extensa, según el asunto, en el que se suplica la toma de postura e intervención del soberano y que incluye la correspondiente súplica. El rey podía responder de diversas maneras, asintiendo en forma de dispositivo de mando: "asy mando e tengo por bien que se faga e guarde segunt que me lo suplicastes e pedistes por merçet», con lo que la súplica se convertía en ordenamiento. En otras ocasiones el rey contestaba con un futurible: "yo mandaré proveer sobre ello commo entienda que cumple a mi serviçio e a bien de mis rregnos". En muchas otras ocasiones se limitaba a reseñar alguna ley $u$ ordenamiento anteriores que hacian referencia al asunto, en ocasiones, insertando el propio ordenamiento.

45 Se puede consultar el trabajo de J. M. NIETo SoriA, Fundamentos ideológicos del poder real en Castilla (siglos xII-xvI), Madrid, 1988. 
El conjunto de las peticiones y sus correspondientes respuestas daban lugar al cuaderno de Cortes que desde el punto de vista de la tipología diplomática se expresaba en forma de Provisión Real, según hemos señalado. Recuérdese que esta tipología diplomática surgida en la baja Edad Media y que la cancillería trastámara utilizó tan frecuentemente, hunde sus raices en los mandatos plenomedievales, que a su vez resultan de la evolución de la documentación astur-leonesa, sólo que a partir del siglo Xl y más concretamente con el reinado de Alfonso X, el sabio, en la segunda mitad del siglo XIII, se van perfilando algunos de sus caracteres comunes que desembocarán en la provisión bajomedieval, a la que algunos autores dan ya el título de documentación moderna y cuya máxima manifestación será la pragmática ${ }^{46}$.

La estructura como tal de los cuadernos de Cortes presenta un protocolo con intitulación objetiva y solemne, con la expresión de todos los títulos del rey y dirección completa, seguida de la salutación real. El cuerpo del documento comienza con una amplia notificación en la que el rey señala la reunión de Cortes, el lugar y fecha de las mismas y los personajes que le acompañan, comenzando, en algunas ocasiones, por la familia real, esposa, hijos y demás parientes, junto a otras personas, tanto de la nobleza laica, como dignidades eclesiásticas, especialmente los miembros del Consejo Real que asesoraban al monarca como órgano consultivo, para finalizar con la mención, que no enumeración, de los procuradores reunidos en Cortes. El final de la notificación termina con el anuncio de las peticiones presentadas por los procuradores, dando paso así a una "expositio» con la enumeración pormenorizada de todas y cada una de las peticiones y respuestas, según el esquema antes mencionado. Termina esta parte con el dispositivo: "las quales dichas leyes suso por mi ordenadas... es mi merçet de mandar guardar e que sean guardadas de aqui adelante para siempre jamas...» seguidas de las respectivas cláusulas derogativas, preceptivas, prohibitivas y penales, aunque según el cuaderno de que se trate no siempre aparecen en este orden, estando siempre presentes las tres últimas, caso lógico si pensamos que toda provisión ordena, prohíbe ir en contra de lo ordenado y establece los mecanismos punitivos necesarios para su obligado cumplimiento.

4. Asi se manifiesta en diversos trabajos donde se señala que la provisión real es el documento por excelencia en la época moderna. De entre ellos destacamos, A. MILLARES CaRLO, «Breves consideraciones sobre la documentación real castellanoleonesa en pergamino entre los siglos xill y xV, Miscelánea de estudios dedicados al profesor Marín Ocete, Granada, 1974, vol. II, 739-774. También M. J. SANZ FUENTES, "Tipologia documental de la baja Edad Media castellana. Documentación real", Archivistica, estudios básicos, Sevilla, 1983, 239-256. En la misma línea A. TANODI, “Reales cédulas y provisiones", Revista del museo Mitre, 7 (1954). Como resumen de lo anterior manifiesta Garcia Oro que la provisión real es el documento por excelencia en la época moderna: J. GARCiA Oro, «Clasificación y tipología documental", Introducción a la paleografía y la diplomática general, A. RIESCO, ed., Madrid, 1999, 207-231. 
Concluye el cuaderno con un anuncio de validación en el que se expresa claramente la «iussio", para terminar con el escatocolo con mención a la data tópica y crónica mediante día, mes y año por el sistema de la Natividad, y la consiguiente validación del rey y del secretario o escribano regio que hizo escribir el cuaderno. También se señala que el documento o cuaderno al que se denomina "carta" ha sido registrado. Como en algunos casos estos cuadernos nos han llegado en forma de traslado notarial, desconocemos si era el rey quien rubricaba personalmente, ya que se ha llegado a plantear la hipótesis de si era la cancillería la que estampaba dicha firma en todos los documentos sin la intervención del rey, aunque en el proceso de validación documental se señala que eran los secretarios reales quienes pasaban el documento al rey para recabar su firma ${ }^{47}$. Lo único que sí parece cierto es que, en todo caso, existía algún tipo de intervención real en la rubricación del documento, siendo la rúbrica del escribano autógrafa.

\section{LA GÉNESIS DOCUMENTAL}

\subsection{La actio}

El ordenamiento de precios y salarios de 1442 , es un documento de carácter público con fuerza de ley que nos ha llegado en forma de traslado notarial. Este documento pertenece a la categoría, ya descrita, de ordenamientos generales de aplicación local, puesto que debían ser los fieles concejiles de cada ciudad y villa los encargados de la ejecución de su contenido, así como velar por su cumplimiento, estableciendo las sanciones oportunas, lo que exigia, en principio, un conocimiento y manejo del documento que, en forma de cuaderno de Cortes, habia sido llevado y presentado públicamente por los procuradores ante el concejo ${ }^{48}$. En este caso al dejar al libre albedrío de cada lugar la determinación de precios para algunos productos, su consulta en forma de arancel debia ser sistemática.

En principio pudiera pensarse que dicho ordenamiento sólo pudiese aplicarse a los municipios con mayor desarrollo industrial y comercial, coincidiendo con aquellos municipios de realengo con representación en Cortes ${ }^{49}$. Sin embargo el contenido del ordenamiento, aún a pesar de ser ex-

47 DE DIOS, op. cit., 431 y sS.

48 C. Olivera Serrano, «Las cortes de Castilla y el poder real (1431-1444)», En La España Medieval, 11 (1988), 223-260.

49 Aunque centrándose básicamente en la disputa entre las ciudades de Toledo y Burgos por la prelación en Cortes, el trabajo de Benito Ruano aporta algunos, aunque escasos datos, sobre la representación ciudadana en las Cortes castellanas; Benito RuANo, op. cit. 
pedido a éstos, iba dirigido a todas las ciudades, villas y lugares del Reino, según se señala en la dirección, no dejando lugar a dudas sobre su ámbito de aplicación general, debiendo tener en cuenta que algunas materias primas necesarias en el vestir $u$ otras mercancías se elaboraban y vendían, aún en los lugares más pequeños como villas y algunos concejos de aldea ${ }^{50}$, y generaban un artesanado de productos básicos, con lo que la tasa debía ser de aplicación efectiva en cualquier lugar.

Fijándonos ya en el proceso que dio principio a este ordenamiento, y a la hora de estudiarlo, debemos tener en cuenta una serie de premisas. Primero que al tratarse de una copia literal de otro traslado, que a su vez fue sacado del documento original, se distinguen varias génesis, o dicho de otra manera, el documento es susceptible de al menos tres análisis en cuanto a la génesis diplomática.

Si nos detenemos en el cuaderno original, como se indica en el mismo texto: "este es traslado de un traslado de un quaderno de ordenanças fecho por el rey nuestro sennor...", tendremos una primera génesis referida a dicho cuaderno. En la misma la "actio" aparece claramente explícita por cuanto se señala que el cuaderno de ordenanzas fue el resultado de una "petitio" previa: "a petiçion de los procuradores de las çibdades e villas e logares de los sus regnos...". Como todos los cuadernos elaborados en Cortes recoge las propuestas presentadas al rey por aquellos representantes de las ciudades y villas de la Corona de Castilla con derecho de asistencia y representación y a las que el rey accedía en forma de "placet».

Sin embargo ya hemos señalado como en la edición de las Cortes de Valladolid de 1442 no aparece mención alguna al ordenamiento de precios y salarios, aunque se hable de la moneda y de potenciar el comercio castellano frente a las importaciones, respondiendo el rey sobre la necesidad de hablar con los mercaderes y otras personas expertas para llegar a un acuerdo ${ }^{51}$. Esto se debe a que el ordenamiento de precios y salarios se publicó con anterioridad y, aunque el documento diga textualmente haber sido hecho a petición de los procuradores del Reino que estaban ayuntados con el rey, no debemos confundirnos

50 Sobre los concejos aldeanos en el siglo $x v$ hemos hecho alguna referencia al tratar las relaciones económicas que se establecen entre la villa de Madrid y las aldeas o lugares de su concejo, poniendo de manifiesto que dichas aldeas, aún dependiendo juridicamente de la villa, tenian su propio sistema de administración y abastecimiento económico con la existencia de los artesanos más básicos del sector textil, del cuero o de la metalurgia; T. PUÑAL FERNÁNDEZ, "Las relaciones villa y tierra en la estructuración del espacio económico madrileño", Orígenes históricos de la actual comunidad autónoma de Madrid. La organización social del espacio en la Edad Media, I, colección Laya, n. ${ }^{9}$ 14, Madrid, 1995, 205-218.

51 «En lo otro que dezides es mi merçet que se platique con mercaderes e otros omes que dello sepan por que se conozca lo que mas cumple a mi serviçio e se execute"; Cortes de Valladolid de 1442, op. cit., 441. 
y pensar que se trata de las Cortes de Valladolid de 1442, aunque el ordenamiento surgiese en el contexto político de las mismas 52 . El interés de lo que se trataba, así como su extensión y contenido exigieron una tramitación legislativa y documental propias. Para ello fue necesario que se convocase un ayuntamiento especial, aprovechando la presencia de los procuradores en Valladolid para la celebración de las Cortes, cuyo único objetivo sería el tratar este delicado asunto que afectaba a los intereses generales de todo el Reino.

Sabemos que la diferencia entre ayuntamientos y reuniones de Cortes era simplemente de matiz. En los ayuntamientos los procuradores se reunían para tratar cuestiones muy concretas, sobre todo de carácter económico y generaban una documentación similar a los cuadernos que, en muchos casos, no se ha conservado ${ }^{53}$. Nuestro ordenamiento pertenece, pues, a un ayuntamiento contemporáneo a las Cortes, pero con su misma estructura y significado, de ahí que en el encabezamiento se diga que se trata de un traslado de un cuaderno hecho en Valladolid a petición de los procuradores del Reino: "este es traslado de un traslado de un quaderno de ordenanças fecho por el rey nuestro sennor en la villa de Valladolid con acuerdo de los de su consejo a petición de los procuradores de las ciudades e villas e logares de los sus reinos...”54. Este ayuntamiento generó un cuaderno aparte con el ordenamiento de precios y salarios, aunque validado por el mismo escribano del cuaderno general de Cortes que se elaboraría después y que, a su vez, es el mismo que aparece en todos los cuadernos de Cortes de este periodo. Avala todavía más esta teoría el hecho de que tanto el cuaderno de las Cortes que publica la Academia de la Historia como el ordenamiento inserto en la copia madrileña van registrados, lo que de nuevo supone dos redacciones distintas y por tanto dos documentos.

El proceso de elaboración del cuaderno $u$ ordenamiento era largo y complejo y se iniciaba una vez presentada la correspondiente petición, pasando por una serie de fases administrativas, y por ende diplomáticas, que concluian con la publicación de dicho cuaderno. Este proceso era la llamada vía de expediente que se producía a instancias del rey y a través, por

52 Las Cortes de Valladolid de 1442 se datan, según la edición de la Academia de la Historia, el 30 de julio, basándose en un códice de la Biblioteca Nacional que no es mas que una copia del siglo xvIII; B. N., Manuscritos, Mss. 9.912, volumen III, h. 57-101. En la misma biblioteca existe otro manuscrito del XVIII que contiene una copia simple del cuaderno de estas Cortes que se conserva en el archivo de la catedral de Córdoba y que se data en la misma fecha; B. N., Manuscritos, Mss. 13.107.

53 De este modo se señala que Juan II convocó numerosos ayuntamientos que, en general, trataban sobre la concesión de los llamados servicios de Cortes para sutragar los gastos provocados por la guerra y cuyo resultado final quedaba reflejado en los otorgamientos cuando el monarca solicitaba dichos servicios y los procuradores los concedian. Ninguno de estos documentos aparece en las ediciones de Cortes de la Academia de la Historia; Olivera Serrano, op. cit., 198 y ss.

54 Ver apéndice documental $n .{ }^{9} 1$. 
tanto, de la Cámara. El procedimiento era el siguiente: Las peticiones, cuando procedían de los procuradores de las ciudades, como en este caso, eran redactadas por el escribano de los hechos de los procuradores y entregadas a los escribanos del Consejo, quienes, a su vez, las entregaban al relator, cuya función era la de elaborar un informe o memorial de las mismas y entregarlo al Consejo para su deliberación. Tomado el acuerdo oportuno, que en 1442 según las ordenanzas del Consejo aprobadas por Juan II, debía ser por las dos terceras partes, se procedia a su publicación en forma de ley y se expedía a través de una provisión, de cuya redacción y elaboración se encargaban los escribanos del Consejo bajo la supervisión del relator, que era el que validaba el documento y quien se encargaba, a su vez, de recabar la firma real como secretario regio, encargándose además de su registro y sello. Más adelante, al referirnos a la "conscriptio" señalaremos de qué manera todas estas funciones que acabamos de describir se centralizaron en una misma persona que actuaba, al mismo tiempo, como relator del Consejo, referendario y secretario real, actuando de puente entre las tres entidades que intervenian en el proceso, las Cortes, el Consejo y la Cámara. Un manuscrito que copia las leyes sobre el Consejo dictaminadas en Valladolid por Juan II en 1442 así lo refiere:

"Que los del Consejo manden llamar al relator y vean sobre que han de ver consejo ... e después desto el relator faga relaçion de la cosa sobre quien oviese de aver consejo. Que el relator faga relación de las peticiones commo vinieren.... 55 .

Sobre las funciones del Consejo Real en el siglo xv se ha destacado su importancia en el proceso de centralización política y acumulación de poder por el rey, puesto que el Consejo actúa siempre por delegación regia ${ }^{56}$. De hecho esta era su labor, la de asesorar y aconsejar al rey en materia de asuntos políticos, sociales o económicos que afectaran al Reino ${ }^{57}$. Ello evidencia aún con más justificación que en lo tocante al asunto y contenido del ordenamiento de precios y salarios el monarca no actuase solo, como tampoco lo hacía en todo lo concerniente a los demás asuntos, pues, a menudo, se olvida que la capacidad de legislar y, por tanto, de decidir, estaba sujeta, a menudo, a un consenso social.

Está claro que existió una "petitio" previa que dio vida diplomática al ordenamiento. Esta "petitio" manifiesta el poder legislativo de la Corona

55 B.N., Manuscritos, Mss. 10.627.

56 DE DIOS, op. cit., 228.

57 Parece ser que la función primordial del Consejo era la de publicar las leyes y hacer que se cumpliesen, además de interpretarlas y declararlas. Sin embargo entre sus competencias estaban también la preservación del orden público y la paz social, la regulación del valor de la moneda y medidas generales de fomento en el comercio, la agricultura y la ganaderia; DE DIOS, op. cit., 394 y ss. 
en la medida en que las peticiones encauzaban la potestad legislativa del rey. Era el monarca quien decidía que las peticiones se convirtiesen en ordenamientos, y que estos ordenamientos fuesen ley: "Quiero que tenga fuerça e vigor de ley..." y la fuerza de la ley se manifestaba a través de un tipo documental que era la Provisión Real ${ }^{58}$. El rey legisla, en este caso, a través de un ayuntamiento de procuradores que, como en las Cortes, actúan como sugeridores de su poder legislativo y tiene también el poder de ejecutar las leyes y hacerlas cumplir como símbolo de su poder polítiCO 59 . Sin embargo, debemos hacer ciertas aclaraciones al respecto. Bien es verdad que la "petitio" es presentada al rey por los procuradores del Reino, pero dicha petición obedece, a nuestro entender, al clamor popular de las ciudades y villas castellanas ante una situación de inflación económica motivada por la devaluación de la moneda y la carestía del oro y la plata, bases del sistema monetario 60 . En estas circunstancias los procuradores que acuden a las Cortes no hacen sino manifestar al rey las quejas de sus convecinos, con lo que en cierto modo su actuación ante el monarca se podría calificar históricamente como de una mediación que más tarde se manifiesta en la «petitio", por lo que diplomáticamente se habla de petición, cuyo origen está en una «intercessio» histórica ${ }^{61}$. De la misma forma podemos hablar también de una «interventio", ya que el mismo documento señala que el cuaderno de orcienanzas se hizo en Valladolid con acuerdo de los miembros del Consejo Real, es decir, la propia acción juridica de estas ordenanzas por su propia dinámica, tuvo que contar con el visto bueno de los consejeros.

La tecnicidad de lo que allí se trata junto a los aspectos de mercado en materia de ventas, mercancias y precios supone unos conocimientos económicos propios de expertos en la materia a los que el rey solicitó consulta. La última modificación parcial del ordenamiento que generó una nueva Provisión Real fechada en Madrigal en 1442, aclara suficientemente esta idea. El rey, al poco de promulgarse la tasa de precios y salarios, recibió las quejas de mercaderes y artesanos, tanto castellanos como

58 Tradicional es ya la obra de ARRIBAs ArRanz, La carta o provisión real.

59 Sobre esta cuestión se puede consultar el trabajo de Nieto Soria sobre la capacidad legislativa de Juan II en función de los ordenamientos de Cortes, basándose precisamente en el estudio del ordenamiento de Medina del Campo de 1433, donde pone de manifiesto la idea del pacto entre el rey y las ciudades a través de las Cortes y las aspiraciones absolutistas de la monarquía; J. M. NiETo SoRIA, Legislar y gobernar en la Corona de Castilla: El ordenamiento real de Medina del Campo de 1433, Madrid, 2000.

60 M. A. LADERO QueSADA, "La política monetaria en la Corona de Castilla (1369-1497)", En La España Medieval, 11 (1988), 79-123, 80 y ss.

61 Sobre el concepto durante el medievo de soberania legislativa por parte del pueblo mediante el principio de representación ver, W. ULLMANN, Principios de gobierno y política en la Edad Media, Madrid, 1985, 281 y ss 
foráneos, sobre ser muy bajos los precios estipulados en el ordenamiento para algunos paños y mercancías: "algunos mercaderes y oficiales $y$ otras personas, asi de Corte como de fuera de ella, se me quejaron diciendo que los precios tasados en dicha mi ordenanza eran bajos, según los precios a que ellos habian comprado y valian los dichos paños y otras mercaderias....»62. Ello significa una intervención de estos agentes, auténticos conocedores de la realidad económica castellana de su tiempo, en la elaboración del ordenamiento, aparte de saber que el propio Consejo Real se asesoraba por una comisión técnica a la que se consultaba sobre asuntos específicos que requiriesen de una información especial 63. Pero es que el propio rey en la misma provisión de Madrigal señala en la "expositio" como había recabado información de los mercaderes castellanos y extranjeros, así como de artesanos y otras personas, relativa al precio de determinadas mercancias, antes de proceder a la modificación del ordenamiento: "lo cual todo yo mandé ver y visto y habida información con algunos mercaderes, asi naturales de mis reinos, como extranjeros $y$ otras personas y oficiales de los oficios y menesteres que en esta mi ordenanza adelante se hizo mención...." 64 . A este respecto también conviene señalar que los contadores mayores que gestionaban la hacienda pública eran miembros del Consejo, aunque no residentes, por razón del título que el monarca les había conferido, pudiendo intervenir en dicho asunto 65 .

Más complejo es intentar dilucidar la génesis del primer traslado fechado el 23 de julio de 1442, y que se hace del cuaderno original, o por lo menos intentar saber quién o quiénes fueron los responsables de la "petitio". En principio no existe ninguna referencia explícita en dicha copia al autor jurídico que nos ayude a solucionar el problema. Tan sólo que el escribano encargado de hacerla es Juan González de Ciudad Real, escribano de Cámara del rey y su notario público, pero no existe anuncio de validación ni otra indicación concreta.

En principio todo apunta a que este primer traslado se relaciona directamente con la Cámara Regia y por lo tanto en su expedición, como en la de otros documentos semejantes, hubo intervención del rey. Ratifica nuestra afirmación la presencia de los testigos durante la "conscriptio": "Alfonso González de Alcalá, portero de Cámara del rey, Alvar González de Ciudad Real, escribano del rey y Juan de Montalvejo, criado, a su vez, de Juan González de Ciudad Real, el rogatario del documento. Todos ellos están

\footnotetext{
62 Ver apéndice documental n. $^{\circ} 2$.

6s DE Dios, op. cit., 423 y ss.

64 Ver apéndice documental $n .^{9} 2$.

65 DE Dios, op. cit., 255 y ss.
} 
vinculados, de una forma u otra, a la Cámara, de modo que intervienen el criado del rogatario, Alvar González de Ciudad Real, emparentado con el mismo, y que es a su vez escribano y un portero de Cámara. Todos ellos literalmente estuvieron presentes y vieron y oyeron leer y concertar la copia con el original y por tanto son testigos directos.

Aparte de esto, podemos sospechar a través de cierta intuición derivada del propio contexto documental, que el primer traslado o copia hubiese podido elaborarse a petición de los procuradores del propio concejo de Madrid, aunque sabemos que todos los procuradores recibían un ejemplar gratuito del cuaderno que llevaban a sus respectivos municipios. Desconocemos cuál pudo ser la razón de esta petición que se haría directamente por vía de Cámara, ya que generalmente los cuadernos de Cortes originales, como el resto de la legislación, se guardaban junto al rey, en la Cámara, debido al concepto de patrimonialización de la ley existente en la Edad Media. En efecto, el rey legisla y, por tanto, la ley le pertenece y es el responsable de su aplicación y custodia. De ahí que la mayor parte de estos cuadernos de leyes se hayan perdido, debido a que dicha documentación viajó con el soberano en la Corte itinerante hasta la creación en Castilla del primer proyecto de archivo regio muy a finales del siglo xv66.

Por otro lado, sabemos que los escribanos de Cámara solían actuar en el Consejo refrendando las cartas y provisiones en nombre del rey, existiendo el título de escribano de Cámara residente en el Consejo ${ }^{67}$. La intervención de la Cámara en este asunto podría deberse a que la «petitio» de los procuradores se hace directamente al rey y recordemos que, en principio, las peticiones dirigidas al soberano se hacían a través de la Cámara, la cual, según su naturaleza, las enviaba al organismo correspondiente para su consulta y posterior despacho. En este sentido Consejo y Cámara Regia formaban parte de un mismo engranaje en lo que respecta a determinados asuntos y en la expedición de algunos documentos como las provisiones que transmitían ordenamientos de Cortes en forma de ley 68 .

Pensamos que, sin embargo, Juan González de Ciudad Real no fue el autor material de la redacción, pues no hay nada que así lo indique, aunque vio, leyó y cotejó la copia con el original en presencia de los mencionados testigos que oyeron leer el documento. Esta testificación constituía una forma más de validación documental, por cuanto el notario dotado de la «fides» pública en nombre del rey autentifica el documento públicamente, es decir en presencia de los testigos que con ello ratifican su actuación.

66 R. CONDE Y DELGADo DE Molina, "Archivos y archiveros en la Edad Media peninsular", Historia de los archivos y de la archivística en España, coordinación de J. J. GENERELO y A. MORENO LOPEZ, Valladolid, 1998, 13-28, 14 y ss.

67 DE DiOs, op. cit., 228 y 314 y ss.

68 DE DIOS, op. cit., 423 y ss. 
La copia en cuestión que analizamos se fecha el 26 de julio, es decir 3 días más tarde de la primera y su autor material es el escribano regio y notario público Juan Sánchez de Sigüenza. Se trata, en principio, de un escribano real con jurisdicción en todo el Reino y sin ninguna adscripción concreta, para los que algún autor ha solicitado coloquialmente la denominación de vagabundos de la fe pública ${ }^{69}$. Decimos material porque en el mismo texto se expresa así: "saqué e escrivi e lo conçerté...». De nuevo la. presencia de testigos que estuvieron presentes y vieron y oyeron leer y concertar el traslado. Se trata de Machín de Tolosa, su criado llamado también Machín y Pedro González de Valladolid, lo que expresa una participación directa en la "conscriptio" documental y también que en presencia del notario y antes de su validación definitiva el traslado era leído, sin duda por el propio notario, en presencia de los testigos. Aparte de todo ello, la relación de testigos constata la existencia del acto al que confieren su asentimiento, aparte de ser una pieza importante de la validación del hecho jurídico documental, aunque no firmen el documento. Volvemos a insistir que la presencia física de los testigos que intervienen y consienten el acto conlleva un reforzamiento de la «fides" notarial en cuanto ésta es pública.

Es importante observar que mientras en el primer traslado no se señala nada sobre la manera en como los testigos fueron partícipes del acto documental, en la copia madrileña se dice que aparte de estar presentes fueron llamados y rogados lo que, a nuestro entender, puede aclarar ciertos aspectos de la génesis del documento, como la existencia de una previa "petitio" que pensamos pudo muy bien haber sido producida por la corporación o gremio textil madrileño ${ }^{70}$. Es más, tenemos identificado a uno de los testigos, Pedro González de Valladolid como uno de los maestros más significativos de esta industria. De profesión sastre tiene una intervención destacada en todo lo relacionado con su sector, y por tanto su presencia en la redacción de este ordenamiento está perfectamente justificada por cuanto la mayor parte de dicho documento se refiere a los precios de determinadas mercancias del sector textil: paños de lana, seda, brocados, lanas, fustanes, lienzos, picotes y xergas, así como a los salarios de tundidores $y$, sobre todo, sastres, con una pormenorización en cuanto a los

69 F. Arribas ARRANZ, “Los escribanos públicos en Castilla durante el siglo XV", Centenario de la ley del notariado, I: Estudios históricos, Madrid, 1964, 167-260. También la edición de P. Ostos SALCEDO y M. L. PARDO, “El notariado andaluz en el tránsito de la Edad Media a la Moderna", I Jornadas sobre el notariado en Andalucia, Sevilla, 1996.

70 Se ha discutido sobre la utilización del término corporación de oficio frente al de gremio, por ser esta última una acepción más aplicable a otras realidades económicas ajenas a la castellana: Con todo ver P. IRADIEL, "Corporaciones de oficio, acción politica y sociedad civil en Valencia", Actas de la XIX semana de estudios medievales en Estella: Cofradias, gremios, solidaridades en la Europa medieval, Pamplona, 1993, 253-284. 
tipos y clases de atuendos masculinos y femeninos, en una relación muy significativa sobre las prendas de vestir en el siglo xv. Todo ello justifica su presencia testifical y corrobora, a nuestro entender, las idea de una "petitio" solicitada en nombre de su sector, así como de los mercaderes locales con los que se relacionaba a través de un "verlagssistem" 71 que ha sido estudiado y puesto de manifiesto en nuestro trabajo sobre la industria medieval madrileña 72 .

Parece evidente que el sastre Pedro González de Valladolid acudiese en dicha representación en compañía del resto de los testigos, a los que no hemos podido identificar, pero que, sin duda, deben estar relacionados también con el sector, puesto que su intención era el disponer de un ejemplar del ordenamiento para su uso y aplicación en la villa y, aunque el gremio no tenía capacidad decisoria en materia de precios y salarios, sino es a través de estos ordenamientos regios o del propio concejo, resultaba muy útil conocer cuáles eran los artículos a los que se aplicaban determinadas tasas y de qué manera se debía proceder en determinados trabajos, no sólo en aras de un cumplimiento más exacto del ordenamiento, sino como forma de ponerse al día en cuestiones económicas que les afectaban directamente.

\subsection{La conscriptio}

En cuanto a la "conscriptio" del documento original señalar que existe una "iussio" dirigida al escribano encargado de la redacción y validación del cuaderno. Se trata del doctor Fernando Diaz de Toledo, oidor, referendario y secretario del rey quien lo escribió por su mandado. Hemos comprobado que este personaje aparece sistemáticamente validando todos los cuadernos de Cortes de la época, así como algunas provisiones, cédulas y cartas reales ${ }^{73}$. Las mismas denominaciones de oidor, referendario y secretario avalan su condición de funcionario al servicio de los intereses regios y su intervención como escribano responde a la centralización en una misma persona de las funciones que ya señalábamos al hablar de la "actio" del cuaderno original.

71 Término de origen norteeuropeo acuñado por P. Iradiel para definir un sistema de relaciones económicas referido a la industria y el comercio textil, basadas en la existencia de mercaderes que controlan todo el sistema de producción y comercialización de paños y otros productos textiles a través de los distintos artesanos, como tejedores, tundidores, sastres y demás, que participan en dicho sistema; P. IRADIEL, Evolución de la industria textil castellana en los siglos XIII al xvi, Salamanca, 1974,103 y ss.

72 Ver Pliñal Fernández, Los artesanos de Madrid..., 65 y ss.

73 Según hemos podido comprobar en la documentación real del Archivo de Villa al examinar dichos documentos desde 1430 en adelante; Cayetano Martín, op. cit. 
Sabemos que Fernando Díaz pertenecía al Consejo Real en su condición de doctor al ser una persona formada intelectualmente, generalmente en leyes, según la tendencia de Juan II de conceder el título de consejero a algunos miembros y funcionarios de la Corte, además de intentar que este organismo consultivo, básico en la administración política del Reino, se profesionalizase a través de expertos jurisconsultos ${ }^{74}$ al margen de la nobleza militar, poco experta en estas cuestiones, abandonando sistemáticamente el carácter de asamblea feudal que le había caracterizado ${ }^{75}$. Además ejercía el cargo de relator encargado de hacer relación, en forma de memorial o informe, de aquellos asuntos que el Consejo había de tratar por petición de las Cortes o de los procuradores del Reino. En realidad el relator actuaba también como referendario real, a la vez que secretario y oidor de las causas que llegaban directamente al monarca, lo que significa la vinculación personal al rey a través de la Cámara, despachando por esta vía todos los asuntos reales ${ }^{76}$. Su intervención en el Consejo explicaría la voluntad del rey de hacer notar su presencia en dicho organismo, aunque no debemos olvidar que el Consejo siempre actúa por delegación real, aunque tuviese capacidad para tratar determinados asuntos con la expedición de los correspondientes documentos que, en ocasiones, no llevan la firma real. En este caso el relator era el encargado de toda la producción documental generada por el Consejo, el cual por su estrecha vinculación con el rey y, en calidad de secretario, actuaba de mediador entre el Consejo y la Cámara y entre estos organismos y las Cortes, todos ellos manifestaciones diversas de un mismo poder real.

No se señalan en el traslado que analizamos otros aspectos de la «conscriptio» del cuaderno original cuyo «mundum» conocemos por el mismo traslado, ni se menciona "recognitio" alguna por tratarse de una copia, aunque tampoco suele ser habitual en los cuadernos de Cortes o procuración, siendo esta fase diplomática más propia de las copias realizadas sobre el original. En cuanto a la validación no hay mención al sello, aunque si al registro, según hemos comentado, permaneciendo sólo la referencia usual al anuncio de validación.

En cuanto al primer traslado, cabe añadir, además, una presencia de los testigos en la "conscriptio" por cuanto literalmente el notario "escribe» el traslado en presencia de los mismos. Debido a la presencia de un escribano

74 Existian básicamente dos tipos de consejeros, los honorificos por razón de su cargo o dignidad, es decir, la nobleza de sangre y título y los honorificos por razón de un título otorgado por el rey; DE DIOS, op. cit., 256 y ss.

75 Se pueden consultar sobre este asunto las reflexiones que en torno al mismo se hacen en el trabajo de J. M. MONSALVO ANTÓN, "Crisis del feudalismo y centralización monárquica castellana (observaciones acerca del origen del "estado moderno" y su causalidad)", Transiciones en la Antigüedad y feudalismo, edición de J. Trias y coordinación de C. ESTEPA y D. PLACIDO, Madrid, 1990, 139167.

76 DE DIOS, op. cit., 329. 
de Cámara, es posible que la «iussio» previa a la elaboración de la copia se debiese al mismo consejero y secretario real Fernando Díaz de Toledo quien, como hemos señalado, dirigía todo el proceso de la génesis documental y estaba en relación con la Cámara y, por tanto, con los escribanos de la misma.

El resultado final, como se indica en el documento, fue un cuadernillo formado por ocho folios de medio pliego cada uno y escrito por ambas caras, cada uno de los cuales iba señalado en la parte superior y posterior con el nombre y la rúbrica del escribano, asi como la validación final del mismo que firma con su nombre y signo. Estas precisiones iban encaminadas a evitar una posible falsedad documental como interpolaciones, correcciones y demás, máxime tratándose de un traslado y a su vez documento de naturaleza legal, no previstas en el negocio jurídico, de manera que el documento en cuestión aparecía perfectamente señalizado y descrito, lo cual constituye una forma más de validez diplomática. También se menciona textualmente la "recognitio" del texto que señala unas dieciocho correcciones entre palabras y frases, escritas sobre raido, cuyo autor sabemos que es el mismo escribano o amanuense. Nada se indica sobre la existencia de otras formas de validación jurídica.

En cuanto al segundo traslado se pueden hacer las mismas consideraciones que en el primero. Existe una "rogatio", propia de los documentos notariales, dirigida al escribano Juan Sánchez de Sigüenza, al que en principio no podemos relacionar con la Cámara Regia, ni por tanto con todo el proceso administrativo y documental descrito en la elaboración del cuaderno original. El traslado de Madrid es un documento privado hecho a petición de parte y por tanto escapa a algunos de los trámites diplomáticos de la documentación real. Existe, sin embargo, una "recognitio» claramente expresa en el texto, así como la "validatio" propia de la redacción del documento definitivo como una fase más de la "conscriptio» manifestada tanto en la rúbrica y señal del escribano ,que aparece en cada folio, como en el definitivo "signum" escribanil en forma de un doble cuadrado con doble aspa en su interior y rodeado de trazos búclicos, para cerrar de nuevo con la rúbrica. El resultado final es un documento en papel de diez folios con la debida validación, la cual le otorga su correspondiente carácter jurídico con plena validez de aplicación.

\section{LA TRADICIÓN DIPLOMÁTICA}

Ya señalábamos en la introducción como este ordenamiento de 1442 nos había llegado en forma de copia notarial ${ }^{77}$ y como el mismo no se re-

77 M. ROMERO TALLAFIGO, “La tradición documental. Originales y copias", Archivistica. Estudios básicos, Sevilla, 1981, 63-80. 
cogía en ninguno de los códices utilizados por la Academia de la Historia para la edición de las Cortes de Valladolid de 1442, puesto que este ordenamiento surge del contexto de dichas Cortes pero no se elabora en ellas. Conviene, pues, hacer ciertas reflexiones al respecto, algunas de las cuales ya se apuntaban en el capítulo anterior.

El traslado de Madrid se data el 26 de julio de 1442 y se dice que a su vez se trata de una copia de otro traslado anterior sacado del cuaderno original y fechado el 23 de julio del mismo año: «Este es traslado de un traslado de un quaderno de ordenanças fecho por el rey nuestro sennor en la villa de Valladolid...". Pensamos que ambos traslados se realizaron de un nuevo ordenamiento que modificaba, en parte, el primero surgido de la celebración del ayuntamiento de Valladolid, de ahí por tanto que se diga estar sacados del cuaderno original, de cuya data dudamos por hallarse ilegible en el documento donde se copia literalmente ${ }^{78}$.

El mismo ordenamiento que publica Liciniano Sáez en el apéndice $n .^{\circ} \mathrm{X}$ de su ya citada obra ${ }^{79}$ señala la data completa del ordenamiento: "Dada en la noble Villa de Valladolid, veinte é dos dias de Junio, anno del nascimiento de nuestro Salvador Jesuchristo de mill, é quatrocientos é quarenta é dos annos". Sin embargo al cotejar el contenido de esta edición con el original madrileño que conservamos en forma de copia contemporánea, observamos dos hechos que invitan a la reflexión: no coinciden ni la data ni parte del contenido de ambos documentos, advirtiendo no pocas discordancias, algunas de ellas por evidentes errores de trascripción, aunque en otros casos las diferencias de precios de determinados productos e incluso ligeras variaciones en la descripción del contenido, nos hicieron sospechar que se trataba de una versión del ordenamiento distinta de la madrileña.

Estos planteamientos nos conducen a la idea de que la edición de Liciniano Sáez constituye el primer ordenamiento emanado del ayuntamiento de Valladolid que, por la data del documento, debió celebrarse durante el mes de junio de 1442. Este ordenamiento debió encontrar serias dificultades en cuanto a su aplicación para determinados productos, ya que en su elaboración predominaron los factores monetarios sobre el resto, provocando el rechazo de mercaderes y artesanos. Estas dificultades provocaron, casi un mes después, una segunda redacción que no afectaba a todo el contenido del ordenamiento y que introducía solamente algunas reformas parciales referidas a determinadas mercancías. Esta segunda versión es la

78 Sobre datación y cronología se puede ver el trabajo de S. GARCia LARRAGUETA, La datación histórica, Pamplona, 1998.

79 Encabeza la publicación del ordenamiento como “Ordenanza Real en que se tasan las manufacturas de dentro y fuera del Reyno, año 1442"; Liciniano SAEz, Apéndice a la crónica nuevamente impresa del señor rey don Juan $11 . ., 107$ 
que aparece mencionada como cuaderno original en la copia que analizamos, datada el 24 de julio, y de la que se realizaron los dos traslados, fechados el primero el 23 de julio y el segundo el 26 del mismo mes.

La data de esta segunda redacción plantea no pocos interrogantes, pues en la glosa marginal realizada en letra humanística posterior figura el 24 de julio, fecha que no coincide con la data del primer traslado, el 23 de julio, ya que no parece lógico que el traslado se realizase antes que el original. En este caso parece lógico que nos debíamos guiar por la glosa, ya que, según señalábamos, un agujero de mediano tamaño afecta básicamente al día de la data, impidiendo parcialmente su lectura. Sin embargo, es perfectamente legible y se puede apreciar en el propio documento, la letra " $\mathrm{V}$ " de la primera palabra que expresa dicho día antes del agujero que dificulta la lectura del resto, observándose, así mismo, una "o» al final de dicho agujero antes de la palabra "dias", con lo que tendríamos "V" inicial de palabra + "o" final, lo cual parece coincidir con la glosa como día 24.

Ante este dato, sólo se nos ocurre pensar que, o bien pudo haber un error en la data por parte del escribano de la segunda versión del ordenamiento, o bien dicho error se debió al escribano del primer traslado, pareciendo más lógico que el original se fechara el 23 de julio y la copia el 24. En cualquier caso nada de esto invalida la autenticidad documental. Lo único cierto es que hacia finales del mes de julio del año 1442 un nuevo ordenamiento de precios y salarios había sido promulgado y estaba vigente, situación que, como hemos comentado, cambiaria de nuevo muy pronto, cuando ante las quejas de los mercaderes y artesanos, Juan II tuvo que rectificar el ordenamiento a través de una nueva provisión fechada en Madrigal en 1442 pero $\sin$ mes ni día, según nos ha llegado a través de copia simple en un manuscrito de la Biblioteca Nacional y que constituye la tercera y, que sepamos, última versión del ordenamiento ${ }^{80}$.

\section{CARACTERES INTERNOS}

\subsection{El protocolo documental}

La primera precisión a destacar es que nuestro documento carece de invocación por tratarse de la copia de un documento real. Sin embargo esta ausencia no se debe tanto a la misma tradición como a que en las Provisiones Reales

80 B.N., Manuscritos, Mss. 13.107, pp. 180-192. 
la invocación falta siempre ${ }^{81}$. La intitulación es la más solemne, como es habitual en esta tipología, y expresa el ejercicio del poder del autor de la "actio", en este caso el rey, a través de sus títulos y señoríos, comenzando con la expresión del nombre del soberano en forma simplemente nominativa, precedido de la fórmula de tratamiento o dignidad "Don», a la que acompaña la correspondiente de «Dei gratia» que no hace sino manifestar la expresión del concepto de soberanía real en la Edad Media ${ }^{82}$. Continua con la enumeración de todos y cada uno de los territorios y señoríos regios que conformaban la estructura administrativa de la Corona de Castilla hacia la mitad del siglo XV ${ }^{83}$. En este sentido la intitulación supone una fuente histórica de primer grado para conocer a fondo esta estructura y al mismo tiempo se convierte también en un signo evidente de veracidad documental ${ }^{84}$. Los reyes leoneses se convierten en reyes de Castilla a partir de 1035 con Fernando | ${ }^{85}$. Desde esta fecha la intitulación expresa el proceso de la llamada "reconquista» 86 de las "extremaduras", significadas en los Reinos de Taifas, primero la del Tajo y luego la del Guadalquivir, comenzando por la taifa de Toledo en $1085^{87}$ por Alfonso $\mathrm{Vl}{ }^{88}$ y continuando con los reinos de Jaén, Córdoba y Sevilla en el siglo XIII por Fernando III ${ }^{89}$, para culminar con la toma de Murcia y Algeciras por Alfonso $X^{90}$ y Alfonso $\mathrm{XI}^{91}$ respectivamente, éste último a comienzos del siglo XIV. Sin embargo hemos apreciado que no existe ninguna correlación cronológica en la enumeración titular

81 T. Marin Martinez y J. M. Ruiz Asencio (directores), Paleografia y diplomática, UNED, tomo 2 , Madrid: 1991, 327.

82 ULLMANN, op. cit., 121 y ss.

83 M. A. LADERO QUESADA, "Las regiones históricas y su articulación política en la Corona de Castilla durante la Baja Edad Media", En La España Medieval, 15 (1992), 213-234.

84 Ver el trabajo de F. MATEU Y LLOPIS, "Rex Navarrae". Notas sobre la intitulación real diplomática en el Reino de Navarra (diplomática, sigilográfica y monetal)", Spanische forschungen der görresgesellschaft, II (1955), 98-108.

85 Consultar la monografía de A. ViñAYo GonzÁlez, Fernando I, el Magno (1035-1065), Corona de España. Reyes de León y Castilla, Burgos, 1999.

86 Sobre el concepto historiográfico de Reconquista y su discusión, resulta básico el trabajo de A. Barbero y M. VIGIL, Sobre los orígenes sociales de la Reconquista, Barcelona, 1984.

87 Resulta de un enorme interés para conocerla estructura territorial y los concejos que formaron parte del antiguo Reino de Toledo el artículo de G. MARTINEZ DiEZ, "Estructura administrativa local en el naciente Reino de Toledo", Estudios sobre Alfonso VI y la reconquista de Toledo. Actas del II Congreso internacional de estudios mozárabes, tomo II, Toledo, 1988, 43-162.

88 Entre la abundante bibliografía sobre el tema se puede consultar el trabajo de R. IZOUIERDO BENiTO, Alfonso VI y la toma de Toledo, Toledo, 1986.

89 G. MARTinez Diez, Fernando III (1217-1252), Corona de España. Reyes de Castilla y León, Burgos, 1993.

90 M. GonzAlez JiMENEZ, "Alfonso X y Andalucia”, Actas del congreso internacional sobre Alfonso $X$ el sabio, vida, obra y época, tomo I, Madrid, 1989, 259-268. También se puede consultar la extensa y completa monografía de A. BALLESTEROS, Alfonso $X$, Barcelona, 1963.

91 J. Sánchez-Arcilla Bernal, Alfonso XI (1312-1350), Corona de España. Reyes de Castilla y León, Burgos, 1995. Sobre el Algarbe se pueden consultar los distintos trabajos recogidos en las Actas de las II Jornadas de historia sobre Andalucía y el Algarbe (Ss. XIII-XVIII). La Rábida, del 24 al 26 de abril de 1986; M. GonZÁLEZ JIMÉNEZ, ed., Sevilla, 1990. 
como cabria esperar, aunque sí de grado con la enumeración primero de los reinos y luego de los señoríos ${ }^{92}$. En cualquier caso el documento refleja la aún no culminada conquista de Granada, último bastión de la «reconquista» que se encontraba en pleno proceso de su incorporación a los reinos cristianos.

En la relación de estos territorios se expresan también los distintos ámbitos de jurisdicción realenga con distinción entre reinos, caso de León, Castilla o Toledo y señoríos como los de Vizcaya ${ }^{93}$ y Molina ${ }^{94}$ incorporados a la Corona y que siempre se ponen de manifiesto en este tipo de documentos. Su enumeración manifiesta que el rey ejerce su soberanía sobre todos ellos y a todos ellos va dirigida la normativa como aplicación territorial de la ley en toda su extensión.

La dirección simultáneamente a la intitulación es de carácter universal y se expresa en dativo, siendo la más completa y solemne y define también la práctica de la soberanía real a través de la estructura social como la intitulación lo hacía sobre la administrativa. Se distinguen entre dignidades civiles y religiosas, asi como entre diversas jurisdicciones dentro de la administración de la Corona, comenzando por la nobleza que aparece perfectamente jerarquizada entre alta (infantes, duques y condes) y baja (caballeros, escuderos y ricos hombres) ${ }^{95}$ para continuar con las órdenes militares ${ }^{96}$ y funcionarios de la administración regia como el Consejo y la Chancillería 97 para seguir con la territorial, caso de los adelantados ${ }^{93}$ y alcaides y terminar con la concejil de los alcaldes, regidores y buenos hombres pecheros. Dentro de esta jerarquía se expresan al mismo tiempo distintos perfiles en función del tipo de jurisdicción real, territorial o local.

En todo caso el protocolo manifiesta que el rey se halla a la cabeza de todas estas jurisdicciones en una estructura de tipo feudal mediante una gradación de valores que va de Dios al rey y de éste a sus súbditos. Como documento normativo, la ley abarca a todos, súbditos y jurisdicciones diver-

92 Sobre jurisdicciones políticas y administrativas se puede ver, M. A. LADERO QUESADA y otros, eds., “Poderes públicos en la Europa medieval: Principados, Reinos y Coronas", XXIII Semana de Estudios Medievales, Estella del 22 al 26 de julio de 1996. Pamplona, 1997.

93 Como recopilación sobre trabajos referidos a la Vizcaya medieval ver “Edad Media y señorio: El señorio de Vizcaya", Simposium en Bilbao del 5 al 7 de marzo de 1971, Bilbao, 1972.

94 J. SANZ Y DIAZ, Historia verdadera del señorío de Molina, Guadalajara, 1982.

95 V. M. Gibello Bravo, La imagen de la nobleza castellana en la Baja Edad Media, Cáceres, 1999.

96 D. W. LomAx, Las órdenes militares en la Península lbérica durante la Edad Media, Salamanca, 1976. También se pueden consultar los trabajos recogidos en R. Izouierdo Benito y F. Ruiz GómEz (coordinadores), Las órdenes militares en la Península lbérica, tomo I, Cuenca, 2000.

97 Como visión de conjunto es interesante la monografía de D. TORRES SANZ, La administración central castellana en la Baja Edad Media, Valladolid, 1982.

98 La figura del adelantado se puede estudiar en C. JULAR PÉREZ-ALFARo, Los adelantados y merinos mayores de León (siglos XII-XV), León, 1990. 
sas, en una concepción del poder político en la que el soberano es la única fuente de poder, quien lo delega. Por tanto no existen diversidad de poderes sino de jurisdicciones a las que el rey abarca como señal de su soberania y poderío real.

La dirección culmina con la tradicional cláusula de salutación que no es sino otra manifestación de la soberanía regia. El rey otorga su gracia. Se trata de la gracia real que a su vez recibe de Dios y comunica a sus súbditos, de ahí expresiones como la de "graciosa majestad" 99 . Es la máxima expresión de la profunda imbricación religiosa en el campo de lo político. El deseo de salud manifiesta la obligación real de velar por el bienestar de su pueblo. Es el concepto de rey "pater" de precedentes taumatúrgicos altomedievales 100 y precedente a su vez de la teoría política moderna que conducirá al absolutismo del periodo moderno.

\subsection{El cuerpo documental: La tasa de precios y salarios}

Comienza con una «notificatio» que viene a ser un complemento del protocolo en forma de fórmula de enlace y al mismo tiempo anuncia el negocio jurídico en cuestión y que a dado pie a la redacción del documento. En la misma Juan II se dirige a sus súbditos, recurriendo al tradicional verbo: "sepades", para comunicarles el ayuntamiento de procuradores en Valladolid donde están presentes todos los miembros de su familia, comenzando por la reina doña Maria, su hijo primogénito el príncipe don Enrique y sus primos los infantes de Aragón, don Juan, rey de Navarra, el infante don Enrique, maestre de Santiago y el almirante don Fadrique. Todo ello indica, por un lado, el papel destacado y la intervención de estos primos del rey, hijos de su tío paterno Fernando de Antequera, en la política castellana del momento que explica los enfrentamientos endémicos que en clave de guerra civil tuvieron lugar en el reinado. Por otra parte significa que nos encontramos en un momento clave de este reinado mediatizado por el rey de Navarra y la liga nobiliaria que le apoya. Le sigue la relación generalizada de algunos nobles, prelados y miembros del Consejo Real que acompañaban al rey en la Corte. La misma notificación señala uno de los aspectos fundamentales de la génesis diplomática cuando se refiere a las peticiones presentadas por los procuradores del reino, para a continuación insertar literalmente una de ellas, la que hacia referencia al

99 La gracia real manifiesta la idea de concesión por parte del rey a sus súbditos y constituia un elemento vital de todas las formas de pensamiento teocrático; ULLMANN, op. cit., 124.

100 Se puede consultar el capítulo dedicado a la realeza feudal inglesa de UlLmanN, op. cit., 155 y ss. 
elevado precio del oro y la plata y la inflación provocada en el precio de algunos productos. Esta "petitio" en forma de exposición tal y como se inserta obedece al mismo esquema que ya señalamos al hablar de los cuadernos de Cortes.

La notificación da paso al amplio dispositivo documental redactado en primera persona: "y yo viendo que lo contenido en la dicha petiçión es muy complidero a mi serviçio...» que supone la parte central y más importante del ordenamiento y que se expresa en forma de mandato: "Es mi merçed y mando y ordeno...", pues constituye la relación en forma de asientos de los precios de determinadas mercancías y el salario de algunos artesanos, de la manera que ya señalamos al referirnos a los caracteres externos. Señalar que en este dispositivo con fuerza de ley el rey se extiende en una pormenorizada relación en la que nos ofrece referencias directas y muy importantes a la reforma monetaria emprendida tanto por su padre y antecesor el rey Enrique III como la llevada a cabo por él mismo, como continuación de la anterior, al referirse a la moneda de oro y plata, así como a la nueva moneda de vellón llamada de blancas.

Esta reforma perseguía básicamente un aumento del dinero en circulación, debido a las necesidades políticas y militares con lo que se recurrió a la devaluación monetaria, mediante la aparición de la nueva moneda de menor ley y talla que las del reinado anterior, de forma que la equivalencia se establecía en tres blancas por maravedí frente a las dos blancas de las antiguas. La repercusión consiguiente fue una inflación generalizada. La reforma se estructuró en varias fases: Un primer ordenamiento de 29 de enero de 1442, un segundo de 10 de marzo del mismo año y el de 6 de abril que viene a coincidir con el ordenamiento de precios y salarios. En el propio texto se señala que los precios estaban tan o más altos que en tiempos pasados en que una dobla de oro valía 160 maravedís y un florín 110. En el último ordenamiento se estableció una cierta revaluación del vellón para conseguir su estabilización, de modo que la dobla equivaliese a 100 maravedís y el florín a 65, intentando unificar el valor de las antiguas blancas con el de las nuevas y que, por tanto, los precios se ajustasen al respecto del valor de las blancas viejas que es lo que se intenta perseguir con la tasa de precios y salarios, aunque todo ello no fue suficiente para que continuase la inflación y los precios del oro y la plata siguiesen subiendo ${ }^{101 .}$

101 Sobre cuestiones monetarias referidas al siglo xv es interesante el trabajo de Liciniano Sáez donde habla de las blancas de cobre, su aparición, valor y equivalencias; Liciniano SáEz, Demostración histórica del verdadero valor de todas las monedas que corrian en Castilla durante el reinado del señor don Enrique IV, y de su correspondencia con las del señor don Carlos IV..., Madrid, 1796, 80 y ss. 
La relación de precios se refiere sobre todo a los productos textiles, más de la mitad del ordenamiento, por las razones que ya hemos apuntado en otro capítulo, con una distinción entre materias primas, caso de la lana, y las distintas clases de paños que se comercializaban en Castilla y que comentaremos más ampliamente en el capítulo dedicado al glosario de términos contenidos en el ordenamiento. En este sentido el documento constituye una fuente histórica de gran valor para conocer la producción textil, no sólo castellana, sino también la de otros reinos peninsulares y extranjeros.

\section{INDUSTRIA TEXTIL:}

\section{Industria de la Producción 102}

Se citan diversos tipos de paños a lo largo de los tres capítulos dedicados a este asunto: "pannos de lana finos", "pannos de seda e bocaranes" $\mathrm{y}$ "los pannos que se fasen en los mis regnos e los que se trahen de Aragon", extendiéndose el primero a lo largo del folio $2 \mathrm{r}$. y casi todo el vuelto, el segundo aparece al final del 2 v., ocupando tan sólo 4 renglones, y se extiende más ampliamente a lo largo de algo más de la mitad del folio 3 r., en cuya otra mitad aproximadamente comienza el tercer capitulo, que es el más largo, y llega hasta la mitad del folio $4 \mathrm{r}$. El primer capítulo consta de 18 asientos con una media de 3 renglones cada uno, siendo los finales más cortos, con una media de dos. La excepción la constituyen los dos últimos que son una explicación de porqué no se pone precio a determinados paños, teniendo cada uno 8 y 6 renglones respectivamente, siendo uno de los asientos más largos de todo el documento. El segundo capítulo se realiza a lo largo de 9 asientos más cortos, de tan sólo 2 renglones, a excepción de los dos penúltimos de 3 y un renglón respectivamente. El capítulo dedicado a los paños de producción hispana, a pesar de ser el más extenso, consta sólo de 15 asientos, pero éstos son más largos, con una media de 4 renglones, excepto el último con 7 , al tratarse de una explicación sobre el proceder técnico de la fabricación de los paños en forma de dispositivo.

Los asientos, que como este último, llamamos explicativos o no tasados, se disponen de manera diferente al resto, ocupando, casi siempre,

102 Hemos definido la producción textil como el proceso de elaboración de los paños en diversas operaciones que van desde el tejido, pasando por el batanado, el tundido y el teñido. Frente a ello la industria de la confección se encargaría de la creación de prendas de vestir; PUÑAL FERNÁNDEZ, LOS artesanos de Madrid..., 33. 
todo el espacio del folio hasta los márgenes, con una caja de escritura más larga, es decir, se quisieron destacar de alguna manera por parte del escribano, utilizándose, en algunos casos, las llamadas en forma de mano, que ya comentamos al referirnos a los caracteres externos.

El capítulo de los paños hispanos, al contener los asientos más largos, nos habla de la importancia que se quiso conceder a la tasación de los mismos, sin duda, los que se podian prestar a una mayor confusión debido a la variedad de clases y lugares de producción. En este sentido las diferencias de precios, que afectan sobre todo a los paños, y que hemos podido apreciar al comparar el ordenamiento que estudiamos con el que en su día publicó Liciniano Sáez, como versión distinta de la madrileña, nos confirma las dificultades que hubo desde un primer momento en la aplicación de la tasa, debido a que el ordenamiento de precios y salarios, que se hizo por una cuestión puramente monetaria, pudo entrar en conflicto con las distintas ordenanzas locales, las corporaciones de oficio y los mercaderes no dispuestos a someterse a unas condiciones económicas que les podían perjudicar. La rectificación del ordenamiento al poco de promulgarse, según la provisión de Madrigal de 1442, ratifica este hecho.

En cuanto a tipos de paños se señalan los de lana, seda y brocados. El capitulo dedicado a los de lana hace una distinción entre los paños extranjeros y los peninsulares. El documento nos informa detalladamente de la procedencia de los extranjeros, básicamente ingleses y flamencos ${ }^{103}$ con una relación minuciosa de cada uno de ellos con sus respectivos precios, que se expresan en piezas y varas ${ }^{104}$. He aquí su relación, según los países y ciudades donde se elaboran y desde donde eran comercializados por los mercaderes tanto castellanos, básicamente burgaleses, vallisoletanos y toledanos, como foráneos ${ }^{105}$. Sobre su significado remitimos al capitulo dedicado al glosario de términos del ordenamiento.

103 Durante la Baja Edad Media en Castilla la mayoría de los paños extranjeros que se comercializaron procedian de los Países Bajos, Flandes y ciudades de la región de Brabante, los llamados bra. banzones. Sobre el particular se puede consultar el trabajo de Ch. VERLINDEN, "El comercio de paños flamencos y barbanzones en España durante el siglo XIII y XIV", B.R.A.H., 1952, 307-321. Del mismo autor, "Aspects de la production, du comerce et de la consommation des draps flamands au Moyen Age", Produzione..., 99-112, 106. También recoge noticias sobre tipos de paños y ciudades productoras siguiendo a Verlinden, M. MARTínez Martínez, La industria del vestido en Murcia (ss. XIII-XV), Murcia, 1988.

104 Cada pieza de paño contenía aproximadamente 20 varas que equivalian a 30 metros de longitud; IRADIEL, Evolución de la industria textil..., 186 y s.

105 Al parecer Castilla exportaba a Flandes, Inglaterra y Francia materias primas como la lana 0 el hierro y recibía a cambio productos elaborados, entre otros, paños y lienzos como mercancias más importantes, debido a la insuficiencia de la industria textil nacional y su falta de competitividad; $B$. CAUNEDO DEL POTRO, Mercaderes castellanos en el Golfo de Vizcaya (1475-1492), Madrid, 1983,99 y ss. 
PAÑOS DE LANA IMPORTADOS: Velartes, mellinas, clusquines, brujas, lirias, yprés, contrays, bervis, cestres, florentines y escarlatas. En la provisión de Madrigal aparecen nuevos como: Mostreviller, verrias y londres.

\section{Procedencia:}

\section{Inglaterra}

- Escarlata de Londres

- Londres

\section{Flandes}

- Bervi de Flandes

- Brujas

- Cestre

- Clusquín de Liria (Lierre)

- Clusquín de Mellinas (Malines)

- Clusquín de verria

- Contray (Courtrai)

- Escarlata de Mellinas (Malines)

- Escarlata de Mostreviller (Montivilliers)

- Escarlata de Yprés

- Escarlata de Yprés

- Lirias (Lierre)

- Mellinas (Malines)

- Mostreviller (Montivilliers)

- Velarte de Contray (Courtrai)

- Velarte de Liria (Lierre)

- Velarte de Mellinas (Malines)

- Verrias

- Yprés

\section{Italia}

- Paños de florentín

- Escarlata de Florencia

PAÑOS DE SEDA Y BROCADOS: Aceituníes, tapetes, damascos, terceneles, cendaies, brocados y paños de Menin de seda 106.

PAÑos hISPANOS: Paños (sin más), sanjuanes, pardillos, bervís y pardos.

106 Sobre la producción de seda y los distintos tipos de tejidos y su terminología es interesante el trabajo de G. Navarro EsPINACH, El despegue de la industria sedera en la Valencia del siglo XV, Valencia, 1992. En lo que respecta a Menin, se trata de una de las muchas ciudades flamencas productoras de paños al igual que Wervicq, Courtrai, Malines o Lierre, entre otras; ver Ch. VERLINDEN, "Aspects de la production, du comerce et de la consommation des draps flamands au Moyen Age", Produzione..., 99-112, 110 y ss. 
Procedencia 107

Castilla

- Paños azules, verde oscuros y de otros colores de Palencia ${ }^{108,}$ Cuenca ${ }^{109}$ y Córdoba 110

- Paños verde oscuros y de otros colores de Ciudad Real 111, Baeza ${ }^{112}$ y Chinchilla ${ }^{113}$

- Pardillos de Valladolid ${ }^{114}$ y Segovia 115

- Pardos de Ciudad Real, Baeza y Chinchilla

- Pardos de Córdoba y Úbeda

- Sanjuanes prietos, pardillos y de otros colores

\section{Aragón}

- Bervís de Valencia

- Pardillos de Zaragoza

- Urebi de Valencia

Aparte de esta relación de paños y procedencias, el ordenamiento deja libertad para que, según las ordenanzas de cada lugar, se establezca el mejor modo de elaborar los paños en cuanto a las características técnicas del tejido: trama, urdimbre, anchura y longitud de cada pieza ${ }^{116}$. Esta disposición del cuerpo documental se configura diplomáticamente en forma de dispositivo: "y es mi merçed y mando que en todos los logares donde se façen estos pannos en mis regnos..."117, y va acompañada de la correspondiente cláusula penal con pérdida de la gracia regia y el pago de las multas pertinentes “in crescendo", es decir, estas penas pecuniarias iban aumentando en cantidad, generalmente el doble de la cantidad o pena ini-

107 Resulta de gran interés consultar el artículo de Gual Camarena que, sin embargo, no cita algunas de las localidades que aparecen en el ordenamiento, asi como algunos de los paños que en ellas se elaboraban, caso de Ciudad Real y Valladolid; M. Gual CAMARENA, "Para un mapa de la industria textil hispana en la Edad Media", A.E.M., IV (1967), 109-167, 121 y ss.

108 M. A. Esteban Recio, Palencia a fines de la Edad Media: una ciudad de señorio episcopal, Valladolid, 1989.

109 Se puede consultar el trabajo de IRADIEL, Evolución de la industria textil..., que se basa en el caso de Cuenca.

110 R. Cómdoba de la llave, La industria medieval de Córdoba, Córdoba, 1990.

111 L. R. VILLEGAS Diaz, Ciudad Real en la Edad Media, la ciudad y sus hombres (1255-1500), Ciudad Real, 1981

112 M. J. Parejo Delgado, Baeza y Úbeda en la Baja Edad Media, Granada, 1988.

113 A. Pretel Marin, Chinchilla medieval, Albacete, 1992. Un trabajo más específico sobre la producción textil de este municipio manchego, J. SÁNCHEZ FERRER y J. CANO VALERO, La manufactura textil en Chinchilla durante el siglo xv, según algunas ordenanzas de la ciudad, Albacete, 1982.

114 A. Rucouol, Valladolid en la Edad Media, Valladolid, 1987.

115 M. R. Asenjo González, Segovia, la ciudad y su tierra a fines del medievo, Segovia, 1986.

116 Se puede consultar P. IRADIEL, Evolución de la industria textil... También sobre aspectos técnicos, entre otros autores, MARTinez, op, cit., Cóndoba de la Llave, op. cit., y PUÑal FERnández, op. cit. 117 Ver apéndice documental n. ${ }^{\circ} 1$. 
cial, a medida que se reiteraba su incumplimiento: "so pena de la mi merçed y de perder los pannos los que lo contrario fiçieren por la primera vez y por la segunda vez que los paguen con el doblo y asi vaya dende adelante creçiendo esta pena» 118.

Siguiendo con el sector textil, se mencionan las diversas procedencias de la lana: merina del condado de Medinaceli, merina de tierra de Cuenca ${ }^{119}$, de tierra de Soria ${ }^{120}$ y de Yangüas ${ }^{121}$, Cameros ${ }^{122}$ y las Cinco Villas ${ }^{123}$. Es decir gracias a esta relación conocemos las principales zonas de producción de lana merina castellana: Cuenca, la comarca de Soria y La Rioja con Cameros. En los dos primeros casos dichos territorios coinciden con la presencia de la cañada real conquense, utilizadas por la Mesta en la trashumancia de los rebaños que hacían la veranada en las frías tierras de Soria e invernaban en las más cálidas de Cuenca y la meseta sur ${ }^{124}$. Sólo se menciona lana de importación en el caso de la comarca aragonesa de las Cinco Villas.

Este capítulo es el único dedicado a establecer los precios de una materia prima textil, sin que se citen la seda, el lino o el cáñamo, entre otras. Se trata de un capítulo muy breve, con tan sólo 4 asientos de 1 renglón, excepto el tercero de 2, ocupando parte del tercio inferior del folio $4 \mathrm{r}$.

La relación de tejidos de otras materias como el algodón, lino o cáñamo es bastante prolija y se expresa también en piezas y varas. Aparecen tejidos de algodón como los fustanes de olmo y acebuche ${ }^{125}$, indicando, en una ocasión, su procedencia: «fustanes que vienen de Genova e de otros logares que son en Levante...»126, así como lienzos de lino, estopa y cáñamos, en relación a todas aquellas telas elaboradas con esta materia prima y que podían

118 Ver apéndice documental $n .{ }^{\circ} 1$.

119 IRADIEL, Evolución de la industria textil..., 60 y ss.

120 Se puede consultar la monografía de M. Diago HERnando, Soria en la baja Edad Media: espacio rural y economia agraria, Madrid, 1993.

121 Sobre esta localidad soriana ver M. C. DELGADo MaRTinEZ, Apuntes sobre la vida rural de la villa y tierra de Yangüas (Soria) (siglos Xil-XVi), Soria, 1981.

122 M. A. Moreno Ramirez de ARellano, Señorio de Cameros y condado de Aguilar: cuatro siglos de régimen señorial en La Rioja, Logroño, 1992.

123 E. Piedrafita Pérez, Las Cinco Villas en la Edad Media (ss. Xl-xiI): sistemas de repoblación y ocupación del espacio, Zaragoza, 2000. También se pueden ver las VI Jornadas de estudios sobre las Cinco Villas $\left(6^{a}, 1990\right)$. Egea de los Caballeros: Los caminos en la historia de las Cinco Villas, Egea de los Caballeros, 1995.

124 Sobre la producción de lana y los tipos de ganadería ovina consultar mi trabajo, T. PUÑAL FERnÁndez, "La ganadería lanar en Madrid y su tierra durante la Edad Media», Espacio, Tiempo y Forma. Serie de historia medieval, 11 (1998), 331-381.

125 El olmo y el acebuche (acebuque en el documento) son sustancias colorantes que se empleaban para teñir los fustanes; M. C. MARTínEz MELÉNDEZ, Los nombres de tejidos en castellano medieval, Granada, 1989, 453.

126 Ver apéndice documental $n .^{9} 1$. 
ser de diferentes formas, tamaños y calidad, por lo que el ordenamiento se limita a dejar su tasación al arbitrio de cada lugar. Concluye esta relación con los picotes y sergas como tejidos bastos para la elaboración de sacos, albardas y costales. Todos ellos se relacionan someramente: los fustanes al final del folio 4 r. con 3 asientos de 2 y 3 renglones, los lienzos en la mitad superior del folio $4 \mathrm{v}$. con tan sólo 3 asientos de 1 renglón, excepto el último de 3 , que aparece como asiento no tasado y, por tanto, destacado del resto respecto a la caja de escritura, y los picotes y sergas al final del folio $5 \mathrm{v}$. con 5 asientos, de los que los dos primeros son de 1 renglón y el resto de 2 .

El apartado de la producción textil se completa con la relación del salario de los tundidores a lo largo de una buena parte del folio $6 \mathrm{r}$., sin que se citen otras operaciones básicas de la elaboración textil como el tejido, el batanado o teñido de los paños. En este caso se proporciona una relación de tipos de paños y el precio de su respectivo tundido en 10 asientos breves de entre 1 y 3 renglones el más largo.

El tundir consistía en refinar el paño, una vez tejido y batanado, cortando con unas tijeras las hilachas y pelos sobrantes para darle mayor uniformidad y un aspecto más limpio ${ }^{127}$. Esta operación sólo se aplicaba a los paños más finos y de mejor calidad, quedando exentos de la misma aquellos más bastos y de producción ordinaria ${ }^{128}$. De este modo se citan entre los paños de producción extranjera: granas, florentines y velartes de Malinas, lirias y countrays, yprés, brujas y bervís, perpiñanes y paños largos de Inglaterra. Todos ellos se denominan paños finos, con una distinción entre mayores y menores. Entre los de producción hispana: blancos y pardillos de Aragón, sanjuanes, pardos, palmelas, paños medianos llamados cuartilla y paños de Aragón en general. El precio del tundir se establece por cada vara de paño, yendo la relación de los 4 maravedís la vara de las granas, florentines, velartes, contrays y otros paños finos, al maravedí de los pardos y palmelas.

Industria de la confección ${ }^{129}$

Las mercancias relacionadas con esta industria son las que merecen una mayor atención en el documento junto a todo lo relacionado con los paños y el sector textil. Son tres los capítulos dedicados a la confección, el

127 Casi todos los autores que se han referido, de una forma $u$ otra, al proceso de elaboración textil han definido esta operación. Se pueden consultar los trabajos de Iradiel, Evolución de la industria textil; Martínez, op. cit.; CódDoba de la llave, op. cit., y Puñal Fernández, op. cit.

128 Puñal Fernández, Los artesanos de Madrid..., 46 y ss.

129 Ver glosario. 
primero de los cuales aparece al final del folio 6 r., extendiéndose más o menos hasta la mitad del vuelto, con el título de: "los presçios que deben levar los sastres", constando de 15 asientos con sus respectivos precios. El segundo lleva por título: "ropas de mugeres", y a lo largo de 14 asientos ocupa toda la mitad del folio $6 \mathrm{v}$., mientras el último dedicado a los jubones, y que aparece con este título, tiene 8 asientos en la mitad del folio $7 \mathrm{r}$. En total son 37 asientos dedicados a citar las distintas prendas de vestir con los precios referidos a la elaboración de las mismas, hechura dice el documento, así como a las operaciones de tajar (cortar) y guarnecer calzas. De hecho los asientos de los dos primeros capítulos comienzan casi todos con la misma expresión, precedida del correspondiente calderón ortográfico: "de fechura de...". Tan sólo en el capítulo de los jubones se cita esta expresión en los dos últimos asientos, comenzando el resto con la frase: «por cada jubon...” 130 .

El apartado de la industria de la confección se refiere básicamente tanto a los sastres generales, como a los especializados, caso de los jubeteros, que elaboran una variada gama de atuendos tanto masculinos como femeninos. De hecho el ordenamiento los distingue, dedicando un capítulo a las ropas de mujeres, así como a la elaboración de distintos tipos de jubones. Esta información es de capital importancia para conocer el complejo mundo de las vestimentas bajomedievales. Muchas de ellas responden a una tradición secular hispana formada por diverso tipo de influencias judias, cristianas y musulmanas, pero en otros casos se denotan influencias europeas, sobre todo francesas y borgoñonas que nos hablan de cierta suntuosidad y de la influencia y el gusto por la moda en el vestir ${ }^{131}$.

Se citan de este modo de manera general: balandranes, sencillos y doblados, mantos cortos y grandes, sencillos y doblados, corochas dobladas y sencillas, capirotes de vestir tanto de paño fino como de otros paños, sayas de paño fino y de otros paños, dobladas y sencillas, así como calzas de paño fino o de Flandes. En cuanto al atuendo femenino se sigue la misma distinción entre prendas elaboradas con paños finos, generalmente los que hemos señalado como de importación, y otros paños más corrientes, también generalmente de producción hispana, con idéntica mención a sencillas o dobladas para algunas prendas. Las mujeres del siglo $x v$ castellano vestían pues con cotas, gramayos, aljubas y mantillos, pellotes, mantones, clochas y sayas. Junto a estas prendas se mencionan las pieles, muy relacionadas con el atuendo femenino, las mismas pren-

130 Ver apéndice documental $n .^{8} 1$.

131 La obra más completa sobre trajes, vestidos y demás atuendos masculinos y femeninos del siglo xv es la de C. BERNIS, Trajes y modas en la España de los Reyes Católicos, tomo l: Las mujeres y tomo II: Los hombres, Madrid, 1978-1979. 
das citadas, pero en seda, y las ropas comunes o de mandados, cuyos precios estarían en función del acuerdo al que llegasen el cliente y el sastre, o en último término si no hubiese acuerdo, quedarian a la tasación de los fieles locales, según se dice en forma dispositiva al final del capítulo dedicado a estas prendas.

Los jubones, prenda de vestir característica del siglo $x v$ por los gustos y modas de la época, merecen un capítulo especial a lo largo de los 8 asientos que conforman el capítulo en la mitad superior del folio $7 \mathrm{r}$. Se trata de una prenda que gozaba de una buena consideración, tratándose de la más cara, existiendo, incluso, un comercio de jubones de segunda mano realizado por los llamados ropavejeros. En este sentido podemos decir que la silueta clásica del siglo Xv era la de un hombre con jubón, lo que explica que los hubiese de todas las formas y tamaños, precios y calidades, básicamente se elaboraban con fustán teñido de diversos colores (olmo, acebuche, etc), o de diversas procedencias o maneras (levante o parella), paño o seda. Había jubones para adultos y para mozos y pajes, según la edad: de 6 a 9 o de 10 a 15 años.

Un apartado importante es el referido al comercio de pieles de vestir o "pennas». La relación de este tipo de prendas es significativa en cuanto es prueba evidente de una suntuosidad característica no sólo de los sectores sociales más importantes, sino incluso de los más humildes como se señala en la petición $n .{ }^{\circ} 37$ de las Cortes de $1442^{132}$. De esta manera toda la mitad del folio $4 \mathrm{v}$. y comienzos del siguiente se dedica a establecer la relación de precios de martas cebellinas, martas comunes, condoites, grises, veros, armiños y abortones blancos y prietos, señalando el precio de la pieza entera, caso de las martas, o el timbre de armiños y la docena de abortones. Se trata en total de 9 asientos de entre 1 y 3 renglones.

\section{LA INDUSTRIA DEL CUERO ${ }^{133}$}

Como sucedía en la industria textil, en este apartado se menciona la materia prima, al referirse a los distintos tipos de cueros, como a los artesanos principales del sector, estableciendo el salario pertinente por su trabajo. Se habla de zapateros, chapineros y borceguineros, todo lo cual de-

132 «Otrosi muy exçelente rrey e sennor, vuestra alteza provea en razón delos traeres que omes e mugeres de baxa manera e labradores trayan el panno del valor que vuestra alteza ordenare segunt su estado, asi mesmo que ninguna muger non traya oro nin cosa dorada, salvo sy su marido mantoviere cavallo e armas, asi mesmo en razón delas pennas martas, veros e grises e arminnos e seda ordene quien e quales personas lo pueden traer..."; Cortes de Valiadolid de 1442, op. cit., 434.

133 ver glosario. 
muestra que esta industria del vestir se desarrolló paralelamente en importancia a la textil ${ }^{134}$.

La relación de cueros ocupa la mitad superior del folio $5 \mathrm{r}$. No se trata de una relación muy prolija, pero lo suficientemente representativa de esta materia prima utilizada mayoritariamente para la elaboración del calzado de los hombres y mujeres del siglo xv. Las referencias de precios son tanto por cuero curtido y adobado, como sin curtir, así como por el trabajo del curtido, existiendo tan sólo una mención al precio de la corteza utilizada para esta operación 135 . Son 11 asientos, la mayoría de tan sólo 1 renglón donde se citan cueros de buey cutral, de vaca y de becerro, asi como cueros vacunos machos sin curtir, es decir, al pelo, cordobanes y badanas. Se mencionan cueros adobados y empegados para vino y el precio del quintal de corteza de "aquende" los puertos para el curtido ${ }^{136}$. En otro caso se habla de la edad del animal: "cueros de beserros de sobre un anno...", debido a que cuanto más joven fuese, más flexible resultaba la piel, elaborándose un cuero de mayor calidad 137.

A los artesanos del calzado se les dedica nada menos que tres capítulos, comenzando por los zapateros que ocupan la mitad inferior del folio $7 \mathrm{r}$. y la otra mitad del vuelto, con las distintas variedades de zapatos que podríamos denominar corrientes, según el tipo de cuero y la persona o edad para la que fueran destinados. De esta forma se habla de zapatos, botas y zuecos, este último calzado de uso exclusivamente femenino. La expresión "puntos" se refiere a las distintos tamaños u hormas de los zapatos, siendo siempre el precio por pares y más elevado cuanto mayor el tamaño.

- Calzado de cordobán: Botas enteras, medias botas, zapatos de 14 puntos, zapatos sin grasa de horma mayor, zapatos engrasados para mozos y pajes de 8 a 14 años, zapatos para mujer, zapatos para mozos de 8 a 14 años, zuecos para mozas de 8 a 14 años.

134 Sobre la industria del cuero medieval se pueden consultar casi los mismos trabajos citados paía la industria textil; CóRDOBA DE LA Llave, op. cit.; MARTínez, op. cit., y PUÑAl FeRnÁNDEZ, op. cit.

:35 El curtido era la operación principal de la transformación de la piel en cuero y constaba de una serie de operaciones de lavado, remojado y preparado de las pieles utilizando sustancias desengrasantes, depilatorias, mordientes y colorantes que se realizaban en la tenería. Más información en cualquiera de las obras citadas en la nota 116.

136 La expresión aquende y allende los puertos es muy utilizada en el lenguaje medieval, se refiere a la cordillera del Sistema Central que divide la peninsula en las dos mitades correspondientes a las mesetas. Se trata de una expresión ya recogida y utilizada por los geógrafos musulmanes del siglo XII cuando se refieren a que el norte de las sierras (Sistema Central) se llama Castilla y el sur España: "La Península española está dividida en dos..., el país situado al sur de los montes de las Sierras se llama España y la parte situada al norte de ellas toma el nombre de Castilla..."; AL-IDRISI, Geografía de España, Valencia, 1974, 161. Idéntica descripción se puede ver en AL-HıMYARI, Kitab arRawd al-Mitar, traducción de M. P. MaEstro GonzÁlez, Valencia, 1963, 324.

137 Ver apéndice documental $n .^{0} 1$. 
- Calzado de badana: Botas enteras, medias botas, zapatos engrasados, zapatos sin grasa, zapatos engrasados para mozos y pajes de 8 a 14 años, valvas.

- Calzado de baldés: Zuecos de baldés para mujer, zapatos de baldés para mozas de 7 a 12 años, zuecos de baldés para mozas de 7 a 12 años.

- Otro calzado: Zapatos blancos de venados para trabajadores.

La única mención específica al trabajo de elaboración del calzado es la que se refiere al precio de cabecear botas y solar calzas, es decir colocar los perfiles superiores correspondientes a las bocas del calzado mediante estrechas tiras de cuero, y poner las suelas. Estas operaciones solían ser comunes en el trabajo de los remendones o zapateros de viejo, encargados de la reparación del calzado.

La existencia de zapateros especializados, según el gusto y las modas imperantes en la época, se define a través de los chapineros y borceguineros. El capítulo dedicado a los primeros al final del folio $7 \mathrm{v}$. y siguiente, define los principales tipos, básicamente los sevillanos 138 elaborados en baldés y que podian ser negros o prietos, así como de otros colores tanto por dentro como por fuera, y también pintados. Los más suntuosos debían ser los dorados y ferreteados, es decir con adornos en metal. También se fabricaban en Córdoba 139: "chapines prietos de valdres fechos en Cordova". Los había de badana y cordobán, fabricados en Burgos ${ }^{140}$, León, Toledo y Valladolid, así como en otros lugares. En cuanto a los borceguíes, en la mitad del folio $8 \mathrm{r}$. y a lo largo de 4 asientos de tan sólo 1 renglón se citan los de cordobán y baldés, con banda y sin ella.

\section{LA INDUSTRIA DEL METAL 141}

Siguiendo el procedimiento del textil y el cuero aparece un capítulo dedicado al comercio de los principales metales que, como materia prima, se utilizaban en esta industria. Desde la mitad inferior del folio 5 r. y comienzos del siguiente se procede a la enumeración con sus respectivos precios, ex-

138 Sobre la actividad económica en la Sevilla bajomedieval se puede consultar el artículo de A. COLlantes de TERAN-SÁNCHEz, "Sevilla: de los gremios a la industrialización", Estudios de historia social, 5-6 (1978), 7-307.

139 CóRdoba de LA LLAVE, op. cit.

140 Sobre la industria del calzado en Burgos se puede consultar la edición de las primeras ordenanzas conservadas sobre los zapateros de la ciudad; G. DiEZ DE LA LASTRA, "Las primeras ordenanzas de los zapateros burgaleses", Anuario de historia del derecho español, VI (1929), 441-443.

141 Ver glosario. 
presados en arrobas y quintales, de los metales a lo largo de 8 asientos, la mayoría de 1 renglón. Las expresiones "en pasta" o "en verga" 142 acompañan a algunos de ellos, asi como los lugares de procedencia, teniendo en cuenta que una buena parte de la producción de metales era foránea. Aparecen de este modo referencias a los tres metales más usuales de la Edad Media, a excepción del hierro y el acero ${ }^{143}$, como son el cobre, el estaño y el plomo: El cobre era, sobre todo, de procedencia norteafricana ya que se señala que era traído de Argel y Berbería, con la mención también a Flandes, no señalándose nada del resto, lo que hace suponer una producción hispana ${ }^{144}$. Junto a ellos el latón, medido en quintales, y la fruslera.

Los artesanos del metal merecen una pormenorizada relación entre herradores y plateros. Los herradores en la mitad inferior del folio 8 r. y siguiente ocupan 13 asientos, de los cuales los tres últimos están dedicados al precio del hierro, el acero y las armas, siendo los más largos. Es curioso como que, tanto estos dos metales, como las armas no se incluyan en sus respectivos capítulos de metales y el dedicado a escudos y lanzas. En el último caso el que la mayor parte de estos artefactos militares se fabricaban en madera, como veremos más adelante, explicaría su inclusión en otro capítulo inmediatamente después del dedicado a la madera. Las armas a las que se refiere el último asiento del capítulo de los herradores eran, pues, de metal. Desgraciadamente al tratarse de uno de los productos no tasados, no se indican tipos ni precios, porque según el ordenamiento: “deven andar segund el tiempo que menester sea» 145 , lo que parece indicar cierta fluctuación en virtud de las necesidades militares del momento ${ }^{146}$. En

142 El metal en pasta era la pieza fundida y sin labrar, es decir, el metal en bruto, mientras la verga era la medida toledana equivalente a dos codos que expresaba la pieza de metal labrada y con unas medidas concretas.

143 La producción de hierro se remonta en la peninsula a época romana. Sobre este asunto ver, L. M. Díez de Salazar-Fernández, Ferrerias en Guipúzcoa (ss. xIV-xvi), San Sebastián, 1983.

144 Se pueden consultar las actas del congreso celebrado en Madrid del 1 al 15 de junio de 1970; VI congreso internacional de mineria: La minería a través del tiempo en España e lberoamérica, Madrid, 1970. También sobre la producción de metales desde época musulmana, A. CARBONELL Trillo-FIGUEROA, La minería y la metalurgia entre los musulmanes en España, Madrid, 1929.

145 Ver apéndice documental $n .^{9} 1$.

146 Téngase en cuenta que durante el reinado de Juan Il las acciones bélicas se sucedian al compas de los acontecimientos políticos derivados del enfrentamiento con los infantes de Aragón, y por ende, con la nobleza castellana del partido aragonés. En este sentido las crónicas son bastante explícitas en cuanto a los continuos giros políticos protagonizados por el condestable don Álvaro de Luna y sus seguidores, representantes de los intereses reales, asi como por el príncipe don Enrique, cuya actitud basculó de un lado a otro, según los intereses y el acontecer político. Se puede consultar con más detenimiento, entre otras, la "Crónica de Juan Il" en Crónicas de los reyes de Castilla, edición de C. RoselL, tomo II en "Biblioteca de autores españoles", 68, Madrid, 1953, 277-695. También la "Crónica del halconero de Juan II, Pedro Carrillo de Huete", edición de J. DE LA MATA CaRRIAżo en Crónicas españolas, VIII, Madrid, 1946; y "Crónica de don Álvaro de Luna, condestable de Castilla, maestre de Santiago", edición de J. DE LA MATA CARRIAzo en Crónicas españolas, II, Madrid, 1940. 
cuanto a los precios, lo mismo sucede con el hierro y el acero, ordenando el rey que fuesen determinados en cada arzobispado y obispado ${ }^{147}$, según las ordenanzas que habían sido establecidas al respecto, lo que indica que dicha tasación ya se había efectuado.

Aunque en el capitulo no se distingan, las labores propias de los herradores se centraban tanto en el herrado de caballos, jacas, acémilas y yeguas, como en el tratamiento y cuidado de determinadas afecciones animales a través del sangrado, siendo esta una de sus labores fundamentales, por lo que recibian también el nombre de albéitares ${ }^{148}$, diferenciándose de los herreros dedicados exclusivamente a la elaboración de herraduras y la reparación de los aperos de labranza. En este sentido el documento señala, aunque sin distinción alguna, la fabricación de herraduras para caballos mayores, trotones y jacas, mulas o acémilas, así como el precio por reherrar a dichas bestias.

El capitulo dedicado a los plateros, como los artesanos más importantes del metal, en cuanto a la delicadeza de su trabajo, es muy significativo por la relación de objetos de plata y oro y está muy en relación con uno de los verdaderos motivos que fundamentó la redacción del ordenamiento debido al elevado precio de los metales nobles. La relación de precios se refiere al trabajo de platería en los 5 largos asientos que componen dicho capítulo: Se trata del labrado de cada marco de plata blanca, la de mejor calidad, en piezas de menaje como escudillas ${ }^{149}$, platos, plateles ${ }^{150}$, tazas y cucharas, jarros, jarras, servillas y picheles. Lo mismo en los objetos de adorno llamados de bisutería, en el caso de cadenas y cintas tanto de plata como de oro, algunas con esmaltes ${ }^{151}$.

147 Las referencias a estas demarcaciones eclesiásticas son usuales en la estructura territorial del momento, sin que de ellas se deriven ningún tipo de connotaciones religiosas, por cuanto coincidian con las mismas estructuras administrativas de la Corona; ver LADERO QUESADA, "Las regiones históricas y su articulación política...", op. cit.

148 Puñal Fernández, Los artesanos de Madrid..., 382.

149 Las escudillas constituían una de las piezas de menaje más importantes de la mesa medieval. En las fuentes se menciona su uso para contener caldo o como plato para comer, mencionándose las llamadas viandas de escudillas o salsas. Según el escritor valenciano Francisco EIXiMENIS en su obra Lo crestiá, entre las normas que todo buen cristiano debia seguir a la hora de comer estaban: "cuando te hayas sentado para comer compórtate del modo siguiente, ... fija los ojos fuera del tajadero o plato de trinchar y de la escudilla en que comes..."; J. L. MARTin y P. LóPEz PitA, Urbanidad y buenos modales en la mesa medieval, Salamanca, 1995, 28.

150 Los plateles eran una de las piezas básicas de la vajilla real donde el rey comía y trinchaba las carnes. Se utilizaban tantos plateles como viandas habia, entre ellos plateles llanos, para poner las rebanadas de pan, para la carne, los llamados plateles trincheros, etc. En uno de los capítulos del Arte de Cortar se dice: "cuando el rey toma vino, quitele de delante el platel donde come, porque no caiga vino o agua en él... y a cada manjar que mudare le mude el platel porque en limpio sea puesto y no se confundan los sabores de las viandas, ni a juicio de los presentes se muestre mengua o poquedad de vajilla..."; J. L. MARTiN, Código y decálogo medieval del manipulador de alimentos, Salamanca, 1995, 50.

151 Puñal Fernandez, Los artesanos de Madrid..., 397 y ss. 
Muy en relación con el trabajo de los artesanos del metal estaba el de los oropeleros en cuanto se encargaban del ornamento y la decoración de códices, libros y manuscritos en el proceso de su encuadernación, siendo una labor compartida con el sector del cuero, de ahí que el capítulo que habla de estos artesanos, auténticos artistas del documento escrito, se sitúe entre el de los zapateros y el de los chapineros. Tan sólo 2 asientos de 4 y 3 renglones cada uno, hacia el final del folio $7 \mathrm{v}$. para mencionar la existencia de libros de oropel de 300 panes, puestos en cabritas y en nocados, es decir, sobre pergamino de piel de cabrito o pergaminos vacunos u ovinos, llamados también doblones ${ }^{152}$. Los panes se refieren al laminado en forma de finas y delgadas hojas que solían ser de latón sobredorado.

La relación de mercancias objeto de la tasa incluye también el papel, la madera, la cera y otros productos similares y los escudos y lanzas. Sobre el papel ya apuntábamos algo en el capítulo de los caracteres externos. En la mitad del folio $4 \mathrm{r}$. se hace la relación en 3 asientos de 2 renglones cada uno de los principales tipos de papel que se comercializaron en la Castilla del siglo XV. El precio se establece por resmas y manos, siendo la resma una medida equivalente a 20 manos de papel y una mano el conjunto de 5 cuadernillos o la vigésima parte de la resma. Predomina la denominación de origen o procedencia: papel ceutí, toledano y de barbadillo.

Sobre la denominación ceutí, ya señalábamos que se trata de un papel elaborado en esta ciudad norteafricana, significando también dicha referencia la vía de penetración en la península a través de los puertos andaluces, básicamente Sevilla, estando su origen de fabricación en Italia ${ }^{153}$. Por otro lado hay serios indicios de la fabricación de papel en Ceuta, que en la Edad Media era una importante ciudad islámica, que superaba en población a otras ciudades de la España musulmana como Badajoz, Mallorca, Málaga y Valencia, entre otras ${ }^{154}$, y que la fabricación del papel era de tradición musulmana. Sabemos que Ceuta fue uno de los puertos comerciales más importantes del Estrecho, con presencia de mercaderes italianos, portugueses, castellanos, sobre todo andaluces, valencianos, judíos y musulmanes, lo que significaba un tráfico mercantil intenso, básicamente con la península. Desde 1415, tras la conquista del rey Joao I, era colonia portuguesa ${ }^{155}$, sin embargo, como también dijimos, en la descripción que de esta ciudad

152 El doblón era también la denominación que se daba a las tripas o callos de vaca u oveja. La misma definición aparece en el glosario de la obra de MARTiNEZ, op. cit., 203.

153 Ver nota 19.

154 C. GozÁlbes Cravioto, “La demografía de la Ceuta medieval», Actas del /l Congreso Internacional: El Estrecho de Gibraltar, ed. de E. RIPOLL y M. F. LADERO, tomo III, Madrid, 1995, 49-59, 56.

155 A. M. CABO GonzÁleZ, "Ceuta y el norte de África a través de algunos textos geográficos andalusies", Actas del II Congreso Internacional..., 211-220. 
nos hacen algunos geógrafos musulmanes en el siglo $x v$ no se cita la existencia de molinos papeleros propiamente dichos, ni de una producción de papel a gran escala objeto de exportación y comercio ${ }^{156}$.

El resto del papel de producción nacional, toledano y de Barbadillo, era de inferior calidad, en especial el de Toledo que venía fabricándose en esta ciudad desde el periodo musulmán y continuó haciéndose después de la conquista cristiana 157.

La madera no fue objeto de tasación: "es mi merçed que los dichos fieles de cada logar tasen lo que debe valer cada carretada de madera..." 158, apareciendo en forma de asiento dispositivo al comienzo del folio $5 \mathrm{v}$. con la respectiva llamada en forma de mano en el margen izquierdo. El precio se establecía por carretas, es decir una carga de madera, una de las medidas usuales del comercio maderero al por mayor ${ }^{159}$. Se cita la madera de Balsaín, Extremadura y tierra de Soria, todos ellos lugares de producción de pinos. En las mismas Cortes de 1442 los procuradores piden al rey que se aproveche de la saca de pinos de los pinares de Moya y la frontera con Aragón que, al parecer, eran custodiados por guardas reales ${ }^{160}$. Sobre la importancia de la madera y el comercio que generaba nos dan cuenta algunos datos como la alcabala, una de las más importantes ${ }^{161}$, ya que la madera en forma de leña fue la principal fuente de energía calorífica del medievo, aparte de un elemento importante en la industria de la construcción. Precisamente con este sentido se cita en el ordenamiento 162.

La cera y otros productos se citan bajo el epígrafe genérico de "çera $e$ otras cosas» hacia el final del folio $5 \mathrm{v}$. Junto a la cera y el sebo, cuyos precios se establecen por arrobas, se habla también de la miel a la que se deja sin tasar. Este producto apicola formaba parte de una misma alcabala, la de la fruta, miel y cera y su comercio era importante no sólo como alimento, sino como endulcorante. La cera fue la principal fuente de iluminación de la

156 A este respecto ver la obra de AL-ANSARI, ljtisar al-Ajbar, trad. de J. VALIVÉ BefMEJo en Descripción de Ceuta musulmana..., op. cit., 398-442.

157 El resto de la información aparece recogida en el capítulo de los caracteres externos al hablar del papel.

158 Ver apéndice documental $n .^{2} 1$.

159 PUÑal FERnández, Los artesanos de Madrid..., 300 y ss.

160 «Iten por quanto vuestra merçet non se puede aprovechar de los pinares de Moya e dela frontera de Aragon e vuestra sennoria da dineros por guardar los dichos pinares, por que non saquen pinos e da los dichos pinos a quien vos los demandan e delos dichos pinos vuestra alteza non ha provecho alguno. Suplicamos a vuestra alteza que dé orden que se pueda aprovechar dela saca delos dichos pinos pues la ha bien necesaria, commo sea mas vuestro serviçio aprovechar vos dellos que otros, pues los dichos pinos de cada dia se sacan"; Cortes de Valladolid de 1442, petición n. ${ }^{\circ}$ 6, op. cit., 404.

161 Ver M. A. Ladero Quesada, La hacienda real de Castilla en el siglo XV, La Laguna, 1973. 162 Puñal Fernánoez, Los artesanos de Madrid..., 293 y ss. 
Edad Media tanto para uso doméstico como público. Recordemos que las calles principales de algunas ciudades y villas ${ }^{163}$, así como castillos, atalayas, alcázares y demás plazas fuertes, eran iluminados mediante cera, de ahí el servicio de velas que aparece citado en las fuentes como una de las obligaciones militares de los pecheros en algunas ciudades ${ }^{164}$. Aparte debemos tener en cuenta la función litúrgica y de culto en ritos y ceremonias religiosas 165 .

El sebo, como grasa animal, tenía un uso menos personal, destinándose básicamente a la producción industrial, estando constatada su aplicación en el zurrado de las pieles y la elaboración del calzado. Ya nos referíamos al hablar de los zapateros como el ordenamiento cita zapatos de badana y cordobán engrasados y sin grasa. Por último el capítulo se cierra con la mención a la pez y la resina, grasas vegetales de diversa utilización, entre ellas la de mordiente para el teñido de los cueros ${ }^{166}$, cuya tasa queda al arbitrio de los fieles de cada lugar.

Los escudos y lanzas son la única mención explícita en todo el ordenamiento a materiales bélicos y de defensa, ya que en el capítulo de los herradores se habla también de armas, según apuntábamos, pero sin especificar ${ }^{167}$. Aparecen justo en la mitad del folio $5 \mathrm{v}$. en forma de 5 asientos de 2 renglones, excepto el final de un sólo renglón. Se citan medios paveses encorados, es decir cubiertos de cuero, y pintados, a prueba de ballesta de garrucha, escudos de infantería de Galicia: "escudos para omes de pie...", también encorados y pintados, así como otros escudos que se dice estar hechos en la montaña. La relación se cierra con lanzas de infantería: "lanças de omes de pie..." y varas de dardos. Como se puede apreciar todo hace referencia al armamento más básico de los llamados peones, escuderos o soldados de a pie: el escudo y la lanza. Se trata en todos los casos de un material sencillo y poco pesado para su transporte y utilización en la

163 J. P. Leguay, La rue au Moyen Age, Rennes, 1984.

164 T. PUÑAL FERNÁNDEZ, «La población pechera de Madrid en el siglo xV. Análisis de una estructura social medieval", La Península Ibérica en la era de los descubrimientos (1391-1492). Actas de las III Jornadas hispano-portuguesas de historia medieval, tomo II, Sevilla, 1997, 1309-1322, 1315.

165 En las mandas testamentarias se solian dejar algunas limosnas para la cera que se utilizaba en los funerales. Del mismo modo la mayor parte de las cofradías recogen en sus estatutos la obligación del hermano cofrade de entregar determinadas libras de cera en concepto de sanción por el incumplimiento de algún hecho. También en las cuentas de los libros de obra y fábrica de algunas parroquias se habla de los gastos de cera destinada al culto. Sobre mandas testamentarias y legados piadosos se puede ver L. GÓmEz NiETo, Ritos funerarios en el Madrid medieval, colección Laya, n. ${ }^{2} 8$, Madrid, 1991, 73 y ss.

166 Puñal Fernandez, Los artesanos de Madrid..., 208.

167 Sobre armas medievales se puede consultar el trabajo de A. SOLER DEL CAMPO, “El armamento medieval hispano", Cuadernos de investigación medieval, n. ${ }^{\circ} 6$, Madrid, 1987; con una interesante recopilación bibliográfica sobre los últimos estudios referentes al tema. 
guerra o como medio de defensa, apto para gentes poco profesionales que debían servir a sus amos o caballeros a través de un contrato de acostamiento o por simple servicio en el caso de aquellos pecheros, artesanos y labradores, obligados a acudir a la llamada regia en caso de necesidad.

\subsection{Las cláusulas de cierre del cuerpo documental}

La tasación de todos estos diversos productos, sí como los salarios que determinados artesanos debían cobrar por su trabajo, cierra la parte principal del cuerpo documental para dar paso al conjunto de fórmulas sancionales y corroborales ${ }^{168}$, llamadas también cláusulas de garantía cuya función es la de asegurar la validez y el cumplimiento de todo lo expresado, como garantía de la acción jurídica del dispositivo ${ }^{169}$. Todas estas cláusulas y sus derivados se introducen en el texto mediante la correspondiente conjunción copulativa "y».

La primera cláusula es preceptiva, propia de las provisiones y ordenamientos legales, llamada de contenido, en cuanto se convierte en un anejo del mismo dispositivo: "lo cual todo suso dicho e cada cosa dello es mi merçed e mando e ordeno que se use e faga e guarde e cunpla..." 170. Esta fórmula sancionadora se define por su carácter universal, ya que el precepto era de obligado cumplimiento en toda la Corona, incluyendo los señoríos jurisdiccionales, tanto laicos como eclesiásticos: "abadengos $e$ ordenes $e$ behetrias e sennorios e otros cuales quier...». En este sentido la cláusula preceptiva define y resume mejor que cualquier otra el carácter legislativo del rey y su capacidad para hacer cumplir la ley por encima de todo.

Esta cláusula ofrece un esquema notificativo en la que se produce el ordenamiento universal del acto jurídico que concluye con la fórmula de entrada en vigor en plazo, es decir, el cumplimiento de lo establecido en el acto debía ser realizado en un determinado periodo de tiempo, desde la promulgación del documento en la Corte y en el resto del Reino hasta los 10 dias siguientes. Este era considerado como el tiempo en que la ley ya era vigente, tomando como referencia la data del documento. En este sentido, sabemos que no todos los cuadernos se fechaban el mismo día, pues la elaboración de tantos documentos como concejos a donde debían ser enviados podía retrasar en algunos días la expedición de alguno de ellos. La fórmula de publicación es, por tanto, complementaria de la cláusula precep-

168 Ver Lorenzo CaDARSO, op. cit, 276.

169 A. TAmaYo, Archivistica, diplomática y sigilografia, Madrid, 1996, 92.

170 Ver apéndice documental $n .{ }^{\circ} 1$. 
tiva, formando parte de ella, pues lo que se ordena debía tener un plazo a partir del cual se hacía efectivo. El plazo de 10 dias debía ser considerado el suficiente para que la ley fuese conocida en toda la Corona, sus ciudades $y$ territorios.

La siguiente cláusula es conminatoria por cuanto incide en el precepto de obedecer y cumplir el ordenamiento, así como en la necesidad de ponerlo en práctica: "Por que vos mando a todos e a cada uno de vos en vuestros logares e juridiçiones que lo guardedes e cunplades e executades e fagades guardar e cunplir e executar...". Esta parte se complementa con la tradicional fórmula de publicación de la ley, que no debemos confundir con la de expedición del documento. Publicar tiene aquí el sentido de hacer público algo, en este caso de hacer llegar el contenido del ordenamiento a todos, utilizando el único sistema de información válido en la Edad Media: el pregón en plazas, calles y mercados por pregonero y ante escribano públi$\mathrm{co}$, con lo que se aseguraba su información como acto jurídico desde el momento en que la presencia del escribano era la garantía certera de que se había producido dicha información, la cual no podía ser ignorada: "que lo fagades asi pregonar por las plaças e mercados e otros logares acostunbrados de la dicha mi corte e de todas las dichas çibdades e villas e logares de los dichos mis reynos e sennorios por pregonero y por ante escrivano publico, por que venga a noticia de todos e dello no puedan pretender ygnorançia ...». En este sentido se ha dicho que la Baja Edad Media supone el triunfo de la cultura escrita sobre la oral. Pero no es lo mismo comunicar que informar. La forma de comunicar es escrita y su máxima manifestación, en este sentido, es la documentación que promulga las leyes. El Estado y el resto de las instituciones, tanto públicas como privadas, se comunican a través de la documentación, sin embargo la información de esa comunicación sigue siendo oral. Por tanto los actos jurídicos se comunican por escrito pero se informa de ellos oralmente. Es la única forma de que el mensaje llegase a una población mayoritariamente analfabeta, teniendo aqui lo oral, al igual que lo escrito, un valor jurídico importante, de ahí que se requiera la presencia de un escribano que dé fe de ello. Este sistema de publicación de lo promulgado era propio tanto de las leyes emanadas de Cortes como de aquellas que obedecian a la sola voluntad real o del Consejo ${ }^{171}$. En cualquier caso el procedimiento era el mismo.

La cláusula conminatoria da paso a las penales que aseguraban en forma de sanción lo estipulado en el precepto. Estas cláusulas pertenecen ai

171 No se puede afirmar, por tanto, que la publicación oral en forma de pregón sólo era privativa de las leyes dictadas fuera de Cortes, mientras las que surgian de este contexto eran sólo leidas en voz alta ante la asamblea reunida; TAMAYO, op. cit., nota 154 de la página 167. 
conjunto de las llamadas tipológicas que son propias de los diferentes tipos diplomáticos ${ }^{172}$. La transición hacia la cláusula sancionadora se hace en forma de prohibición estableciendo que nadie, a pesar de su condición social, pudiese ir en contra de la ley, alegando razones de interés público, - lo que es lo mismo, por el bien de la "res pública»173: "por que asy es cunplidero a mi serviçio e a pro e bien comun de los dichos mis reynos e sennorios".

Las penas son económicas, puesto que el siglo $\mathrm{xv}$ supone el triunfo del comercio y la moneda ${ }^{174}$, y por tanto las penas se expresan de forma pecuniaria. El sistema pecuniario es «in crescendo", es decir la pena va aumentando a medida que se incumple sistemáticamente lo ordenado. La primera vez se debía pagar el precio (estimación dice el documento) de la mercancia vendida, la segunda el doble de su precio, la tercera el triple y así sucesivamente. Este dinero se repartía en tres partes, de las cuales los dos tercios se destinaban a las arcas privadas del rey: "para la mi camara...", mientras el tercio restante se dejaba a disposición de aquellas personas que denunciasen el hecho. Era una forma de recompensar a los acusadores y de favorecer, al mismo tiempo, la participación del pueblo como forma de generar un sentimiento colectivo de que la ley era de todos y para todos y que, por tanto, todos debian involucrarse en su cumplimiento. De esta forma el pueblo debía tener una participación activa en la aplicación de la norma, cuestión que manifiesta, de algún modo, el principio de consentimiento legislativo del pueblo, "consensus populi» 175 .

Las dos tercias partes de la pena destinadas a la Cámara regia eran arrendadas, entrando a formar parte del sistema hacendístico real ${ }^{176}$. Se establece que el rey no pudiese utilizar esta renta en la concesión de gracias, mercedes y privilegios, siguiendo la costumbre del otorgamiento de juros de heredad a determinados miembros de la nobleza, funcionarios de la Corte e instituciones religiosas a cobrar sobre algunas de las rentas reales, básicamente alcabalas. La frecuencia de esta situación, sobre todo a partir de los reinados trastámaras, provocó frecuentemente las quejas de los procuradores en Cortes por la mengua que ello suponía para el erario público, lo cual repercutia en el aumento de las imposiciones y pechos.

172 TAMAYO, op. cit, 94 y ss.

173 Sobre este concepto en relación a la idea aristotélica y tomista de política ver ULLMANN, op. cit., 235 y ss.

174 P. SPUFFoRd, Dinero y moneda en la Europa medieval, Barcelona, 1991.

175 Sobre la formulación de este principio medieval basado en las teorias de juristas romanos, ver ULLMANN, op. cit., 281 y ss.

176 M. A. LADERO QUESADA, Legislación hacendística de la Corona de Castilla en la Baja Edad Media, Madrid, 1999. 
El rey decide no arrendar este dinero y, por tanto, evitar cualquier tipo de especulación, logro o beneficio que ello pudiese generar. Téngase en cuenta que la capacidad de cualquier persona para poder denunciar posibles transgresiones de la ley, podía generar determinados abusos difíciles de controlar. Las cláusulas que se utilizan proceden del derecho romano, y son las habituales en la documentación regia. Según estas, cualquier posible concesión real de dichas rentas o actuación en contra de lo establecido no tendría validez jurídica. Se trata de la tradicional cláusula derogativa por la que se anulaba cualquier derecho o privilegio contradictorio con lo dispuesto 177: "y si fisiere la tal merçed que aya sido e sea por el mismo fecho e por ese mismo derecho ninguna e de ningund valor e avida por obrretiçia e subrretiçia e ganada por inportunidad de tiempo, non enbargante que se diga proceder de mi çierta ciencia e propio motu e poderio real absoluto..." 178. Estas expresiones, tomadas de los formularios altomedievales de origen mayoritariamente italiano ${ }^{179}$, proceden del derecho romano y combinan la jurisprudencia con la teoría política bajomedieval, al hacerse mención al poder absoluto del rey 180 que puede quedar contradicho con la ley ${ }^{181}$. Recordemos que por encima del rey está Dios y la justicia ${ }^{182}$, en cuanto el soberano legisla ${ }^{183}$ pero debe, al mismo tiempo, ser respetuoso con su propia ley ${ }^{184}$.

Esta fórmula se acompaña de la respectiva sanción, en caso de que fuese recurrida o impetrada, con pena pecuniaria, establecida en el pago para la Cámara del doble de lo concedido por el rey y cierta fórmula renunciativa por la

177 Lorenzo CADARSO, op. cit., 276.

178 El ser habida por obrreticia, procede del verbo latino obrogo que significa anular o derogar una ley mediante otra, por tanto este término es usual en la cláusulas derogativas que persiguen, precisamente, esta finalidad, y su importancia es extraordinaria en los documentos legales como el que analizamos; ver Marín Martinez y Ruiz AsEnClo, op, cit., 183.

179 Se han conservado muy pocos formularios medievales hispanos, con todo se puede consultar la obra de Granell que reproduce una serie de formulas relacionadas, mas bien, con documentación privada y notarial; V. GranelL, Colección de fórmulas juridicas castellanas de la Edad Media, Madrid, 1935.

180 J. M. NiETO SORIA, «EI "poderío real absoluto" de Olmedo (1445) a Ocaña (1469): la monarquía como conflicto", En La España Medieval, 21 (1998), 159-228.

181 Resulta de gran interés en relación con las cláusulas derogativas el artículo de B. GONZALEZ ALONSO, "La fórmula "obedézcase, pero no se cumpla" en el derecho castellano de la Baja Edad Media”, Anuario de Historia del Derecho Español, L (1980), 469-487.

182 M. A. Pérez de la Canal, "La justicia de la Corte en Castilla durante los siglos Xill al xv", Historia, Instituciones, Documentos, II (1975), 383-481. También se puede consultar, J. SÁnCHEZ-ARCILLA BERNAL, La administración de la justicia real en León y Castilla en la Baja Edad Media (1252-1504). Madiid, 1980.

183 Las pragmáticas y demás documentación con sus cláusulas derogatorias recuerdan las aspiraciones absolutistas de la monarquía y lo que se ofrece como apariencia de formas pactistas de relación del rey con sus súbditos, se transforma en una oportunidad de imponer criterios absolutistas; NIETO SORIA, Legislar y gobernar en la Corona de Castilla.... 122 y ss.

184 J. L. Bermejo CABrero, "Principios y apotegmas sobre el rey y la ley en la Baja Edad Media castellana", Hispania, 129 (1975), 31-47. 
que se anulan cualesquier reclamaciones o demandas, tanto en juicio como fuera de él, que tal hecho pudiese ocasionar. Al mismo tiempo se concede facultad al arrendador de la parte real para poder denunciarlo en el plazo de tres días, o en su defecto, a cualquier persona en caso de fraude u omisión de denuncia por su parte, con la correspondiente recompensa pecuniaria.

Estas cláusulas cierran, de momento, el cuerpo documental para dar paso a un nuevo y extenso dispositivo que ocupa todo el folio $9 \mathrm{v}$. El documento se estructura, pues, en dos partes. Una primera que mediante su dispositivo y respectivas cláusulas se refieren a los precios tasados en el ordenamiento, y una segunda referente a lo que se deja sin tasar y en cuyo dispositivo el rey señala que aquellas mercancías que no van tasadas en el ordenamiento debian serlo por los respectivos lugares, véase concejos, cuyas autoridades se debían encargar de establecer los precios más convenientes para cada producto, según las características propias de cada ciudad y territorio. Esto indica que la realidad económica castellana del siglo $x v$ no era homogénea y que existían claras diferencias entre unas regiones y otras, en virtud, sin duda, del mayor o menor desarrollo comercial. Otro indicador en la tasación de precios debía ser la inflación referida al valor de la moneda de oro después que el rey procediese a su devaluación por motivos puramente políticos. Este hecho coincidía con la última reforma monetaria emprendida por el soberano y la acuñación de las nuevas blancas devaluadas con respecto al reinado anterior, según se señaló. Juan II ordena que el referente de los precios debía ser el de antes de procederse a dicha devaluación y que, en todo caso, debían crecer un cuarto más según fuese aumentando el valor del oro.

"por ende es mi merçed e mando que en cada una çibdad e villa e logar de los dichos mis reynos se ponga presçio convenible a cada una cosa de las que aqui non son especificadas, tasandolo todo razonablemente, aviendo respeto e acatamiento a las tierras e logares e comarcas e al valor que el oro solia valer antes que se labrase la dicha mi moneda nueva... e acresçentando el tal presçio al respecto del cuarto mas segund se acresçentare o mande acresçentar en el valor del oro..." ${ }^{185}$.

El dispositivo se complementa con el mandato de su aplicación, ordenando a los oficiales municipales que en el plazo de entrada en vigor de la ley, es decir 10 días, procedan al nombramiento de fieles ejecutores juramentados que se encarguen de hacer la tasación, según los criterios antes señalados. Se insiste en que su labor debía ser objetiva: "pospuesta toda afición e odio e intereses e toda otra cosa que enbargar pueda el bien comun" 186.

185 Ver apéndice documental $n .^{8} 1$.

186 Ver apéndice documental $n .^{9} 1$. 
De nuevo aparece la cláusula conminatoria que impele al cumplimiento de lo establecido, bajo la amenaza de las penas contenidas en el primer dispositivo, de las que se dice deberán ser aplicadas por las justicias, tanto de la Corte ${ }^{187}$ como del resto de las ciudades y villas, cuya misión era velar por el cumplimiento de las leyes en nombre del rey ${ }^{188}$.

Del mismo modo, se concede autoridad a los fieles municipales encargados de establecer las tasas, para que puedan obligar al cumplimiento de las mismas, pero sin utilizar procesos judiciales, es decir, sin capacidad de juicio y de aplicar las sanciones pertinentes, cuestión reservada exclusivamente a los oficiales de la justicia ${ }^{189}$. El único procedimiento era el juramento de la persona en cuestión, como se deduce de la expresión: "sabida solamente la verdat", y el justo y honrado proceder del fiel encargado de su aplicación mediante la frase: «mandando lugar a luengas de maliçia mas abreviando 10 mas que ser pueda».

"que lo libren e determinen e executen e conoscan de todo ello sinplemente e de plano sin estrépito e figura de juiçio, sabida solamente la verdat, mandando lugar a luengas de maliçia mas abreviando lo mas que ser pueda» 190 .

A continuación se procede a determinar, como en el primer dispositivo, la prohibición a los arrendadores de las penas en que pudieran incurrir los trasgresores, de actuar en contra de lo establecido, mediante cohecho o cualquier otra figura delictiva, así como la capacidad a cualquier persona del pueblo para poder acusar tal delito con la obtención de la tercera parte de la cuantía y la pérdida para el arrendador de las otras dos terceras partes que debían ir a parar al fisco regio o Cámara. De igual forma se establece el «modus procedendi» en estos supuestos. Los arrendadores que cometiesen fraude debían ser juzgados por los oficiales de justicia, quienes, además, debían ser los encargados de notificar al rey las sanciones pertinentes. Al igual que veíamos en el primer dispositivo, se repite la voluntad y el compromiso del rey de no hacer gracia ni donación de estas sanciones pecuniarias.

En el mismo expositivo y mediante la correspondiente cópula se establece que sean los mismos oficiales quienes designen a personas, "llanas

187 Se puede consultar el trabajo de A. Gomez IzQuierdo, Cargos de la Casa y Corte de Juan II de Castilla, Valladolid, 1968.

${ }^{188}$ La literatura bajomedieval ofrece la imagen del rey guardador de las leyes, según la teoría del buen rey, que debia destacar por el "celo de la ley" o por ser "gran celador de la ley" o "firme poste de la leym. Ver Bermejo Cabrero, op. cit., 33.

189 J. M. García Marin, El oficio público en Castilla durante la Baja Edad Media, Madrid, 1987.

180 Ver apéndice documental $n .{ }^{2} 1$. 
e abonadas" encargadas de recibir y entregar el dinero de estas penas al rey, como, así mismo, la orden para que sean estos quienes se encarguen de que mercaderes y artesanos cumplan la tasa, vendiendo y trabajando a los precios establecidos.

Como se puede ver, el ordenamiento va desarrollando a lo largo de toda su estructura diplomática los preceptos y las maneras en como han de ser cumplidos, dejándonos testimonio indirecto no sólo de todo el proceso legal implícito, sino también del judicial: causa de las sanciones, jueces que las aplican, tipos de penas y forma de ser aplicadas y cobradas. De la misma forma se preveen los casos de fraude contra la ley y su aplicación ${ }^{191}$, ofreciéndonos uno de los mejores repertorios jurídicos posibles.

Terminado este segundo dispositivo con las fórmulas de cumplimiento, se pasa a cerrar el cuerpo documental del ordenamiento con las tradicionales cláusulas tipológicas, prohibitiva la primera, «e los unos e los otros non fagades ende al por alguna manera» 192, seguida de la penal con expresión de la pérdida del favor o merced real ${ }^{193}$, así como de los oficios en el caso de los oficiales públicos 194 y la sanción pecuniaria pertinente con la elevada suma de 10.000 maravedís para la Cámara regia.

Después de éstas aparecen la cláusula de emplazamiento a los trasgresores para comparecer ante el tribunal regio de la Corte en el plazo de 15 días, seguida de la de cumplimiento con la que el soberano se aseguraba del total conocimiento de la ley por medio del escribano público encargado de su publicación 195.

\subsection{El escatocolo}

El ordenamiento se cierra con la data y la correspondiente validación que le otorga su carácter jurídico. Se inicia la data del primer documento original con la expresión habitual en este tipo de documentos reales a

191 Ver SÁNCHEZ-ARCHILLA, op, cit, 20.

192 Sobre el significado de esta cláusula estereotipada, Tamayo señala que "al» es la contracción del "aliud" latino, con el significado de otra cosa, con lo que la traducción vendría a significar que ninguna persona hiciese otra cosa contraria a lo que por el dispositivo está establecido en el documento; TAMAYo, op. cit, 94 y ss.

193 La ira regia es una fórmula que ya encontramos en documentos altomedievales. A partir de la 8aja Edad Media se transforma en pérdida del favor real, lo que suponía, en algunos casos, el destierro y la confiscación de los bienes del inculpado, de ahi que dicha cláusula se utilice con asiduidad y cumpliese una función sancionadora importante; TAMAYO, op. cit., 95.

194 Ver Garcia MaRín, op. cit., 34.

195 TamaYo, op. cit., 95. 
través del participio del verbo dar, para dar paso al lugar de redacción y expedición del documento o data tópica. En esta caso la villa de Valladolid, a la que se define como noble ${ }^{196}$. Ya comentamos que la presencia tanto de la Corte como de los procuradores en Valladolid se debió a la convocatoria de Cortes por el rey en 1442. Aparte de todo conocemos por diversos documentos que la ciudad del Pisuerga fue una de las residencias favoritas de Juan II. En ella convocó varias Cortes durante su reinado, lo que significa prolongadas estancias como demuestran los muchos documentos datados en esta ciudad. Se puede afirmar que Valladolid fue, en cierto modo, la capital de Castilla durante la primera mitad del siglo xv, ya que el rey convirtió a la ciudad y su territorio en un extenso feudo de resistencia contra los infantes de Aragón y la nobleza levantisca que les apoyaba. En este sentido se podría trazar una geografía política de la guerra civil del reinado de Juan II, donde Valladolid figura como el principal centro de operaciones.

En lo que se refiere a los dos traslados, su mención aparece en forma de sendos escatocolos en el último folio y en ellos figura la misma data tópi$\mathrm{ca}$, lo que quiere decir que fueron realizados también en Valladolid muy poco después de la expedición del original. En este caso comienzan con la mención a que se trata de dos traslados, uno sacado directamente del cuaderno original y el segundo realizado a partir del primero que, a su vez, se sacó del original: "fecho e sacado fue este traslado del dicho quaderrno de ordenanças original del dicho sennor rey... $\mathrm{y}$ «fecho e sacado fue este traslado del dicho traslado del dicho quaderno de las dichas ordenanças originales del dicho sennor rey...» 197.

La data tópica se continúa con la crónica a través del estilo de la $\mathrm{Na}$ tividad (anno nativitatis) ${ }^{198}$, también denominado estilo romano por haberse utilizado en la cancillería pontificia con la expresión de día, mes y año ${ }^{199}$. No nos extenderemos de nuevo en la problemática que plantea tanto esta data como la del primer traslado. Tan sólo añadir que ésta y la de la segunda copia del documento que analizamos siguen el mismo estilo.

La validación del original lleva la firma autógrafa del rey, cuestión de capital importancia, pues sólo la firma real, en este caso, confería al do-

195 Se puede consultar el estudio monográfico de Rucquoi sobre esta importante ciudad castellana, sede en numerosas ocasiones de la Corte de Juan II y donde nació y murió; Rucouol, op, cit.

197 Ver apéndice documental n. ${ }^{9} 1$

198 El estilo de la Natividad como fórmula cronológica fue promulgado en las Cortes de Segovia de 1383, reinando Juan I, TAMAYO, op. cit., 101.

199 J. DOMINGUEZ APARICIO, "La datación cronológica", Introducción a la paleografía y la diplomática, op. cit., 285-301, 293. También se puede consultar la obra de GARCIA LARRAGUETA, op. cit. 
cumento su auténtico carácter legal. Se ha comentado a este respecto como a lo largo del siglo XV debido a una mayor burocratización de la administración real y a la complejidad de las ocupaciones de la Corona se hizo cada vez más difícil que el soberano firmase todos los documentos, delegando estas funciones ${ }^{200}$. La firma es la habitual en este tipo de documentos, expresada mediante el pronombre personal en primera persona: "Yo el rey».

En el ordenamiento no sólo firma el rey, sino el referendario real, en este caso Fernando Díaz de Toledo, secretario y oidor real. Ya comentamos en su momento al hablar de la génesis diplomática el papel importante que desempeñaba esta figura del referendario y secretario regio en la validación de determinados documentos en los que intervenía, por un lado la Cámara y por otro el Consejo, tratando de aunar en una misma persona relacionada con ambas instituciones la validación documental.

Fernando Díaz de Toledo figura, pues, como el rogatario del documento: "lo fis escribir por su mandado...". Hemos comprobado que este personaje aparece sistemáticamente validando la documentación de Juan II en forma tanto de cuadernos de Cortes, como de provisiones, cédulas, cartas de justicia y demás, a lo largo de una buen parte de su reinado desde 1430201 . Del mismo modo suponemos que el primer ordenamiento de precios y salarios de 22 de junio de 1442 que publica Liciniano Sáez llevaba su validación, aunque no figure en la edición. Del mismo modo suponemos también dicha validación en la provisión de Madrigal donde el rey rectificaba, en parte, el ordenamiento de julio de 1442. Suponemos, porque en la copia simple de la Biblioteca Nacional no aparece ninguna forma de validación. Cabe sólo añadir que la función de referendario y secretario, al tiempo que relator del Consejo, estuvo vinculada en tiempo de los Reyes Católicos a Luis Diaz de Toledo quien había sucedido a su padre Fernando Díaz ${ }^{202}$. Esto demuestra la patrimonialización del cargo en el seno de la Corte, como sucedía con la mayoría de los oficios públicos ${ }^{203}$, máxime teniendo en cuenta que los relatores y referendarios percibían determinada quitación. Otros rogatarios de Juan II

209 TamaYo, op. cit., 142 y ss

201 Según hemos visto en la documentación real del Archivo de Villa, aparece en el cuaderno de las Cortes de Burgos de 1430, en el ordenamiento sobre derechos de los oficiales de la Corte de Medina del Campo de 1433 (véase NiETO SORIA, op. cit.), en una provisión enviada a Madrid en 1446, en otra provisión fechada en 1447, en una cédula de 1447 y en una carta de justicia de 1449, entre otras. Sólo una provisión sobre la moneda forera fechada el 27 de enero de 1448 lleva el refrendo de otro de los secretarios, Pedro Fernández de Lorca.

202 DE DiOS, op. cit., 329.

203 Ver García Marin, op. cit. 
fueron Diego Romero, Pedro Fernández de Lorca y Alonso González de Tordesillas ${ }^{204}$.

Señalar que el original llevaba la correspondiente certificación cancilleril, ya que aparece registrado, según figura en la copia con la palabra: "registrada" y suponemos que también sellado con sello de placa adherido ${ }^{205}$.

En cuanto al primer traslado lleva la validación del escribano de Cámara y notario público Juan Gonzáiez de Ciudad Real quien actúa en presencia de los testigos que avalan el acto jurídico. La expresión: "va çierto" indica la total correspondencia entre el contenido del original y la copia de lo que dicho escribano da su fe mediante la firma: "lohan Gonçales" y el respectivo "signum» escribanil como testimonio de su actuación. Todo ello corroborado por los testigos presentes.

El segundo traslado repite el mismo esquema que el primero, mencionando al escribano Juan Sánchez de Sigüenza quien actúa de nuevo en presencia de testigos que corroboran la conscriptio, pero no validan el documento. En este caso se señalan las rúbricas que, en forma de línea de cierre, aparecen delimitando la caja de escritura al final de cada hoja. Al final el signo de este escribano que aparece precisamente formando parte de la palabra "signo" que se escribe con "S" sigmática, la cual enlaza por la parte superior con una figura en forma de vientre, que indicaria la «i» y que, a su vez, se une mediante un prolongado trazo horizontal con el signo propiamente dicho, que tendría el valor de la "g", para escribir a continuación la «n» $y$ " 0 » finales de palabra. Este signo se estructura en forma de un doble cuadrado con doble aspa en su interior y rodeado de signos búclicos.

Cierran el documento tres líneas horizontales. La primera desde la última palabra hasta enlazar con el signo por la parte inferior, mientras la segunda y la tercera corresponden a la rúbrica del escribano, la misma que aparece al final de cada folio. A diferencia del primer traslado no hay firma autógrafa, sólo rúbrica.

204 Copiamos literalmente el siguiente párrafo de una de las peticiones de las Cortes de Valladolid de 1447 extraído del trabajo de Olivera Serrano sobre las Cortes de Castilla: «Otrosí... que vuestra alteza plega de mandar al doctor Fernando Díaz de Toledo, vuestro oidor e referendario e secretario e del vuestro Consejo e a Diego Romero e a Pedro Fernández de Lorca e a Alonso González de Tordesillas, vuestros secretarios, que hagan juramento que no librarán ni darán librar a vuestra Alteza ni refrendarán alvalaes ni cartas ni otros mandamientos algunos para vuestra Alteza para que mande tomar ni librar cuantias algunas de los dichos maravedís..."; OLIVERA SERRANO, op, cit., 198 y ss.

205 Sobre el valor jurídico y diplomático del sello se puede consultar la obra de A. RIESCO TERRERO, Introducción a la sigilografía, Madrid, 1978. 


\section{PRECIOS Y SALARIOS DEL ORDENAMIENTO: ESTUDIO COMPARATIVO}

El ordenamiento de precios y salarios de 1442 fue el resultado de una política monetaria incierta debido a dos aspectos básicos: la carestía del oro y la plata, bases del sistema monetario, y una fuerte inflación producida por la devaluación de estas monedas al producirse un gran desequilibrio entre el valor nominal o de curso y su precio real ${ }^{206}$. Esta devaluación obedeció, según todos los autores, a motivos mas bien de tipo político: las necesidades militares de la guerra de Granada, una de las últimas de la "Reconquista", la falta de numerario en circulación 207 , por el aumento demográfico y la intensificación de las relaciones comerciales, las necesidades políticas planteadas por la guerra civil que vivía Castilla por el enfrentamiento con los infantes de Aragón y la lucha de bandos, y hasta hay algún autor que plantea la posibilidad de que dicha devaluación obedeciese a los criterios puramente personales del condestable don Álvaro de Luna, privado del rey, para perjudicar a la nobleza levantisca haciendo disminuir el valor de sus rentas, base de su sistema económico ${ }^{208}$. Las consecuencias de este hecho intentaron solucionarse con la intervención real a través de tres reformas monetarias a lo largo de 1442 , encaminadas, todas ellas, a estabilizar la moneda.

La primera reforma es de 29 de enero de 1442. En ella se estableció el valor de la dobla de oro, llamada de la banda, en 82 maravedís. Al mismo tiempo el rey había ordenado labrar moneda de vellón a imitación de las de su padre y antecesor, el rey Enrique III, las llamadas blancas, pero con un valor nominal menor, ya que en las viejas o enriqueñas la correspondencia era de 2 blancas por maravedi, mientras en las nuevamente acuñadas era de 3 blancas. Para que la reforma surtiese efecto se estipula que el maravedi o moneda de cuenta equivaliese a dos blancas de las viejas y que, por tanto, sólo circulasen las viejas monedas de vellón, mandando refundir las nuevas y unificándolas en su valor con las viejas, pero manteniendo su misma baja ley 209 .

206 Existe una ley económica universal a lo largo de todos los tiempos que relaciona la devaluación de la moneda con la subida inmediata de los precios. Sobre este asunto se puede consultar de forma general el libro de A. BELTRÁn, Introducción a la numismática universal, Madrid, 1987.

207 De este modo lo señala Sáez cuando trascribe literalmente las palabras del rey: "cuando mande labrar las blancas, yo era neçesidad de dinero... para los debates de mis reynos... y continuar la guerra con los moros y por la mengua de blancas que habia en mis reynos..."; Liciniano SÁEZ, Demostración histórica del verdadero valor de todas las monedas que corrían en Castilla..., 7.

208 A. MaCKAY, op. cit. Del mismo autor, Money, prices and politics in fifteenth-century Castile, London, 1981.

209 Ladero Quesada, La política monetaria en la Corona de Castilla, 97 y ss. 
Sin embargo esta reforma no produjo los efectos deseados, volviéndose a una nueva reforma monetaria el 10 de marzo de 1442 en que se revocaba la orden de refundición de las blancas nuevas y se permitía la doble circulación de nuevas y viejas con valores desiguales, incluso hubo varias acuñaciones de las nuevas. Sin embargo este sistema no favorecia a los mercaderes, sobre todo extranjeros, que se negaron a recibir el precio de sus mercancías en la devaluada blanca nueva, admitiendo solamente doblas y florines de oro que luego, por su elevado precio, sacaban de Castilla ${ }^{210}$.

La tercera reforma de 6 de abril de 1442 es la que guarda mayor relación con el ordenamiento de precios y salarios. En ella se pretendió una revaluación monetaria, con un nuevo valor de curso legal de la dobla de oro en 100 maravedís, mientras seguian circulando blancas viejas y nuevas, lo que provocó un rechazo generalizado de las devaluadas nuevas y tan sólo su aceptación en el valor de las viejas ${ }^{211}$. En este marco monetario hay que situar los precios contenidos en el ordenamiento, cuyo objetivo último sería evitar la inflación y contener la ascendente subida de los precios.

Sin embargo, ya hemos comentado, la problemática planteada por la existencia de hasta tres versiones distintas del mismo ordenamiento. La primera versión se data el 22 de junio de 1442 y es la que publica Liciniano Sáez. A nuestro entender existen dos hechos básicos que constatan esta apreciación: la diferencia de precios en algunos artículos con respecto al ordenamiento de Madrid y, lo que es más importante, la diferencia de datas. Aparte hemos constatado también diferencias de estilo en la redacción e, incluso, la no aparición de algunas mercancías. Creemos que esto se puede achacar a dos redacciones distintas y, por tanto, a dos documentos diferentes, no quedando otra posibilidad que la de aceptar una primera versión, luego modificada en parte casi un mes más tarde, que es cuando se fecha la copia de Madrid que analizamos, el 23 de julio. Es decir, en el interim entre las datas de ambos documentos se debió producir la segunda modificación.

Sabemos que esta segunda versión conservada en Madrid no fue la definitiva. El rey, en provisión fechada en Madrigal, pero sin data crónica, vuelve a modificar parcialmente el ordenamiento ante las quejas de artesanos y mercaderes. En efecto, sabemos del corto vigor de este ordena-

210 El ordenamiento de reforma dela moneda de 10 de marzo de 1442 se produjo en Tordesillas. Algunas semanas después de su entrada en vigor se tienen noticias de la circulación de blancas viejas, concretamente el $\mathbf{2 8}$ del mismo mes. Estas convivian con las nuevas que tenían en el anverso un castillo y el en reverso una banda y un escudo. Parece ser que el motivo de su reiterada acuñación es que resultaban muy útiles para el comercio cotidiano; Liciniano SÁEZ, Apéndice a la crónica..., 30 y ss.

211 LAdero QUESADA, La política monetaria..., 100. 
miento que tuvo que ser reelaborado a finales de 1442 y principios del año siguiente, siguiendo unos criterios económicos más reales y menos teóricos, relacionados con los precios que regían en las ferias de Medina del Campo ${ }^{212}$. Todo ello no hace sino demostrar las continuas vacilaciones que hubo respecto a poder establecer una política de precios coherente con la reforma monetaria, una reforma que al no seguir índices económicos, sino básicamente políticos, estuvo llamada al fracaso ${ }^{213}$ como lo estuvo también la tasa de precios.

A continuación vamos a establecer las diferencias existentes entre las tres versiones del ordenamiento, diferencias que atañen no sólo a los precios, sino también a determinadas expresiones, algunas de ellas achacables exclusivamente a errores de trascripción en la edición de Liciniano Sáez. También aparecerán aquellos paños que no se citan en las dos primeras versiones y que sólo aparecen en la provisión de Madrigal. Decir que sólo nos detendremos a comentar los casos que irán apareciendo en los respectivos cuadros, sin pretender realizar un estudio exhaustivo de precios ni de la industria hispana de la baja Edad Media.

La primera discordancia es la que afecta a algunos paños de importación:

\begin{tabular}{llll}
\hline \multicolumn{4}{c}{ Cuadro de comparación de precios de paños importados } \\
\hline & Liciniano Sáez & Copia de Madrid & Madrigal \\
\hline Berví de Flandes & Pieza: 2.000 & Pieza: 2.000 & Pieza: 2.000 \\
& Vara: 80 & Vara: 80 & Vara: 80 \\
\hline Brujas de suerte & Pieza: 2.500 & Pieza: 2.500 & Pieza: 2.000 \\
& Vara: 100 & Vara: 100 & Vara: 80 \\
\hline Brujas de ventaja & Pieza: 3.500 & Pieza: 3.500 & Pieza: $3.300-3.800$ \\
& Vara: 140 & Vara: 140 & Vara: - \\
\hline Cestre fino & Pieza: 2.250 & Pieza: 2.250 & Pieza: 2.850 \\
& Vara: 90 & Vara: 90 & Vara: 112 \\
\hline Contray de suerte & Pieza: 2.000 & Pieza: 2.000 & Pieza: 2.000 \\
& Vara: 60 & Vara: 80 & Vara: 80 \\
\hline Clusquin de Liria (Lierre) & Pieza: 3.000 & Pieza: 3.000 & - \\
& Vara: 120 & Vara: 120 & \\
\hline
\end{tabular}

212 LADERo Quesada, La política monetaria..., 100. En la página 99 cita en la nota 5, siguiendo a Mackay, el texto del nuevo ordenamiento de la Biblioteca Nacional, que es el que nosotros trascribimos en el apéndice $n .^{2} 2$ de este trabajo.

213 Un dato significativo es que tras la reforma monetaria del 6 de abril que establecia el valor de la dobla en 100 maravedís de blancas, ese mismo año cada dobla podia valer 101 maravedi y medio y hasta 190 maravedis; Liciniano SAEZ, Apéndice a la crónica..., 78. 
Cuadro de comparación de precios de paños importados (continuación)

\begin{tabular}{|c|c|c|c|}
\hline & Liciniano Sáez & Copia de Madrid & Madrigal \\
\hline Clusquín de Mellinas & - & - & $\begin{array}{l}\text { Pieza: } 3.400 \\
\text { Vara: } 132\end{array}$ \\
\hline Clusquín de Verria entrefino & - & - & $\begin{array}{l}\text { Pieza: } 3.300 \\
\text { Vara: } 135\end{array}$ \\
\hline Escarlata de Florencia & - & - & Vara: 360 \\
\hline Escarlata de Londres & $\begin{array}{l}\text { Pieza: }- \\
\text { Vara: } 400\end{array}$ & $\begin{array}{l}\text { Pieza: - } \\
\text { Vara: } 400\end{array}$ & $\begin{array}{l}\text { Pieza: } 12.000 \\
\text { Vara: } 400\end{array}$ \\
\hline Escarlata de Mellinas & - & - & $\begin{array}{l}\text { Pieza: } 10.000 \\
\text { Vara: } 350\end{array}$ \\
\hline Escarlata de Mostreviller & - & - & $\begin{array}{l}\text { Pieza: } 12.000 \\
\text { Vara: } 400\end{array}$ \\
\hline Escarlata de Yprés & $\begin{array}{l}\text { Pieza: }- \\
\text { Vara: } 200\end{array}$ & $\begin{array}{l}\text { Pieza: }- \\
\text { Vara: } 200\end{array}$ & $\begin{array}{l}\text { Pieza: } 5.500 \\
\text { Vara: } 220\end{array}$ \\
\hline Florentín de suerte mayor & $\begin{array}{l}\text { Pieza: }- \\
\text { Vara: } 177\end{array}$ & $\begin{array}{l}\text { Pieza: }- \\
\text { Vara: } 175\end{array}$ & $\begin{array}{l}\text { Pieza: } 7.000 \\
\text { Vara: } 290\end{array}$ \\
\hline $\begin{array}{l}\text { Florentín que no sea de suerte } \\
\text { mayor }\end{array}$ & - & - & $\begin{array}{l}\text { Pieza: }- \\
\text { Vara: } 150\end{array}$ \\
\hline Londres de la ciudad & - & - & $\begin{array}{l}\text { Pieza: }- \\
\text { Vara: } 200\end{array}$ \\
\hline Londres fino & - & - & $\begin{array}{l}\text { Pieza: } 3.500 \\
\text { Vara: } 140\end{array}$ \\
\hline Mellinas mediano & $\begin{array}{l}\text { Pieza: } 3.000 \\
\text { Vara: } 120\end{array}$ & $\begin{array}{l}\text { Pieza: } 3.000 \\
\text { Vara: } 120\end{array}$ & $\begin{array}{l}\text { Pieza: } 3.000 \\
\text { Vara: } 120\end{array}$ \\
\hline Mostreviller negro y pardillo & - & - & $\begin{array}{l}\text { Pieza: } 5.000 \\
\text { Vara: } 200\end{array}$ \\
\hline Velarte de Contray mayor & $\begin{array}{l}\text { Pieza: } 4.000 \\
\text { Vara: } 160\end{array}$ & $\begin{array}{l}\text { Pieza: } 4.000 \\
\text { Vara: } 160\end{array}$ & $\begin{array}{l}\text { Pieza: } 4.500 \\
\text { Vara: } 280\end{array}$ \\
\hline Velarte de Mellinas & $\begin{array}{l}\text { Pieza: } 4.500 \\
\text { Vara: } 150\end{array}$ & $\begin{array}{l}\text { Pieza: } 4.500 \\
\text { Vara: } 180\end{array}$ & $\begin{array}{l}\text { Pieza: } 6.000 \\
\text { Vara: } 240\end{array}$ \\
\hline Velarte dei Verrio mayor & - & - & $\begin{array}{l}\text { Pieza: } 5.000 \\
\text { Vara: } 204\end{array}$ \\
\hline Verria menor fina & - & - & $\begin{array}{l}\text { Pieza: } 2.650 \\
\text { Vara: } 110\end{array}$ \\
\hline Yprés mayores & $\begin{array}{l}\text { Pieza: } 3.000 \\
\text { Vara: } 120\end{array}$ & $\begin{array}{l}\text { Pieza: } 3.000 \\
\text { Vara: } 120\end{array}$ & $\begin{array}{l}\text { Pieza: } 2.850-3.150 \\
\text { Vara: } 120-130\end{array}$ \\
\hline Yprés menores & $\begin{array}{l}\text { Pieza: } 2.150 \\
\text { Vara: } 85\end{array}$ & - & $\begin{array}{l}\text { Pieza:- } \\
\text { Vara: } 66-95\end{array}$ \\
\hline
\end{tabular}


Como se puede observar, entre los paños de importación ${ }^{214}$ los más caros son las escarlatas con un precio que oscila entre los 10.000 y los 12.000 maravedís la pieza, según la procedencia. Le siguen los florentines de suerte mayor y los velartes de entre 4.000 y 6.000 maravedis. Por debajo se sitúan el resto como contrays, clusquines, mellinas, brujas, yprés, cestres, londres, bervís, verrias y mostreviller, siendo los bervís los más baratos de esta lista, junto a contrays y brujas de suerte. Conviene aclarar que algunos de los paños citados en la provisión de Madrigal no aparecen ni en la edición de Sáez ni en la copia madrileña, caso de los mostreviller, los londres o los verria. Tampoco se citan determinadas tipos en furıción de la procedencia, como los clusquines de Mellinas o las escarlatas de Florencia, Mellinas o Mostreviller.

En cuanto a la tipología predominan las expresiones toponímicas con las que se denominaba genéricamente al paño: bervís (Wervicq) brujas (Brujas), contrays (Courtrai), clusquines (L'Ecluse) ${ }^{215}$, florentines (Florencia), lirias (Lierre), londres (Londres), mellinas (Malines), mostreviller (Montivilliers) e yprés (Yprés). Todas ciudades flamencas, italianas o inglesas, coincidiendo con los principales núcleos de producción europeos en la Edad Media. Sin embargo fue frecuente a lo largo del siglo $x v$ aplicar estas denominaciones a paños de producción hispana, en la medida en que ésta procedió también a la elaboración de paños más baratos, imitando las técnicas de producción, y por tanto, mejorando las calidades de los paños que hasta entonces se habian producido ${ }^{216}$, aunque se detectan numerosas falsificaciones y malas imitaciones que fueron objeto continuado de denuncia en algunos concejos ${ }^{217}$. Sucede con los llamados bervís, que se fabricaban en Valencia y en otros lugares, nombre derivado de la ciudad flamenca de Wervicq ${ }^{218}$. Lo mis-

214 Cuando hablamos de paños de importación no nos referimos sólo a los europeos o extranjeros, sino también a todos aquellos procedentes de fuera de la Corona de Castilla que debian pagar aduana por entrar y comercializarse en territorio castellano, véase el resto de los reinos peninsulares del siglo XV. La misma apreciación se hace en otros autores; ver MARTiNEZ, op. cit., 147.

215 Con el nombre genérico de clusquines se denominaba a todos aquellos paños procedentes del puerto flamenco de L'Ecluse, cerca de Brujas. Sabemos que desde 1391 y durante todo el siglo XV las naves hispanas comerciaron con este importante puerto. Además por clusquines se entendia toda aquella producción textil de distintas ciudades flamencas que se comercializaba a través de dicho puerto, véase el ejemplo de los clusquines de Mellinas (Malines) o de Liria (Lierre); Contributo alla storiografia economica della Fiandra e del Brabante da fonti italiane della seconda metà del trecento e degli inizi del quattrocento, en F. MELIS, I mercanti italiani nell Europa medievale e rinascimentale, Firenze, 1990. También de la misma obra, Mercanti-imprenditori italiani in Fiandra alla fine del '300, 297-316.

216 IRADIEL, Evolución de la industria textil..., 123 y ss.

217 Sucede en Murcia; MaRtinez, op. cit, 143 y ss.

218 Los paños bervís procedían de la ciudad de Wervicq, situada en el Flandes occidental belga, que aparece desde tinales del siglo XIII como uno de los más importantes centros pañeros; VERLINDEN, El comercio de paños flamencos..., 317. 
mo sucedía con los contrays de la ciudad flamenca de Courtrai, los londres y las brujas, entre otros ${ }^{219}$. Este dato nos lleva a considerar que dichos paños se fabricaban en España, bien en Castilla, bien en los territorios de la Corona de Aragón, lo que explicaría su bajo precio en relación a los otros paños que si se importaban.

Otra manera de referirse a los paños era por el color. De este modo se define a las escarlatas o las granas, precisando posteriormente su procedencia. La mayor o menor diferencia de precios entre unos y otros estribaba en los aspectos técnicos: número de hilos del tejido o textura, peso del mismo, la calidad de la lana y el color. Se supone que los más caros eran los llamados 30nos, con una trama de unos 3.000 hilos, y, por tanto, más tupidos y resistentes, debiéndose fabricar con hilo de lana fina de la mejor. Eran los que el documento llama paños más finos. Posteriormente el teñido encarecía bastante el producto, siendo los de color grana o carmesí uno de los más apreciados y, por tanto, de los más caros 220 .

Un dato importante a tener en consideración es la expresión de los precios en piezas y varas, es decir el paño entero o al por menor, en forma de retal. En otras ocasiones sólo se cita la vara. Pero lo significativo es la no coincidencia, a veces, entre las dos primeras versiones, de precios por vara cuando el precio de la pieza es el mismo ${ }^{221}$. Sucede con los velartes de Mellinas o los contrays de suerte, por poner algunos ejemplos, permaneciendo los precios de la pieza siempre iguales. Sólo se nos podría ocurrir pensar en una modificación del tamaño de la vara. Sin embargo no creemos que este fuese el motivo de dichas subidas, pues la longitud de los paños permaneció inalterada, estando mas bien la causa en un más asiduo y dinámico comercio de paños al por menor, es decir, en varas, frente a la compra de la pieza entera, lo que motivaría a los mercaderes a exigir la subida del precio de algunos de los paños.

Las expresiones de paños mayores y menores también introducen variaciones significativas de precios, en cuanto se entendia por paño mayor aquel de la mejor calidad, es decir, el de mejor textura en cuya composición se habian empleado 2.100 hilos o más, los llamados 21 nos, 24 nos o 30nos

219 Iradiel afirma que desde mediados del siglo xv y, sobre todo, a finales del mismo siglo se manifestó en Castilla una tendencia a la imitación de estos paños extranjeros. Se generaliza la tintura de la lana en velartes y otros paños superiores para imitar a los contrays originales, al igual que en los londres, mediante paños 22 nos y 24 nos teñidos de colores. En Cuenca constata la aparición antes de 1450 de los camelotes que trataban de imitar a los paños de Brujas; Iradiel, Evolución de la industria textil..., 131 .

220 Seguimos a Iradiel en su capítulo de los factores técnicos de la producción textil; IRADIEL, op. cit., 167 y ss.

221 Se señala que la relación entre precio por vara y precio total o por pieza daba una media de 20 varas por paño, equivalentes a 30 metros de longitud; IRADIEL, Evolución de la industria textil..., 213. 
(ventiuncenos, etc.). Por el contrario los paños menores eran los fabricados con un número de hilos inferior. La denominación de menores es muy amplia, pues abarca diversas clases, como los llamados medianos o comunes que eran $18 \mathrm{nos}$ (deciochenos) o 16nos (secenos) y los de inferior calidad con un cuento de hilos menor de 1.600, es decir los 14nos o 12nos. A su vez la textura dependía de los aspectos técnicos, como el tipo de telar empleado, con peine ancho o estrecho 222.

En lo que respecta a los paños ingleses, el ordenamiento no pone precio alguno, esgrimiendo el argumento de una gran diferenciación de precios entre unos y otros. Este dato confirma que el comercio de estos paños en la península y, más concretamente, en Castilla, empezaba a relegar paulatinamente a la tradicional pañería flamenca, que desde el siglo xill, había copado el mercado hispano ${ }^{223}$. Los paños ingleses eran más baratos 224 y se comercializaron a la par que los flamencos, pues las naos que venían de retorno a los puertos del Cantábrico procedentes de Flandes hacian escala en Londres, atravesando después el Canal de la Mancha y el Golfo de Vizcaya a través de los puertos comerciales franceses, trayendo también paños de Inglaterra 225.

Del mismo modo tampoco se tasan los brocados, dejando su precio a la consideración de los fieles locales en función de la cantidad de hilo de oro o seda por vara, así como los gastos generados por la importación y el beneficio del mercader.

Pero donde mayores diferencias de precios se establecen entre las tres versiones del ordenamiento es en el capítulo de los paños hispanos, tanto los castellanos como los aragoneses. En el siguiente cuadro se referencian:

\begin{tabular}{llll}
\hline \multicolumn{4}{c}{ Cuadro de comparación de precios de los paños hispanos } \\
\hline & Liciniano Sáez & Copia de Madrid & Madrigal \\
\hline Paño de Palencia fino & Pieza: 850 & Pieza: 850 & Pieza: - \\
& Vara: 34 & Vara: 34 & Vara: $35-45$ \\
\hline Pardillos o mezcla o verde-azul & Pieza: 4.000 & Pieza: 1.000 & Pieza: 900 \\
de Segovia & Vara: 40 & Vara: 40 & Vara: 37 \\
\hline
\end{tabular}

222 Estas consideraciones se pueden consultar tanto en la obra de IRADIEL, $O p$. cit, como en la de MARTinez, op. cit., 42 y ss.

223 Iradiel, op. cit., 103 y ss. y Martinez, op. cit., 143.

224 Caunedo del Potro, op. cit., 20. De la misma autora, Reflexiones en torno al comercio exterior castellano, op. cit.

225 M. SÁNCHEZ MARTíN, “Mercaderes burgaleses en Flandes. Actividad económica y vida privada según el cartulario del antiguo consulado de España en Brujas (1. " parte, de 1280 a 1550)", La Peninsula lbérica en la era de los descubrimientos..., tomo 1, 453-468, 454 y ss. 


\begin{tabular}{|c|c|c|c|}
\hline \multicolumn{4}{|c|}{ Cuadro de comparación de precios de los paños hispanos (continuación) } \\
\hline & Liciniano Sáez & Copia de Madrid & Madrigal \\
\hline Pardillo fino de Valladolid & $\begin{array}{l}\text { Pieza: } 4.000 \\
\text { Vara: } 40\end{array}$ & $\begin{array}{l}\text { Pieza: } 1.000 \\
\text { Vara: } 40\end{array}$ & $\begin{array}{l}\text { Pieza: } 1.000 \\
\text { Vara: } 30\end{array}$ \\
\hline Pardillos de Zaragoza & $\begin{array}{l}\text { Pieza: } 900 \\
\text { Vara: } 35\end{array}$ & $\begin{array}{l}\text { Pieza: } 900 \\
\text { Vara: } 36\end{array}$ & $\begin{array}{l}\text { Pieza: } 1.000 \\
\text { Vara: } 42\end{array}$ \\
\hline $\begin{array}{l}\text { Otros pardillos de Valladolid no } \\
\tan \text { finos }\end{array}$ & - & - & $\begin{array}{l}\text { Pieza: } 700 \\
\text { Vara: } 30\end{array}$ \\
\hline $\begin{array}{l}\text { Pardillos de otros colores o } \\
\text { bervís de Valencia }\end{array}$ & $\begin{array}{l}\text { Pieza: } 4.050 \\
\text { Vara: } 45\end{array}$ & $\begin{array}{l}\text { Pieza: } 1.100 \\
\text { Vara: } 45\end{array}$ & - \\
\hline $\begin{array}{l}\text { Pardo limpio y subido en color de } \\
\text { Ciudad Real y Baeza y Chinchilla }\end{array}$ & $\begin{array}{l}\text { Pieza: } 600 \\
\text { Vara: } 24\end{array}$ & $\begin{array}{l}\text { Pieza: } 600 \\
\text { Vara: } 24\end{array}$ & - \\
\hline $\begin{array}{l}\text { Pardos limpios y subidos de } \\
\text { color de Córdoba y Úbeda }\end{array}$ & - & $\begin{array}{l}\text { Pieza: } 700 \\
\text { Vara: } 28\end{array}$ & - \\
\hline $\begin{array}{l}\text { Pardo canillo de pardo cerrado } \\
\text { no subido en color }\end{array}$ & $\begin{array}{l}\text { Pieza: } 500 \\
\text { Vara: } 20\end{array}$ & $\begin{array}{l}\text { Pieza: } 500 \\
\text { Vara: } 20\end{array}$ & - \\
\hline Sanjuan deciocheno & - & - & $\begin{array}{l}\text { Pieza: } 1.960 \\
\text { Vara: } 70\end{array}$ \\
\hline Sanjuan dioceceno & - & - & $\begin{array}{l}\text { Pieza: } 1.660 \\
\text { Vara: } 65\end{array}$ \\
\hline Sanjuanes de otros colores & $\begin{array}{l}\text { Pieza: } 4.250 \\
\text { Vara: }-\end{array}$ & $\begin{array}{l}\text { Pieza: } 1.250 \\
\text { Vara: }-\end{array}$ & - \\
\hline Sanjuanes prietos y pardillos & $\begin{array}{l}\text { Pieza: } 4.400 \\
\text { Vara: } 60\end{array}$ & $\begin{array}{l}\text { Pieza: } 1.500 \\
\text { Vara: } 60\end{array}$ & - \\
\hline $\begin{array}{l}\text { Urebi de Valencia rosado o } \\
\text { pardillo }\end{array}$ & - & - & $\begin{array}{l}\text { Pieza: } 1.560 \\
\text { Vara: } 62\end{array}$ \\
\hline
\end{tabular}

Al respecto de los paños hispanos solamente hacer algunas consideraciones referentes a los llamados sanjuanes, los más caros, entre 1500 y 1900 maravedís la pieza, por ser paños mayores de mejor calidad. Les siguen los pardillos, que eran paños secenos, y los pardos de inferior calidad. Todos ellos de fabricación tanto castellana como aragonesa. Los primeros llamados también manchegos o del Marquesado de Villena, por lo que respecta a los de Chinchilla, en Albacete, y Ciudad Real, seguidos de los andaluces, en el caso de Córdoba, Baeza y Úbeda. Se nombran también los castellanos de Segovia, Palencia y Valladolid, todos centros textiles de primer orden.

De procedencia aragonesa son los pardillos de Zaragoza, junto a los bervís y los urebi de Valencia. Recuérdese que los paños valencianos, tan- 
to de la ciudad como de la tierra, sobre todo los bervís, eran muy renombrados y su comercio, con el de otros paños de importación, estaba extendido en Castilla.

Las diferencias de precios siguen los mismos criterios que los paños de importación: calidad de la textura y color. La expresión de paños subidos en color demuestra este hecho.

En cuanto a las diferencias de expresión de términos textiles entre la versión de Liciniano Sáez y la madrileña, existen algunas que no afectan tan sólo al estilo, sino, lo que es más importante, a la propia comprensión del término en cuestión. La mayor parte se deben a errores de trascripción y comprensión. Se pueden anotar las siguientes:

- Paños de importación: Testre por cestre.

- Paños de seda: Trapetes por tapetes

El resto de la diferencias de precio referidas al sector textil afectan a los lienzos llamados de cerro y de lino: 6 maravedís en la edición de Sáez y de 6 a 7 en la copia de Madrid. El capítulo de los tundidores es el más significativo. De hecho es la referencia que aparece en el expositivo del documento cuando los procuradores se quejan al rey de los elevados precios del tundir: "e sabra vuestra merçed que espeçialmente los tondidores del tondir, e de cada vara de panno llievan ocho maravedis e dies e mas, non enbargante que quando mas solian levar eran tres maravedis e dende ayuso..."226. Las diferencias no son demasiado significativas: 7 maravedís y medio en Sáez y 7 en la copia de Madrid en el tundir del sayal pisado y batanado, y 3 blancas, suponemos que de las viejas, y 2 maravedís repectivamente en las brujas de suerte, bervís, contrays e yprés.

Las únicas diferencias de expresión que hemos encontrado son las referidas al precio del tundir la vara de algunos paños, como palpinilla en vez de palmela, tal y como aparece en el documento que trascribimos. En este caso pensamos que no se trata de un error de Sáez sino en diferentes maneras de denominar a un mismo paño.

La industria de la confección está ampliamente representada en el ordenamiento a través del precio de cada una de las prendas de vestir más habituales del siglo xv. En este caso, como en los restantes, prescindimos de la provisión de Madrigal, por cuanto ésta sólo modificó el precio de algunos paños, sin que variasen el resto de las mercancias con respecto al or-

226 Ver apéndice documental n. ${ }^{9} 1$. 
denamiento. Las diferencias en el salario de los sastres por hechura o confección de determinadas prendas es la que sigue:

\begin{tabular}{lll}
\hline \multicolumn{3}{c}{ Cuadro de comparación de precios de prendas de vestir } \\
\hline & Liciniano Sáez & Copia de Madrid \\
\hline Capirote de vestir & 12 & 10 \\
\hline Corocha (clocha) sencilla & 15 & 25 \\
\hline Manto corto doblado & 20 & 30 \\
\hline Sayas de paño fino dobladas & 20 & 25 \\
\hline
\end{tabular}

Sin duda las diferencias de precio más evidentes son las que se refieren a este sector. En cuanto a prendas femeninas sólo aparece una variación en lo que toca a los gramayos de paño fino, cuyo precio en la primera versión es de 60 maravedís y de tan sólo 15 en la copia de Madrid.

Los nombres de algunas prendas de vestir aparecen trascritos de otra forma: clocha por corocha, caperotes por capirotes, en otras ocasiones trascribe capotes y no menciona el asiento que tasa el precio de tajar y guarnecer calzas de paño fino. Del mismo modo en el capítulo de los jubones trascribe mición por cisión, referente a la confección de jubones cortados de paño y seda: "jubon de panno con toda çision...".

La industria del cuero es, después de la textil, la que más aparece representada a través de los precios tanto de cueros como del calzado en general. En lo que respecta a la materia prima sólo una diferencia de precios en el cuero de macho vacuno al pelo: 75 maravedís en la edición de Sáez y 65 maravedís en la segunda versión del ordenamiento. Mayores contrastes se reflejan en el calzado, según el siguiente cuadro:

\begin{tabular}{lll}
\hline \multicolumn{3}{c}{ Cuadro de comparación del precio del calzado } \\
\hline & Liciniano Sáez & Copia de Madrid \\
\hline Medias botas de badana & Par: 20 & Par: 30 \\
\hline Zapatos de badana para mujer & Par: 6 & - \\
\hline Zuecos para mozos de 8-14 años & Par: 12 & - \\
\hline Zuecos de cordobán para mozas & - & Par: 12 \\
\hline Zuecos de baldés para mozas de 7-12 años & Par: 7 & Par: 8 \\
\hline
\end{tabular}

Se observan diferencias notables en la tasa de las medias botas, no apareciendo variables significativas en el resto, exceptuando la mención a zuecos para mozos, cuando sabemos que este calzado era habitual- 
mente femenino. En esta ocasión no podemos confirmar del todo un error de trascripción, pero resulta bastante probable. En cuanto a los borceguíes, la primera versión tasa el par de los de cordobán sin banda a 35 maravedís, mientras la segunda lo hace a 40 maravedís. No se menciona en la primera versión el precio de los borceguíes de cordobán con banda.

Las diferencias de expresión se refieren mayoritariamente a términos técnicos: cuero cutrial por cutral, forma por horma y picados por pintados al referirse a los chapines de colores.

El capítulo del metal ofrece también diferencias significativas:

\begin{tabular}{llc}
\hline \multicolumn{3}{c}{ Cuadro de comparación de precios del metal } \\
\hline & Liciniano Sáez & Copia de Madrid \\
\hline Cobre de Berbería en pasta & Arroba: 150 & Arroba: 170 \\
\hline Estaño en verga & Arroba: 205 & Arroba: 225 \\
\hline Latón & Quintal: 3.500 & Quintal: 1.500 \\
\hline & Libra: 500 & - \\
\hline Fruslera & Arroba: 575 & Arroba: 375 \\
\hline
\end{tabular}

La diferencia más importante es la del precio del quintal de latón. Llama poderosamente la atención los 1.500 maravedís de la copia de Madrid frente a los 3.500 maravedís. En el resto de los oficios metalúrgicos las diferencias son escasas. Tan sólo 1 maravedi frente a las 3 blancas de la primera versión por el trabajo de los herradores de sangrar mulas o acémilas. La única diferencia en los plateros es la de labrar oro en cintas y cadenas: 10 florines el marco en la edición de Sáez y de 8 a 10 florines en la copia madrileña.

En cuanto a determinadas expresiones, Sáez trascribe aniel por Argel, del cobre en pasta que procedia de este país, callialta por talla alta al referirse al tamaño de las herraduras para caballos, asnal por acemilar y herrar por reherrar, al confundir la «r" inicial de doble trazo en forma de vientre caído con una "h». Los nombres de piezas de menaje que aparecen en el capítulo de los plateros son objeto también de distintas expresiones como escodillas por escudillas, pero que, en este caso, no afectan demasiado a su significado.

En el resto de los capítulo dedicados a las pieles de vestir, los escudos y lanzas y los oropeleros las diferencias son las siguientes:

- Pieles de vestir: conduytes por condoites, pago de azor por papo de civor y grises de cote por tocada. 
- Escudos y lanzas: paveses dorados por encorados, ballesta de garruialos por garrucha, escudos endorados por encorados.

- Oropeleros: libra de oropel por libro de oropel y locados por nocados al referirse a los panes de oro del oropel.

\section{GLOSARIO DE TÉRMINOS}

Industria textil227

ACEITUNi: Paño de seda procedente de Oriente en forma de terciopelo de color aceituna, aunque los habia de otros colores. El ordenamiento cita el vellud vellotudo, es decir, el terciopelo velludo y tupido, áspero al tacto y que formaba una especie de cordoncillo. El ordenamiento habla de aceituníes de labores, es decir bordados y también rasos, en el sentido de con menos pelo.

BERvis: Paño de lana de cierta calidad procedente de la ciudad brabanzona de Wervicq, en Flandes. Desde el siglo xv se elaboraba también en la península, sobre todo en Valencia.

Brocado: Paño de seda de la mejor calidad bordado con motivos en relieve de hilo de oro o plata para la confección de los atuendos más suntuarios.

BruJus: Paño de lana fino original de esta ciudad flamenca, cuya producción acabó también realizándose en la península con el nombre de camelotes.

CEndAL: Tejido de seda de gran valor considerado como paño de lujo, muy delgado y transparente, utilizado para la confección de calzas, casullas, forros, capas, sayas, mantos, tocas y demás.

Cestre: Paño de lana fino procedente de Flandes.

CLusquín: Paño de lana fino procedente de la ciudad portuaria de L'Ecluse, puerto comercial flamenco, cerca de Brujas, que mantuvo un intenso tráfico comercial con los puertos del Cantábrico y el Mediterráneo durante toda la Edad Media.

CONTRAYS: Paño de lana fino y de calidad procedente de la ciudad flamenca de Courtrai.

DAMASCO: Paño de seda que aparece como una variedad del brocado con dibujos formados por la trama del propio tejido. Se utilizaba como adorno en las fiestas y ceremonias litúrgicas y solemnes.

227 Para el glosario de términos textiles seguimos a MARTiNEZ MELÉNDEZ, op. cit., de consulta imprescindible para cualquier significado relacionado con esta materia y a BERNIS, op. cit., en lo relativo a prendas de vestir. 
Escarlata: Paño de lana teñido de este color de gran calidad, introducido por los musulmanes en España y que más tarde se fabricó en Europa. Era considerado como paño de lujo para vestimenta de reyes y personajes importantes.

EstopA: Tela basta o gruesa de lino o cáñamo para prendas de baja calidad.

FLORENTín: Paño de lana de calidad elaborado en Florencia, que fue objeto de comercio e importación en toda Europa.

FUSTÁN: Tela gruesa mezcla de algodón y lino con pelo por una de las caras que solía importarse de Europa occidental, bien Italia o las zonas del Levante, aunque también se fabricaron en España. Se teñían con sustancias colorantes como el zumaque, el olmo o el acebuche, de ahí las expresiones fustán de olmo o de acebuche. El fustán se utilizó para la confección de casullas, mantos, sayas y, sobre todo, jubones.

Grana: Paño fino de lana de gran calidad teñido de esta sustancia de color rojo, que admitía también otras tonalidades como el morado, el violeta o el rosado. Se utilizó para la confección de capuces, capirotes, calzas, sayas, clochas, jubones, aljubas, etc. Fue el tejido predilecto de los estamentos sociales más elevados, ya que aparece en casi todas las leyes suntuarias.

LIENZO: Tela de lino o cáñamo de escasa calidad y de diversos colores empleada para forros, cortinas, camisas, tocas, colchas, cojines, sábanas, manteles, etc. Se podían importar y los de mejor calidad eran los de Holanda. LIRIA: Paño de lana fino y de calidad fabricado en la ciudad flamenca de Lierre. LONDRES: Paño de lana de calidad elaborado en dicha ciudad inglesa. Su producción empezó a imitarse también en la península desde el siglo xV conservando la denominación de origen.

MelLinas: Paño de lana de calidad procedente de la ciudad flamenca de Malines, cuyo comercio estuvo muy extendido en la península durante la Edad Media. El término se refiere a los paños fabricados en esta ciudad como denominación de origen. A su vez existían otros paños, como los velartes, también de Mellinas.

Mostreviller: Paño de lana fino elaborado en la ciudad flamenca de Montivilliers.

PALMELA: También denominado palmilla, era un paño de lana que se elaboraba en Cuenca y otras ciudades textiles como Murcia. El más estimado era el de color azul. Con él se confeccionaban ropas de abrigo.

PARDILLO: Paño de lana tosco, grueso y basto sin teñir, de ahí su nombre, utilizado por gente de baja condición social.

PARDO: Paño de lana de poca calidad, de color gris oscuro utilizado por las gentes más humildes para las prendas de vestir o para la confección de mantas y otros enseres domésticos. 
PERPIŃán: Paño de lana fino procedente de esta ciudad francesa.

PICOTE: Tela áspera y basta de piel de cabra, bastante barata, empleada para la confección de vestimentas rudimentarias o de poca calidad.

SANJUANES: Paño de lana de los de mejor calidad que se fabricaban en la península.

SAYAL: Tela de lana burda de poca calidad y bajo precio que la nobleza y el clero acostumbraba a dar como limosna a los pobres. Del sayal se hacian capas, sayas, mantos, etc

SERGA: Se dice también xerga o paño basto de lana, grueso y tosco, de escasa calidad empleado para hacer costales, sacos y albardas para las bestias de carga.

TAPETE: Paño de seda de terciopelo utilizado como cobertor o pequeña alfombra.

TERCENEL: Paño de seda fino utilizado para estandartes, banderas y adornos de trompetas.

VelaRTE: Paño de lana lustroso de color negro que servía para capas, sayos y otras prendas exteriores de abrigo. De origen europeo, básicamente flamenco, está también constatada su elaboración en la península desde el siglo $\mathrm{xV}$.

VerRia: Paño de lana fino de Flandes.

YpRÉs: Paño de lana fino fabricado en esta ciudad de Flandes.

\section{Pieles de vestir}

ABORTON: Piel de animales non natos o nacidos antes de tiempo. El abortón blanco era la piel del cordero y el prieto la de otros animales de estas características. Todas ellas pieles suaves y flexibles debido a la naturaleza del animal o feto.

ARMIÑo: Mamífero de corta longitud y de piel suave y delicada muy empleada en peletería.

CONDOITE: Piel extremadamente suave y flexible

GRISES: Llamados también petigrises o variedad de ardilla de Siberia cuya piel de este color era muy estimada.

MARTA CEBELLINA: Mamífero más pequeño que las llamadas comunes, de color parduzco, procedente del norte de Europa, de piel suave y fina, muy apreciada en la industria peletera.

MARTA COMÚN: Mamífero de pequeña longitud y larga cola, de pelo suave y espeso de color leonado abundante en la península y cuya piel era una de las más apreciadas.

VERO: Piel de una especie de marta cebellina manchada de varios colores. 
Industria de la confección 228

AlJUBA: Traje de encima utilizado por ambos sexos, aunque en el ordenamiento se cite como atuendo femenino, que se vestía sobre la saya. También se dice que aljuba y mantillo formaban parte de la misma vestimenta.

BALANDRÁN: Traje largo de llevar encima, muy holgado y con mangas, abierto por delante de arriba abajo y de uso muy común, sobre todo entre nobles y caballeros, así como entre doctores y letrados en la época de Juan II. Los había doblados y sencillos, siendo los primeros los más caros.

CALZAS: Prenda que básicamente los hombres llevaban ceñida a las piernas y el cuerpo hasta la cintura donde se sujetaban al jubón por medio de agujetas. Se forraban de lienzo para lograr que se ciñesen mejor al cuerpo.

CAPIROTE: Especie de capuchón rematado en punta que a partir del siglo XIV podía llevar una cola llamada manga. Se empleaba en el vestir como complemento de la loba o traje largo de llevar encima muy empleado por los letrados. También se documenta su uso por los hombres como traje de duelo junto al capirote que colgaba sobre los hombros. Otro tipo de capirote era el de rollo, usado como tocado. El ordenamiento cita los de vestir.

Clocha: Traje de llevar encima muy holgado, documentado por $\mathrm{C}$. Bernis básicamente en Aragón, pero que en el ordenamiento aparece repetidamente, habiendo clochas dobladas y sencillas, masculinas y femeninas, asi como de camino, lo que indica que se utilizaba como especie de abrigo.

COTA: Traje masculino y femenino de llevar encima, aunque en el ordenamiento aparezca como ropa de mujer. Parecidos a la saya, no eran tan ceñidos y se podían plegar con un cinturón a la cintura.

GramaYo: Traje muy holgado y largo de llevar encima utilizado para vestir de duelo y para protegerse de la lluvia.

JUBÓN: Prenda masculina, elaborada generalmente en fustán, aunque también los había de paño y de seda. Fue muy habitual en el siglo xv, y se ponía sobre la camisa y cubría la mitad superior del cuerpo hasta la cintura, donde se sujetaba a las calzas con agujetas. Se forraba de lienzo para darle mayor rigidez, ya que se trataba de una prenda muy ceñida, marcando la silueta.

228 Seguimos a BERNIS, op. cit., que ofrece una relación pormenorizada y acompañada de ilustraciones de las principales prendas de vestir masculinas y femeninas del siglo xv en España. 
MANTILLO: Manto pequeño de mujer de forma semicircular de carácter muy popular. En el ordenamiento se cita junto a las aljubas y pellotes como formando parte del mismo atuendo femenino.

MANTO: Prenda habitualmente femenina que se usaba para cubrirse, elaborada con paño de lana. Según el ordenamiento los había grandes, en forma de segmento de círculo y cortos o en forma de capa, que se acoplaban a la forma de los hombros. A su vez podían ser dobles o sencillos.

PELLOTE: Traje de encima de ambos sexos, pero mencionado en el ordenamiento como ropa de mujer. Junto con el mantillo formaba parte de la misma vestimenta femenina.

SaYA: Traje que tanto hombres como mujeres vestian sobre la ropa interior, diferenciándose de los trajes de llevar encima en que no era una prenda holgada sino ceñida. Para que la saya quedase estirada y ajustada al cuerpo se forraba con lienzo, al igual que los jubones y calzas. Así aparece en el ordenamiento como sayas "guarnidas en lienço". Las había dobles y sencillas.

Cueros $^{229}$

BADANA: Piel curtida de carnero $u$ oveja, muy flexible y de mejor calidad que el baldés.

BALDÉs: También se dice baldrés o piel curtida de carnero u oveja de inferior calidad, suave y endeble.

CORDOBÁN: Piel curtida de cabra o macho cabrío, cuya denominación procede de la ciudad de Córdoba donde estos cueros eran elaborados desde época musulmana. Se trata del cuero de la mejor calidad y el más caro.

\section{Calzado}

Balva: Especie de zapatilla flexible elaborada con badana.

BorCEgui: Calzado que llegaba hasta más arriba del tobillo, abierto por delante y que se podía sujetar por medio de correas o bandas de cuero, de ahí la expresión de borceguíes con banda.

CHAPíN: Especie de chancla femenina realizada en corcho con alta suela forrada de cordobán, badana o baldés, que podía ir pintada de diversos colores y decorada con adornos de metal. Eran de cierto renombre los sevillanos.

229 Tanto para los cueros como el calzado me remito a mi trabajo, Puñal FERnÁndez, Los artesanos de Madrid..., 159 y ss y 236 y ss para los tipos de calzado. 


\section{Metales}

FRUSLERA: Latón o azófar.

\section{Armas}

PAVÉS: Escudo oblongo de gran tamaño utilizado como defensa para cubrir la mayor parte del cuerpo. Se fabricaban de madera y luego se recubrian o forraban de cuero, los llamados encorados. También se pintaban. Había paveses enteros, llamados vulgarmente escudos y medios paveses que sólo cubrían medio cuerpo. Su función era la de sortear las flechas y dardos lanzados con ballesta. Junto al resto de armamento de infantería, eran de cierto renombre los gallegos y los de la montaña, en el sentido de los fabricados en el norte de España.

\section{Menaje}

Platel: Especie de plato o bandeja para comer o servir la comida.

ESCUDILLA: Vasija ancha en forma de esfera para contener líquidos, básicamente caldos.

SeRVILLA: Procede del latín "servir" y no es otra cosa que la salvilla o bandeja con encajaduras donde se aseguraban las tazas o copas que se servían en ella, de ahí el nombre.

PICHeL: Vaso alto y redondo, más ancho en la base que en la boca, con tapa engarzada en el asa. 
1'psind cilangffinat

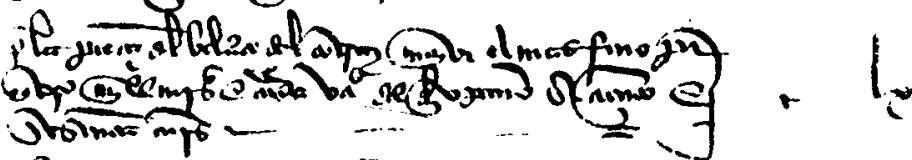

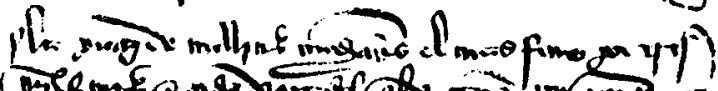

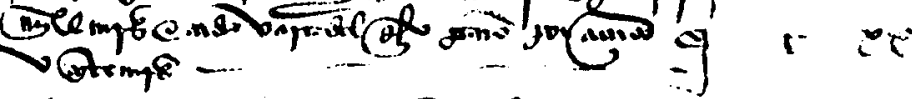

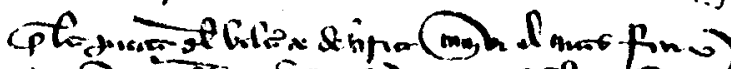

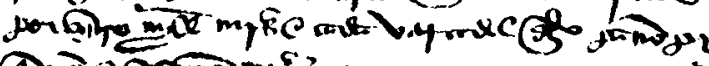

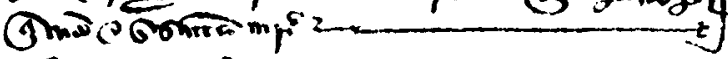

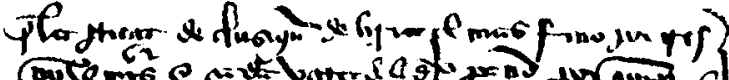

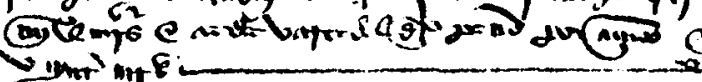
Sintrint

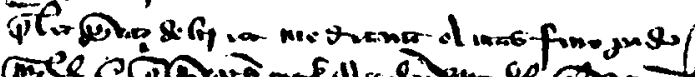

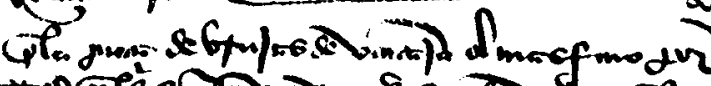

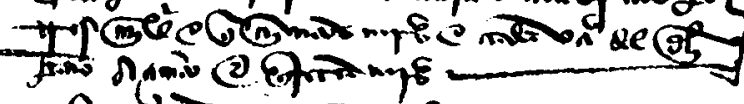

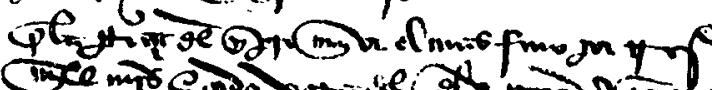

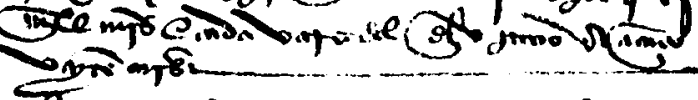

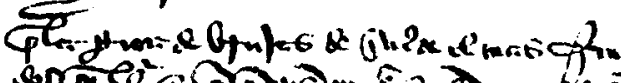

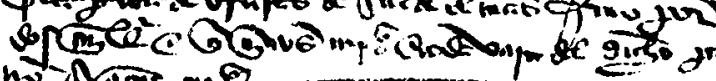
nv-drm me

QPe

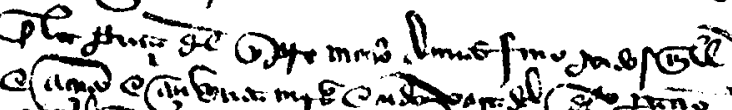

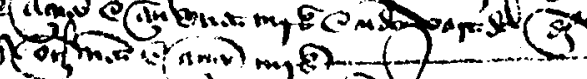

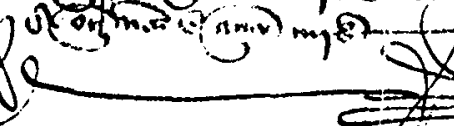




\section{APÉNDICE DOCUMENTAL}

Normas de trascripción:

Primero, se han actualizado las grafias, aunque respetando los nombres y expresiones, tal y como vienen en el texto.

Segundo, se actualiza la ortografía, con puntos, comas, acentos, mayúsculas, separación de algunos párrafos y demás.

Tercero, se colocan en cursiva el desarrollo de las abreviaturas.

Cuarto, se señalan los saltos de folio.

Quinto, los correspondientes calderones ortográficos se señalan con un +.

Archivo de Villa de Madrid

1442, julio. Valladolid.

Secretaría, sin signatura

(microfilms 777/90)

«Documentos reales» (1403-1473)

Ordenamiento general de los precios de las mercancias y salarios de determinados artesanos en tiempo de Juan II de Castilla.

Provisión Real. Ordenamiento. Copia. Manuscrito. 10 f. r-v. $24,5 \times 33 \mathrm{cms}$. Papel. Cortesana. R. (pequeñas manchas por hongos y algunas taladraduras por insectos).

(f. 1 r.)

+ Este es traslado de un traslado de un cuaderno de ordenanzas hecho por el Rey nuestro señor en la villa de Valladolid firmado y signado de escribano y notario público, según que por él parecía, el tenor de la cual es este que se sigue.

Este es traslado de un traslado de un cuaderno de ordenanzas hecho por el Rey nuestro señor en la villa de Valladolid con acuerdo de los de su Consejo a petición de los procuradores de las ciudades y villas y lugares de los sus reinos y firmada de su nombre y sellada con su sello, su tenor de la cual es este que se sigue. 
Don Juan por la gracia de Dios, rey de Castilla, de León, de Toledo, de Galicia, de Sevilla, de Córdoba, de Murcia, de Jaén, del Algarbe, de Algeciras, y señor de Vizcaya y de Molina, a los infantes, duques, condes, prelados, ricos hombres, maestres de las órdenes, priores, y a los del mi Consejo y oidores de la mi Audiencia y alcaldes y alguaciles de la mi Casa y Corte y Chancillería, y a los mis adelantados y merinos y a los comendadores, subcomendadores, alcaides de los castillos y casas fuertes y llanas, y a los concejos, alcaldes, merinos, alguaciles, regidores, caballeros, escuderos, oficiales y hombres buenos de la muy noble ciudad de Burgos, cabeza de Castilla, mi Cámara, y de todas las otras ciudades y villas y lugares de los mis reinos y señoríos y a otros cualesquier mis súbditos y naturales de cualquier estado y condición, preeminencia o dignidad que sea, y a cada uno y cualquier de vos, salud y gracia.

Sepades que yo estando en la noble villa de Valladolid, estando y conmigo la reina doña María, mi muy cara y muy amada mujer y el rey don Juan de Navarra, mi muy caro y muy amado primo y el principe don Enrique, mi muy caro y muy amado hijo primogénito, heredero en los mis reinos y el infante don Enrique, maestre de Santiago, mi muy caro y muy amado primo y el almirante don Fadrique, mi primo y cuantos condes, prelados y ricos hombres y caballeros y doctores del mi Consejo, por los procuradores de las ciudades y villas de mis reinos que conmigo están ayuntados, fueron dadas ciertas peticiones, entre las cuales se contiene una, su tenor de la cual es este que se sigue

Muy alto y esclarecido príncipe y muy poderoso rey y señor.

+ Vuestros servidores los procuradores de las ciudades y villas de los vuestros reinos, besamos vuestras manos y nos encomendamos en vuestra merced, la cual bien sabe como hubo ordenado que el marco de la plata valiese quinientos y sesenta maravedis y ${ }_{1} 1$ so ciertas penas contra aquellos que lo no guardasen, lo cual no embargante, no se halla platero alguno que quiera vender sólo un marco de plata, salvo terçiado, so color de hechura de ello, cinco tantos de lo que merece y de aquello que solía llevar.

\section{(f. 1 v.)}

+ Otrosí muy exçelente Rey y señor, no embargante que el oro está en tan grandes precios, según que vuestra alteza sabe, según la ordenanza

1 llegible en el documento. Parece por el contexto de la frase que pudiera poner "impuso" o palabra parecida. 
por vuestra merced hecha, asi los paños mayores y menores como lienzos y fustanes y cera y otras mercaderias y cosas que están en tan altos precios y más, que al tiempo que valía la dobla ciento y sesenta maravedís y un florín ciento y diez maravedís. Y así mismo así los sastres como tundidores y jubeteros y zapateros y otros oficiales llevan grandes precios inmensos por la hechura de las ropas y por el calzado, de más y allende de lo que solian llevar. Y sabrá vuestra merced que especialmente los tundidores del tundir, y de cada vara de paño llevan ocho maravedís y diez y más, no embargante que cuanto solían llevar era tres maravedís y dende ayuso. $Y$ si en esto no se remediase redundaría gran deservicio a vuestra alteza y gran daño así a los que andan en vuestra Corte como a los otros de vuestros reinos.

Por ende muy virtuoso señor Rey suplicamos a vuestra alteza que mande poner tasa en los fardeles de paños mayores, asi ypres como londres y brujas y berlartes (sic) y cestres y contrays y de los otros paños y en la pieza de cada paño mayor y por consiguiente en la vara de cada uno de los dichos paños y en las lanas y cera y en el herraje y en las otras cosas que menenester fuere y que se guarde asi en vuestra Corte y en las ciudades y villas de vuestros reinos, lo cual se haga so grandes penas, las cuales sean ejecutadas en aquellos que lo no guardaren y contra ello fueren, por que así cumplan con vuestro servicio y a pro y bien común de vuestros reinos.

$Y$ yo viendo que lo contenido en la dicha petición es muy cumplidero a mi servicio y al bien común de mis reinos y señoríos y queriendo proveer y proveyendo sobre ello, habido respeto y consideración al valor que las mercaderías y cosas valían en mis reinos al tiempo que el rey don Enrique, mi padre y mi señor, mandó labrar su moneda de blancas y así mismo al valor que entonces valía la moneda del oro hasta el tiempo que mandé labrar la mi moneda de blancas. $Y$ otrosí habido respeto y consideración a los precios que yo ahora mandé y ordené que valiese y fuese recibida en mis reinos la dicha mi moneda de blancas, y eso mismo al precio que ahora mandé y ordené que valiese la moneda del oro y plata de la dicha mi moneda de blancas y de la moneda de blancas del dicho rey mi padre y mi señor, que es toda una, según el precio en que la yo ahora mandé poner y valer en que anduviese y fuese recibida, es mi merced y mando y ordeno por la presente, la cual quiero y mando que haya fuerza y vigor de ley y sea habida y guardada como ley y de aquí adelante, así en la mi Corte como en todas las ciudades y villas y lugares de mis reinos, asi realengos como abadengos y órdenes y behetrías y señoríos y otros cualesquier, valgan y se vendan y compren y paguen las mercaderías y las otras cosas que en esta mi ordenanza sean declaradas a los precios siguientes y no más ni allende. 
(f. 2 r.)

\section{+ Paños de lana finos}

+ Primeramente es mi merced que valga y se venda y pague la pieza del bellarte de mellinas, el más fino por cuatro mil y quinientos maravedís y cada vara del dicho paño a ciento y ochenta maravedis

180 maravedís.

+ La pieza del belarte del contray mayor, el más fino por cuatro mil maravedís y cada vara del dicho paño a ciento y sesenta maravedís

+ La pieza de mellinas medianas, el más fino por tres mil maravedís y cada vara del dicho paño por ciento y veinte maravedís

+ La pieza del belarte de liria mayor, el más fino por cuatro mil maravedís y cada vara del dicho paño por ciento sesenta maravedís

+ La pieza de clusequín de liria, el más fino por tres mil maravedís y cada vara del dicho paño por ciento y veinte maravedís

+ La pieza de liria mediana, el más fino por dos mil y quinientos maravedís y cada vara del dicho paño a cien maravedís

+ La pieza de brujas de ventaja, el más fino por tres mil y quinientos maravedís y cada vara del dicho paño a ciento y cuarenta maravedís

+ La pieza del ypre mayor, el más fino por tres mil maravedís y cada vara del dicho paño a ciento y veinte maravedís

+ La pieza de brujas de suerte, el más fino por dos mil y quinientos maravedís y cada vara del dicho paño a cien maravedis

+ La pieza del ypre menor, el más fino por dos mil y ciento y cincuenta maravedís, y cada vara del dicho paño a ochenta y cinco maravedís

160 maravedís.

120 maravedís.

160 maravedís.

120 maravedís.

100 maravedís.

140 maravedís.

120 maravedís.

100 maravedís.

85 maravedís.

\section{(f. 2 v.)}

+ La pieza de contray de suerte, el más fino por dos mil maravedis y cada vara del dicho paño a ochenta maravedís

+ La pieza de berví de Flandes por dos mil maravedis, la vara a ochenta maravedis

+ La pieza de cestre, el más fino por dos mil y doscientos y cincuenta maravedis y cada vara del dicho paño, noventa maravedís

+ De paños de florentín que no sean de grana, que valga la vara del más fino ciento y setenta y cinco maravedis

+ La vara del escarlata de Londres, el más fino cuatro cientos maravedís

80 maravedis.

80 maravedis.

90 maravedís.

175 maravedís.

400 maravedís. 
+ La vara del escarlata de Ypre, el más fino doscientos maravedís

200 maravedís.

+ A los otros paños ingleses, así de grana como de otros colores no se pone precio en ellos por esta mi ordenanza por que hay mucha diferencia de un paño a otro, puesto que sean de una suerte y así es en los paños de grana florentines e ypres y de otros paños, por ende es mi merced de lo dejar y que quede a la discreción de los fieles de cada lugar que pongan en ellos precios razonables, habiendo la consideración susodicha.

+ Así mismo a los paños de seda brocados no se pone precio por esta mi ordenanza y por la diferencia que hay de un paño a otro, pero es mi merced que los dichos fieles los tasen razonablemente considerando que peso quieran de oro y de seda en la vara y puesto las costas del traer y la razonable ganancia.

\section{+ Paños de seda y bocaranes}

+ Aceituníes de todas colores vellud vellutado, el más fino cada vara de ello cuatrocientos maravedís

(f. 3 r.)

+ Aceituníes de todas colores de labores, el más fino cada vara a trescientos maravedis

+ Tapetes de todas colores, el más fino cada vara a doscientos y cincuenta maravedís

+ Damascos de todas colores, el más fino cada vara a doscientos y cuarenta maravedis

+ Aceituníes rasos de todas colores, lo más fino cada vara a ciento y ochenta maravedis

+ Terceneles de todas colores, lo más fino cada pieza, trescientos maravedís

+ Lo de Mesin (sic) de todos estos dichos paños de seda debe valer más precio según la fineza y subimientos de color que en ellos hubiere, lo cual quede a consideración y buena tasación de los dichos fieles.

+ Cendales de todas colores, lo más fino cada vara cuarenta maravedís

+ Bocaranes de todas colores, lo más fino cada pieza setenta maravedís

\section{+ Los paños que se hacen en los mis reinos y los que se traen de Aragón}

+ Sanjuanes prietos y pardillos y de semejantes paños, cada pieza de lo más fino por mil y quinientos maravedís y cada vara del dicho paño a sesenta maravedís
400 maravedís.

300 maravedís.

250 maravedís.

240 maravedís.

180 maravedís.

300 maravedís.

40 maravedís.

70 maravedis.

60 maravedís 
+ Sanjuanes de todas otras colores y de semejantes paños, cada pieza de lo más fino por mil y doscientos y cincuenta maravedís y cada vara del dicho paño a cincuenta maravedís

+ Paños pardillos y de otras colores que sean bervíes de Va- lencia, cada pieza del más fino por mil y ciento maravedís y cada vara del dicho paño, cuarenta y cinco maravedis

50 maravedís.

45 maravedís.

(f. 3 v.)

+ Pardillos de Zaragoza y otros semejantes, cada pieza de lo más fino por novecientos maravedis y cada vara del dicho paño a treinta y seis maravedís

+ Pardillos de Valladolid y Segovia y otros semejantes, cada pieza de lo más fino por mil maravedís y cada vara del dicho paño, cuarenta maravedís

+ La pieza de otros pardillos que hacen en otros lugares, lo más fino por setecientos y cincuenta maravedís y cada vara de los dichos paños a treinta maravedís

+ Paños de Palencia y Cuenca y Córdoba y azules y verdes oscuros, cada pieza de lo más fino por ochocientos y cincuenta maravedís y cada vara de los dichos paños a treinta y cuatro maravedís

+ Cada pieza de los paños que se hacen en todos estos dichos lugares de todas las otras colores, lo más fino por setecientos y cincuenta maravedís, y cada vara de los dichos paños a treinta maravedís

+ Los paños verde oscuros y azules que se hacen en Ciudad Real y en Baeza y Chinchilla y de semejantes, cada pieza de lo más fino por setecientos y cincuenta maravedis y cada vara de los dichos paños a treinta maravedís

+ Cada pieza de los paños que se hacen en estos dichos lugares de todas las otras colores, lo más fino por setecientos maravedís y cada vara de los dichos paños por veinte y ocho maravedís

+ Los paños pardos limpios y salidos de color de Córdoba y Úbeda y de otros lugares semejantes, cada pieza de lo más fino por setecientos maravedís y cada vara de los dichos paños a veinte y ocho maravedis

+ Cada pieza de pardo canillo, que no sea pardo cerrado en color, que se hacen en los dichos lugares, por seiscientos maravedís y cada vara de los dichos paños a veinte y cuatro maravedís

36 maravedís.

40 maravedís.

30 maravedís.

34 maravedís.

30 maravedis.

30 maravedís.

28 maravedís.

28 maravedis.

24 maravedís.

(f. 4 r.)

+ Cada pieza de pardo limpio y salido en color que se hacen en Ciudad Real y en Baeza y en Chinchilla y en otros semejantes 
lugares por seiscientos maravedís y cada vara de los dichos paños a veinte y cuatro maravedis

24 maravedis.

+ Cada pieza de pardo canillo y no salido en color de pardo cerrado que se hace en estos dichos lugares por quinientos maravedis y cada vara de los dichos paños por veinte maravedís

20 maravedis.

$+Y$ es mi merced y mando que en todos los lugares donde se hacen estos paños en mis reinos, los que los hicieren echen la trama y verdumbre en cada pieza cuanto está ordenado en cada lugar, por que en ello no se pueda hacer arte ni engaño y se hagan de la anchura y longura que hasta aquí se han hecho y labrado, so pena de la mi merced y de perder los paños los que lo contrario hicieren por la primera vez y por la segunda vez que los paguen con el doblo y así vaya dende adelante creciendo esta pena.

\section{+ Papel}

+ Cada resmada de papel cebtí del carro a ciento y veinte y cinco maravedís y cada mano de ello por siete maravedís

7 maravedís.

+ Cada resma de papel cebtí de lo otro por ciento y cinco maravedís y cada mano de ello a seis maravedís

+ Cada resma de papel toledano y de lo de barbadillo por ciento y diez maravedís y cada mano de ello a seis rnaravedís

6 maravedís.

6 maravedis.

\section{+ Lanas}

+ Cada arroba de lana merina en el condado de Medinaceli

65 maravedis.

+ Cada arroba de lana merina en tierra de Cuenca

+ Cada arroba de lana merina en tierra de Soria y de Yanguas y los Cameros

+ Cada arroba de lana merina en tierra de las Cinco Villas

65 maravedís.

75 maravedis.

77 maravedis.

\section{+ Fustanes}

+ Cada pieza de fustán de olmo por doscientos y cincuenta maravedís y cada vara del dicho fustán a quince maravedis

15 maravedís.

(f. 4 v.)

+ Cada pieza de fustán de acebuque por ciento y noventa maravedís y cada vara de ello a doce maravedís

12 maravedís.

+ De los otros fustanes que vienen de Génova y de otros lugares que son en Levante, cada pieza de ellos por ciento y noventa maravedis y cada vara de ellos a doce maravedis

12 maravedís. 


\section{+ Lienzos}

+ Cada vara de lienzo de cerro y de lino de seis a siete maravedís

7 maravedis.

+ Cada vara de estopa, cuatro maravedís y medio

4,5 maravedis.

+ $Y$ en los otros lienzos y cáñamos no se pone precio en esta mi ordenanza por que son de diversas maneras y no se podría bien poner, pero es mi merced que quede a bien vista y tasación de los dichos fieles de cada lugar.

\section{+ Peñas}

+ Martas cebellinas enteras, las más finas cada una por doscientos maravedis y cada una de las dichas martas cebellinas, el más fino setenta maravedís

70 maravedís.

+ Martas comunes enteras, las más finas cada una setenta maravedís y cada iomo de las dichas martas comunes, el más fino veinte y ocho maravedis

+ Condoites, el más fino cuatrocientos maravedís

+ Grises del mazo de los más finos que dicen papo de civor, cada uno seis maravedís y los de cotada, cada uno el más fino tres maravedís

+ Veros cada uno, el más fino, dos maravedís

+ Armiños cada timbres (sic) de la marca mayor, el más fino setecientos maravedís

+ Cada trimbre (sic) de armiños de la marca menor, el más fino seiscientos maravedís

+ Abortones blancos, cada docena de los más finos

28 maravedis. 400 maravedis.

3 maravedis.

2 maravedis.

700 maravedis.

600 maravedís.

42 maravedis.

(f. 5 r.)

+ Abortones prietos, cada docena de los más finos cuarenta y dos maravedis

42 maravedís.

\section{+ Cueros}

+ Cada cuero de buey que llaman cuitral, curtido y adobado, el mejor ciento y quince maravedís

115 maravedis.

+ Cada cuero de vaca curtido y adobado, el mejor noventa maravedís

+ Cada cuero de becerro curtido y adobado, el mejor cincuenta maravedís

+ Cueros para vino adobados y empegados y bien aderezados, cada uno el mejor de tres cántaras y media, treinta maravedís

90 maravedís.

50 maravedís.

30 maravedís. 
+ Cada quintal de la corteza aquende los puertos, cincuenta y cinco maravedís

+ Curtir un cuero de buey cuitral, veinte maravedís

+ Curtir un cuero de vaca, diez y siete maravedís

+ Curtir un cuero de becerro, doce maravedís

+ Cada cuero vacuno macho al pelo, sesenta y cinco maravedís y de vaca cincuenta y cinco maravedís y de dos cueros de becerros de sobre un año, tanto como un cuero mayor

+ Cordobanes adobados prietos cada uno de ellos, el mejor treinta maravedis

+ Badanas adobadas prietas cada una, la mejor catorce maravedís

55 maravedis.

20 maravedís.

17 maravedís.

12 maravedis.

55 maravedis.

30 maravedis. 14 maravedis.

\section{+ Metales}

+ Cada arroba de cobre del Argel en pasta, doscientos maravedis

200 maravedís.

+ Cada arroba de cobre de Flandes en pasta a doscientos maravedis

+ Cada arroba de cobre de Berbería en pasta, ciento y setenta maravedis

+ Cada arroba de estaño en verga, doscientos y veinte y cinco maravedís

+ Cada arroba de estaño en pasta, doscientos y veinte y cinco maravedis

+ Cada arroba de plomo en pasta, ciento y setenta maravedís

+ Cada quintal de latón por mil y quinientos maravedís

200 maravedís.

170 maravedís.

225 maravedis.

225 maravedis.

170 maravedís. 1500 maravedís.

(f. 5 v.)

+ Cada arroba de fluslera, trescientos y setenta y cinco maravedís 375 maravedis.

\section{+ Madera}

+ Es mi merced que los dichos fieles de cada lugar tasen lo que debe valer cada carretada de madera, asi de Valsain, como de toda la otra madera, así en Extremadura y tierra de Soria, como en todas las otras ciudades y villas y lugares de los dichos mis reinos y señoríos, considerando los precios de los tiempos pasados antes que subiese el oro y lo reduzcan a lo que ahora puja, y así lo pongan al respecto de como valía entonces, pujando el cuarto más.

\section{+ Escudos y lanzas}

+ Medios paveses encorados y pintados que sean a prueba de ballesta de garrucha, los mejores cada uno

50 maravedis. 
+ Escudos para hombres de pie, encorados y pintados de Galicia, cada uno el mejor treinta y cinco maravedis

35 maravedis.

+ Otros escudos que se hacen en la montaña encorados y pintados, cada uno el mejor veinte y cinco maravedís

+ Lanzas de hombres de pie, de la montaña, cada una la mejor veinte y cinco maravedís

+ Varas de dardos que se hacen en la montaña, cada uno 2 maravedis

25 maravedís.

25 maravedís.

2 maravedis.

\section{+ Cera y otras cosas}

+ Cada arroba de cera donde más valiere, la mejor por doscientos y sesenta maravedis

260 maravedís.

+ La miel quede a tasación y arbitrio de los dichos fieles según el lugar y el tiempo.

+ Cada arroba de sebo, lo mejor a setenta y cinco maravedís 75 maravedís.

+ La pez y resina quede a tasación y arbitrio de los dichos fieles de cada lugar.

\section{+ Picotes y xergas}

+ Cada vara de picote pisado y batanado, lo mejor

+ Cada vara de sayal pisado y batanado, lo mejor

+ Cada vara de xerga de la larga que es para saquería, lo mejor a cinco maravedís

15 maravedis.

7 maravedís.

5 maravedis.

(f. 6 r.)

+ Cada vara de la otra xerga de que se hace sacas y albardas y otros semejantes menesteres, lo mejor de ello a cinco maravedís

5 maravedis.

+ Cada vara de la otra xerga de que se hacen costales, lo mejor a cinco maravedis

5 maravedis.

\section{+ Tundidores}

+ De tundir paños de grana y florentines y belartes de mellinas y lirias y contrays mayores y otros paños finos, por cada vara cuatro maravedís

4 maravedís.

+ De cada vara de ypre mayor, de brujas, de ventaja y mellinas medianas, tres maravedís

3 maravedís.

+ De cada vara de brujas de suerte y berví y contray e ypres menores, dos maravedis

2 maravedis.

+ De cada vara de blao y de los pardillos de Aragón, tres blancas

1 maravedí y medio. 
+ De cada vara de sanjuan y perpiñán, dos maravedís

2 maravedis.

+ De cada vara de pardo y palmela que se hace en mis reinos, un maravedí

1 maravedi.

De cada vara de los otros paños de mayor cuantía que se hace en mis reinos, dos maravedis

2 maravedís.

+ De todo paño largo de Inglaterra, cada vara tres maravedís

3 maravedís.

+ De paños medianos que se llaman cuartilla, cada vara

1 maravedi y medio.

+ De otro paño de Aragón, tres blancas

1 maravedi y medio.

\section{+ Los precios que deben llevar los sastres}

+ De hechura de un balandrán doblado cuarenta maravedís

40 maravedís.

+ De hechura de un balandrán sencillo, veinte y cinco maravedís

25 maravedís.

+ De hechura de un manto corto doblado

+ De hechura de un manto corto sencillo, quince maravedís

30 maravedis.

15 maravedís.

+ De hechura de una corocha doblada, veinte y cinco maravedís

+ De hechura de un manto grande sencillo, veinte y cinco maravedís

+ De hechura de unos capirotes de paño fino

25 maravedís.

25 maravedís.

15 maravedis.

(f. 6 v.)

+ De hechura de unos capirotes de otro paño, diez maravedís

10 maravedis.

+ De hechura de unas sayas de paño fino dobladas, veinte cinco maravedis

+ De hechura de una corocha sencilla

+ De hechura de sayas de otro paño dobladas, quince maravedís

+ De hechura de sayas sencillas guarnidas en lienzo, diez maravedis

De hechura de un capirote de vestir, diez maravedís

25 maravedís.

25 maravedis.

15 maravedis.

10 maravedís.

10 maravedis.

+ Por tajar y guarnecer unas calzas de paño fino con el lienzo, veinte maravedís

+ Por tajar y guarnecer unas calzas de paño de Flandes con el lienzo, quince maravedís

20 maravedis.

15 maravedís.

\section{+ Ropas de mujeres}

+ De hechura de una cota de paño fino, cincuenta maravedis

50 maravedís.

+ De hechura de una cota de otro paño, treinta maravedís

+ De hechura de un gramayo de paño fino

30 maravedis.

15 maravedís.

+ De hechura de un gramayo de otro paño, diez maravedís

10 maravedís.

+ De hechura de una aljuba y mantillo de paño fino

40 maravedís.

+ De hechura de una aljuba de otro paño, treinta maravedís

30 maravedís. 
+ De hechura de un pellote y mantillo, treinta maravedís

30 maravedis.

+ De hechura de unas corochas de camino dobladas

20 maravedís.

+ De hechura de unas corochas sencillas, diez maravedís

10 maravedis.

+ De hechura de una saya de paño fino, treinta maravedís

30 maravedís

+ De hechura de una saya de otro paño, veinte maravedís

20 maravedis.

+ Las pieles asi de paño como de fustán, sean al precio de los mantones

+ Las ropas de seda de las maneras susodichas, sean al precio el dos tanto de lo susodicho

+ De otras ropas de mandados de otra guisa de las comunes, es mi merced que sea avenencia del sastre con el que las mandaron hacer y si no se aveniere que quede a tasación de los dichos fieles.

(f. 7 r.)

\section{+ Jubones}

+ Por cada jubón para hombre de cualquier guisa, de fustán de olmo

+ Por cada jubón de acebuque o de levante o de parrilla

+ Por cada jubón para pajes y mozos, de fustán de olmo de cualquier guisa, que sea de edad de diez y quince años

+ Por cada jubón de fustán de acebuque o de levante y parrilla, por cada uno para los susodichos

120 maravedís. 100 maravedís.

85 maravedis.

65 maravedís.

+ Por cada jubón para mozos de seis años hasta nueve, de la manera que se hace que sea de fustán de olmo

+ Por otros tales jubones de acebuque o levante o parrilla, por cada uno cuarenta maravedís

+ Por hechura de cada un jubón de paño con toda cisión, sin el paño, cien maravedís

+ Por hechura de cada un jubón de seda con toda cisión, ciento y veinte maravedís

50 maravedis.

40 maravedis.

100 maravedís.

120 maravedis.

\section{+ Zapateros}

+ Por cada par de botas de cordobán enteras, ochenta maravedis

80 maravedis.

+ Por cada par de medias botas de cordobán

+ Por cada par de botas de badanas enteras

50 maravedis

+ Por cada par de medias botas de badanas

40 maravedis.

30 maravedís.

+ Por cada par de zapatos de cordobán catorce puntos

14 maravedís.

+ Por cada par de zapatos de badana engrasados, doce maravedís y dende ayuso cuatro cornados menos por cada punto

12 maravedis.

+ Zapatos de cordobán sin grasa de horma mayor, por cada par once maravedís

+ Zapatos de badana sin grasa, cada par, diez maravedís de horma mayor

11 maravedis.

10 maravedís. 
+ Zapatos de cordobán engrasados para mozos y pajes de la dicha edad de ocho hasta catorce años, cada par diez maravedis

10 maravedis.

(f. 7 v.)

+ Zapatos de badana engrasados para mozos y pajes de la dicha edad, el par ocho maravedís y sin grasa, siete maravedís

+ Cada par de valvas de badanas, veinte y un maravedis

+ Cada par de zapatos de cordobán para mujer, ocho maravedis

+ Cada par de zapatos de cordobán para mozos de ocho años hasta catorce años, seis maravedis

+ Cada par de zuecos de valdrés para mujer, diez maravedís

+ Cada par de zuecos de cordobán para mozas de ocho hasta catorce años, doce maravedís

+ Zapatos de valdrés para mozas de siete hasta doce años, siete maravedís

7 maravedis.

21 maravedís.

8 maravedís.

6 maravedis.

10 maravedis.

12 maravedis.

7 maravedís.

+ Zuecos de valdrés para mozas de siete hasta doce años, cada par ocho maravedís

8 maravedís.

+ Por cabecear botas y solar calzas al precio contenido en los zapatos

+ Zapatos blancos de venados y otros cueros blancos para trabajadores sean puestos en cada lugar a bien visto de los jueces.

\section{+ Oropeleros}

+ De carneros delgados y de ovejas que llaman allende los puertos nocados y aquende el puerto se llaman doblones, por cada docena de los mayores por cincuenta y siete maravedis

57 maravedís.

+ Por cada libro de oropel en que haya trescientos panes puesto en cabritas, noventa maravedis y puesto en nocados, ochenta y cinco maravedis

85 maravedís.

\section{+ Chapineros}

+ Chapines dorados y ferreteados sevillanos para mujer, seis maravedis

6 maravedis.

(f. 8 r.)

+ Chapines de valdrés sevillanos por la misma horma, cinco maravedís

+ Chapines sevillanos negros, cinco maravedís

5 maravedis.

5 maravedís. 
+ Chapines prietos de valdrés sevillanos para mujer

4 maravedís.

+ Chapines dorados pintados de todas colores de dentro y de fuera, once maravedís

+ Chapines de la misma guisa de badana, nueve maravedís

11 maravedís.

9 maravedís.

6 maravedís.

+ Chapines prietos de valdrés hechos en Córdoba, cinco maravedís

+ Chapines de Burgos y León y Toledo y Valladolid y de las otras partes del reino, prietos, seis maravedís

+ Chapines pintados, seis maravedís

5 maravedís.

6 maravedís. 6 maravedís.

\section{+ Borceguies}

+ De cordobán con banda, cuarenta maravedís

+ Borceguies de cordobán sin banda

+ Borceguíes de valdrés con banda

40 maravedís. 35 maravedis.

+ Borceguies de valdrés sin banda 35 maravedís. 30 maravedís.

\section{+ Herradores}

+ Sangrar un caballo grande, tres maravedis

3 maravedís.

+ Sangrar otro cualquier caballo o jaca

2 maravedis.

+ Sangrar una mula o acémila

1 maravedi.

+ Sangrar una yegua, tres blancas 1 maravedí y medio.

+ Una herradura hechiza talla alta para caballo mayor, al herrero que la hiciere, tres maravedís y al herrador por clavos y echarla, dos maravedis, que son

5 maravedís.

+ Por esta vía se pague la herradura que se mandare hacer para trotón o jaca

+ Una herradura de las comunes que sea caballar que se hierre y dé por tres maravedís

3 maravedis.

(f. 8 v.)

+ Una herradura de las semejantes para mula o acémila que se hierre y dé, dos maravedis

2 maravodis.

+ Una herradura acemilar que se hierre y dé por 1 maravedi y medio.

+ Reherrar cada una de las dichas bestias por la mitad de los dichos precios

+ El precio del hierro es mi merced que se ponga en cada arzobispado y obispado, guardando la forma y manera que se tuvo en el poner de las cosas sobre dichas.

+ En el acero es mi merced que se ponga en cada arzobispado y obispado por esta misma vía.

+ De las armas mi merced es de no poner precio señalado por que deben andar según el tiempo que menester sean. 


\section{+ Plateros}

+ Por labrar cada marco de plata blanca llana en plateles y platos y tazas y cucharas y escudillas y otros semejantes con sus menguas, treinta maravedís, tanto que las menguas sean de plata marcada

30 maravedis.

+ Por labrar cada marco de plata blanca llana de jarros y jarras y servillas y picheles y otros semejantes, cincuenta y cinco maravedís

55 maravedis.

$+\mathrm{Y}$ al respecto de los precios sobre dichos se debe considerar que merece labrar el marco de plata en cadenas y cintas y otras semejantes cosas.

+ Por labrar cada marco de oro de cada manera de las sobre dichas, sea dos tanto precio.

$+Y$ del oro que se labrare en cintas y cadenas y otras cosas semejantes, aunque sea de hilo de oro tirado y haya en ello esmalte, que sea el precio de ocho a diez florines el marco según fuere la obra.

\section{(f. 9 r.)}

+ Lo cual todo susodicho y cada cosa de ello es mi merced y mando y ordeno que se use y haga y guarde y cumpla asi en la mi Corte y en todas las dichas ciudades y villas y lugares de los dichos mis reinos y señoríos, así realengos como abadengos y órdenes y behetrías y señoríos y otros cualesquier, como suso dicho es. Y que desde el día que esta mi carta y ordenanza fuere mostrada y publicada en la dicha mi Corte y en esas dichas ciudades y villas y lugares hasta diez días primeros siguientes en adelante, se use y guarde y cumpla todo y cada cosa y parte de ello así y según y por la forma y manera que suso es dicha.

Por que vos mando a todos y a cada uno de vos en vuestros lugares y jurisdicciones que lo guardades y cumplades y ejecutades y hagades guardar y cumplir y ejecutar y que lo hagades asi pregonar por las placas y mercados y otros lugares acostumbrados de la dicha mi Corte y de todas las dichas ciudades y villas y lugares de los dichos mis reinos y señorios, por pregonero y por ante escribano público, por que venga a noticia de todos y de ello no puedan pretender ignorancia. $Y$ que ningunas ni algunas personas de cualquier estado, condición, preeminencia o dignidad que sean, no vayan ni pasen ni consientan ir ni pasar contra ello, ni contra alguna cosa ni parte de ello en algún tiempo por alguna manera, causa o razón que sea y se pueda, por que así es cumplidero a mi serviçio y a pro y bien común de los dichos mis reinos y señoríos. Y si alguna o algunas personas fueren 0 pasaren contra ello o contra cosa alguna o parte de ello que aquel o aquellos que fueren o pasaren contra ello o lo no guardaren, que por la primera 
vez que contra ello o contra cosa alguna de lo susodicho fuere o viniere, pague la estimación de la cosa que así vendiere y por la segunda vez el dos tanto y por la tercera vez el tres tanto y dende en adelante por cada vez que suba por esta misma forma el quinto tanto y cinco tanto y dende arriba. $Y$ que las tales penas sean las dos tantas partes para la mi Cámara y la otra tercia parte para el acusador que lo acusare. $Y$ que las dichas dos tercias partes que son para la dicha mi Cámara sean arrendadas y se arrienden para mí y que yo no pueda hacer ni haga merced de ellas a persona alguna y si hiciere la tal merced que haya sido y sea por el mismo hecho y por ese mismo derecho ninguna y de ningún valor y habida por obreticia y subreticia y ganada por importunidad de tiempo, no embargante que se diga proceder de mi cierta ciencia y propio motu y poderío real absoluto y aunque contenga cualquier cláusulas derogatorias y otras promesas. $Y$ demás que el que la impetrare por el mismo hecho allende de lo susodicho, pague en pena otro tanto para la mi Cámara y no pueda ser ni sea habido por parte ni recibido en juicio ni fuera de juicio para la demandar ni recibir ni litigar sobre ello y aunque haga mención de esta mi ordenanza. $Y$ que el arrendador que así arrendare las dichas dos tercias partes de la dicha mi Cámara sea habido de lo acusar dentro en el tercero día y sí dentro en el dicho tercero día no lo acusare o hiciere en ello algún fraude, que dende en adelante cualquier del pueblo lo pueda acusar y haya para si (f. 9 v.) dicha tercia parte y las otras tercias partes que queden para la dicha mi Cámara.

Y por cuanto en esta mi ordenanza no van declaradas y especificadas todas las otras cosas en que deben ser puestos precios de más y allende de las aquí contenidas, por ende es mi merced y mando que en cada una ciudad o villa o lugar de los dichos mis reinos se ponga precio convenible a cada una cosa de las que aquí no son especificadas, tasándolo todo razonablemente, habiendo respeto y acatamiento a las tierras y lugares y comarcas y al valor que el oro solía valer antes que se labrase la dicha mi moneda nueva que yo mandé labrar en los dichos mis reinos y acrecentando el tal precio al respecto del cuarto más, según se acrecentare o mande acrecentar en el valor del oro este dicho año de la fecha de esta mi carta, esto en aquellas cosas que razonablemente se debiere acrecentar. $Y$ que en la dicha mi Corte los dichos mis alcaldes de ella y en cada una de las dichas ciudades y villas y lugares, los concejos y justicias y oficiales de ellas pongan fieles y buenas personas juramentados, a los cuales sean habidos de nombrar y nombren desde el dicho día de la publicación de esta mi ordenanza hasta diez días primeros siguientes. $Y$ que los tales fieles asi nombrados hagan juramento en forma debida de lo hacer y tasar bien y leal y conveniblemente, pospuesta toda afición y odio e interés y toda otra cosa que embargar pueda el bien común. $Y$ que los tales dichos fieles tasen y 
pongan los dichos precios razonables a todas las otras cosas de que en esta dicha mi ordenanza no se haga mención. $Y$ aquello se guarde y cumpla so las penas susodichas y de las justicias de la dicha mi Corte. Y así mismo de las dichas ciudades y villas y lugares de los dichos mis reinos y señoríos lo hagan guardar y cumplir y ejecutar, cada uno en su jurisdicción, según y por la forma y manera y so las dichas penas que en la dicha mi ordenanza se contienen. $Y$ así mismo según que los dichos fieles lo hicieren y tasaren moderante en las cosas que de suso en esta mi ordenanza no van tasadas y moderadas. $Y$ que lo libren y determinen y ejecuten y conozcan de todo ello simplemente y de plano, sin estrépito y figura de juicio, sabida solamente la verdad, mandando lugar a luengas de malicia, más abreviando lo más que ser pueda. $Y$ que el arrendador que así arrendare las dichas penas no pueda permitir ni dar lugar que persona ni personas algunas vayan ni pasen contra esta dicha mi ordenanza, ni contra alguna cosa de lo en ella contenido, ni contra parte de ello y que si lo hiciere, que sin embargo de ello, cualquier del pueblo lo pueda acusar como es dicho y haya para si la tercia parte de las dichas penas y las otras dos tercias partes que las pierda el arrendador en el caso que hiciere o consintiere cualquier fraude contra lo contenido en esta dicha mi ordenanza y sea para la mi Cámara. Y que las dichas justicias de los dichos lugares sean tenidos de me lo enviar y envien notificar las penas que de esto juzgaren para la dicha mi Cámara y fisco por que yo lo mande cobrar y mejor sean ejecutadas. $Y$ yo no haga merced de ellas ni puedan ser dadas a persona alguna como susodicho es, más que todavía se cobren para mí. Y que las justicias de la dicha mi Corte y así mismo de las dichas ciudades y villas y lugares, cada uno en su jurisdicción, diputen personas llanas y abonadas ( $f 10 \mathrm{r}$.) que reciban y traigan de manifiesto para mí, y para los mis arrendadores en mi nombre, las penas que fueren juzgadas para la mi Cámara contra los que no guardaren esta dicha mi ordenanza. $Y$ otrosí que las dichas justicias apremien y constriñan a los mercaderes y oficiales y otras personas que acostumbran vender las tales cosas, que las vendan a los precios susodichos y no más ni allende como dicho es. Y asi mismo apremien a los oficiales y menestrales que hagan labrar y den por los precios susodichos y no más ni allende las cosas susodichas, según y por la forma que en esta mi ordenanza se contiene. Y las que ai no están tasadas que las hagan y labren por los precios que fueren tasados por los dichos fieles como susodicho es. Y los unos ni los otros no fagades ende al por alguna manera, so pena de la mi merced y diputación de los oficios y de diez mil maravedís a cada uno para la mi Cámara. $Y$ de más mando al hombre que vos esta mi carta mostrare que vos emplace que parescades ante mi en la mi Corte doquier que yo sea, del día que vos complaciere hasta quince días primeros siguientes so la dicha pena. So la cual mando a cual- quier escribano público que para esto fuere llamado que de 
ende al que vos esta mi carta mostrare testimonio signado con su signo por que yo sepa en como cumplides mi mandado.

Dada en la noble villa de Valladolid, v— días del mes de julio, año del nacimiento del Nuestro Señor Jesucristo — y cuatrocientos y cuarenta y dos años.

Yo el rey, yo el doctor Fernando___ de Toledo, oidor y refrendario del rey y su secretario lo hice escribir por su mandado. Registrada.

Hecho y sacado fue este traslado del dicho cuaderno de ordenanzas original del dicho señor rey, en la noble villa de Valladolid, veinte y tres días del mes de julio, año del nacimiento del Nuestro Señor Jesucristo de mil y cuatrocientos y cuarenta y dos años. Testigos que fueron presentes y vieron y oyeron leer y concertar este dicho traslado con el dicho cuaderno de ordenanzas del dicho señor rey original, Alfonso González de Alcalá, portero de cámara del dicho señor rey y Alvar González de Ciudad Real, escribano del dicho señor rey y Juan de Montalvejo, criado de Juan González de Ciudad Real, escribano de cámara del dicho señor rey.

Va escrito sobre raído do dice noventa y do dice sesenta, do dice setenta, do dice setenta, do dice fustán de olmo, do dice tres maravedís y al, do dice juntas por merced y entre renglones, do dice la pieza de bervi de Flandes por dos mil maravedís, la vara a ochenta maravedís, do dice cuatro, do dice del carro, do dice catorce añores, do dice zapatos de badana engrasados para mozos y pajes de la dicha edad, el par a ocho maravedís y sin grasa siete maravedís, do dice prietos y do dice si y do dice - y do dice según no -

\section{Y yo Juan González de Ciudad Real, escribano (f. 10 v.)}

de cámara de nuestro señor el rey y su notario público en la su Corte y en todos los sus reinos, vi y leí y concerté este dicho traslado con el cuaderno de ordenanzas del dicho señor rey original en presencia de los dichos testigos y va cierto. El cual va escrito en ocho hojas de papel de medio pliego cada una escritas de ambas partes y más ésta en que va mi signo, las cuales van señaladas de mi señal de nombre de partes de ayuso y de arriba, rayadas con tinta y por ende hice aqui el mío signo en testimonio: Juan González.

Hecho y sacado fue este traslado del dicho traslado del dicho cuaderno de las dichas ordenanzas originales del dicho señor rey en la noble villa de Valladolid, a veinte y seis días del mes de julio, año del nacimiento de Nuestro Señor Jesucristo de mil y cuatrocientos y cuarenta y dos años. Testigos que fueron presentes $y$ vieron y oyeron leer $y$ concertar este dicho traslado con el dicho traslado del dicho cuaderno de las dichas ordenanzas del dicho 
señor rey original donde fue sacado: Machín de Tolosa y Machín, su criado, y Pedro González de Valladolid, para esto llamados y rogados.

Escrito sobre raído do dice $y$, y do dice de ellos el mejor y entre renglones do dice de diez vala y no lo empastar.

Y yo Juan Sánchez de Sigüenza, escribano de nuestro señor el rey y su notario público en la su Corte y en todos los sus reinos y señoríos, este dicho traslado del dicho traslado del dicho cuaderno___ ordenanzas originales del dicho señor rey saqué y escribí y lo concerté-_los dichos testigos y va cierto. El cual va escrito en diez hojas de papel con esta en que va mío signo y de yuso de cada plana va señalado de la rúbrica y señal de mi nombre y por ende hice aquí este mío signo a tal, en testimonio de verdad.

Signum

Rúbricas 
cuers

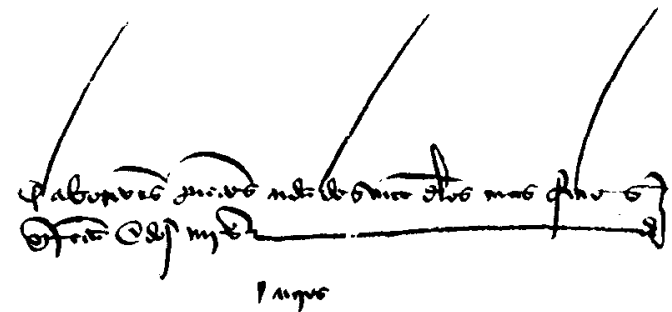

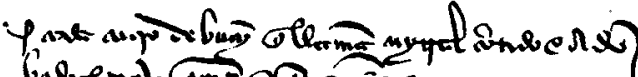

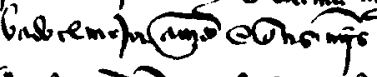

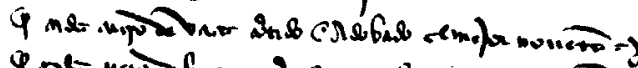

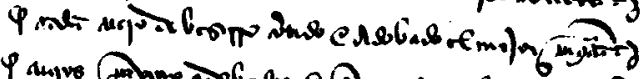

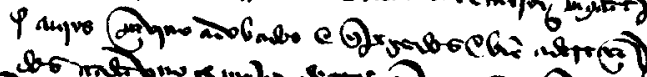

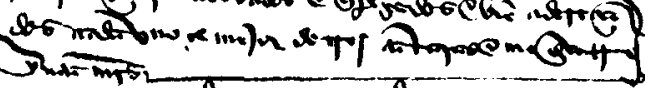

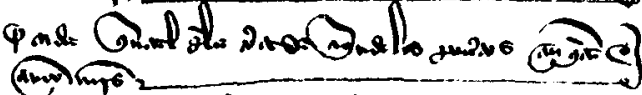

aminge

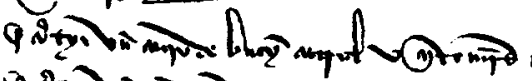

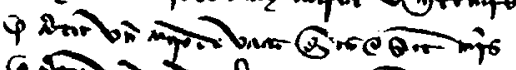

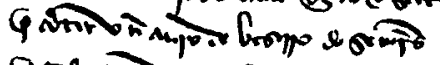

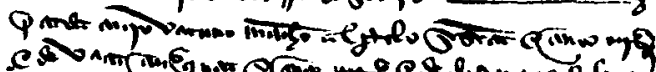

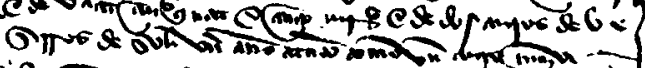

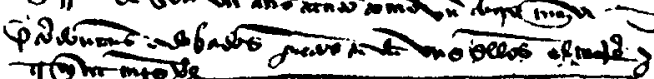

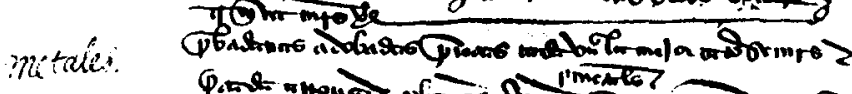

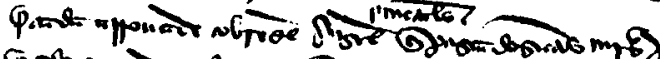

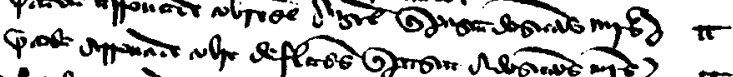

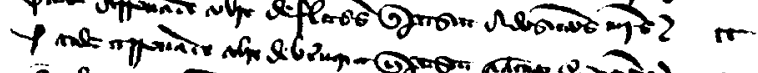

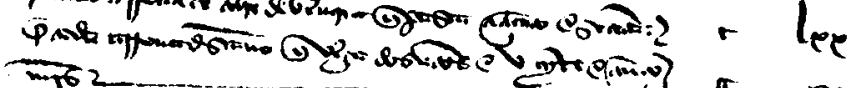

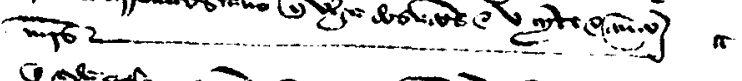

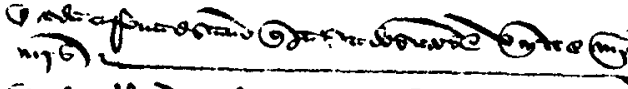

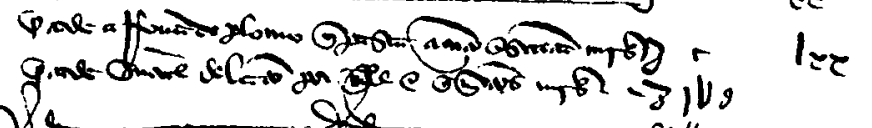

Xi

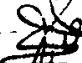

Sity. 
Biblioteca Nacional

Manuscritos, Mss.13.107, pp. 180-192

1442, s.m. s.d. Madrigal.

"Ordenamientos en tiempo de don Juan II, rey de Castilla»

Juan II rectifica en parte el ordenamiento de precios y salarios promulgado en Valladolid el 22 de junio de 1442

Provisión Real. Ordenanzas. Copia. Manuscrito. 12 f.-1 f.r. $24 \times 30$ cms. Papel. Humanística. B.

Contiene título: «LEYES HeCHAS en MAdRigal SOBRe LOS PRECIOS DE LOS PAÑOS, AÑO DE 1442 EN QUE SE CITAN OTRAS ORDENANZAS HECHAS SOBRE EL VALOR DE MONEDAS Y SOBRE PRECIOS DE TODAS LAS COSAS COMERCIABLES»

Don Juan, por la gracia de Dios, rey de Castilla, de León, de Toledo, de Galicia, de Sevilla, de Córdoba, de Murcia, de Jaén, del Algarbe, de Algeciras y señor de Vizcaya y de Molina, a los infantes, duques, condes, ricos hombres, maestres de las órdenes, priores, comendadores, subcomendadores, alcaldes de los castillos y casas fuertes y llanas y a los del mi Consejo e oidores de la mi Audiencia y alcaldes y alguaciles y notarios y otras justicias de la mi Casa y Corte y Chancillería y al concejo, alcaldes, merinos y regidores, caballeros, escuderos y hombres buenos de la muy noble ciudad de Burgos, cabeza de Castilla, mi Cámara, y a todos los otros concejos, alcaldes, merinos, alguaciles, caballeros y escuderos, regidores y oficiales y hombres buenos de todas las ciudades y villas y lugares de todos los mis reinos y señoríos y a otros cualesquier de fuera de mis reinos que a ellos vinieren a comprar y a vender en cualquier manera de cualquier estado y condición, preeminencia y dignidad que sean y a cualquier o cualesquier de vos a quien esta mi carta fuese mostrada o el traslado de ella signado de nuestro escribano, salud y gracia.

Bien sabéis que yo acatando todas las mercaderías así de paños de oro y de seda y de lana como de todas las otras mercaderías y mantenimientos y estaban y andaban en mis reinos en grandes precios de más de lo que solían valer y valian y de cada día se iban pujando fuera de toda razón y medida y porque se decía que esto era por causa de la moneda de blancas que yo había mandado labrar en los tiempos pasados no ser de tanto valor como la moneda blancas que fue mandada labrar por el rey don Enrique mi padre y mi señor de esclarecida memoria que Dios de eterno paraíso y 
como quier que la dicha moneda que yo así mandé labrar era asaz razonable y se podia bien sostener y tolerar según el verdadero valor de ella, pero considerando que a los reyes pertenece no solamente tener en justicia a los sus reinos y naturales, más aunque les conviene considerar y catar remedios para las cosas que son provecho y guarda de ellos y remediar en lo contrario. Por ende yo como rey y señor, pospuesto todo interés y queriendo proveer al bien común de los dichos mis reinos y naturales de ellos y quitar opinión de las gentes, con consejo y acuerdo de la reina doña Maria, mi mujer y del rey don Juan de Navarra, mi muy caro y muy amado primo y del príncipe don Enrique, mi muy caro y muy amado hijo primogénito heredero de los mis reinos y del infante don Enrique, maestre de Santiago, mi muy caro y muy amado primo y de el infante don Fadrique, mi primo y de ciertos condes y prelados y ricos hombres y caballeros y doctores de el mi Consejo, ordené y mandé abajar y reducir la dicha moneda de blancas al valor de la moneda de blancas que el dicho rey mi padre y mi señor hubo y mandó hacer y librar y mandé que tres blancas de las que yo mandé labrar valiese tanto como dos blancas de las que el dicho rey mi padre mandó labrar y que la dicha mi moneda de blancas valiese más del dicho precio en que la yo mandé reducir.

Otrosí reducí y mandé reducir la moneda de oro y plata a ciertos precios, conviene a saber que las doblas castellanas que yo había mandado labrar, valiesen ciento y un maravedís y medio a dar y tomar y que el cambiador la tomase a ciento maravedís y uno y medio y que el florín valiese a sesenta y seis maravedis a dar y tomar y el cambiador diese por ella sesenta y cinco maravedís y los diese por los dichos sesenta y seis maravedís y el marco de la plata quebrada en pasta que valiese quinientos y sesenta maravedis, teniendo que las dichas mercaderías con esto se abajarian y tornarian al estado que debían y se habría respecto a la baja que yo habia mandado hacer en la dicha moneda de oro y de blancas y en plata, no se ha hecho ni hizo así, según la experiencia lo ha mostrado y mostraba de cada día. Por lo cual los procuradores de las ciudades y villas que conmigo estaban, viendo que por lo susodicho el dicho daño no se remediaba, antes de cada día se subian y pujaban las dichas mercaderías y otras cosas, me dieron su petición, el tenor de la cual es este que se sigue:

Muy alto y muy poderoso señor, vuestros servidores los procuradores de las ciudades y villas de vuestros reinos besamos vuestras manos y nos encomendamos en vuestra merced, a la cual suplicamos y bien sabe como hubo ordenado que el marco de plata valiese a quinientos y sesenta maravedís y no más, so ciertas penas contra aquellos que lo no guardaren, lo cual, no embargante, no se halla que platero alguno quiera vender solo un marco de plata, salvo cargando, so color de la hechura de ello, cinco tanto de 
lo que merece y aquello que solía llevar. Otrosí, no embargante, que el oro está en tan bajos precios, según que vuestra alteza sabe, según la ordenanza por vuestra merced hecha, así los paños mayores como lienzos y fustanes y xerga y otras cosas y mercaderías están en tal altos precios y más que al tiempo que valía una dobla ciento y sesenta maravedís y un florín ciento y diez maravedís y así mismo así los sastres como tundidores, jubeteros y zapateros y otros oficiales llevan grandes precios por la hechuras de las ropas y por el calzado y demás y allende de lo que solian llevar y sabrá vuestra merced especialmente los tundidores del tundir llevan de cada vara de paño ocho maravedís y diez y más, no embargante, que do más solian llevar eran tres maravedís y dende abajo y si en esto no se remediase redundaría en gran deservicio de vuestra alteza y en gran daño así a los que andan en vuestra Corte, como a los otros que andan en vuestros reinos. Por ende suplicamos a vuestra alteza que mande poner tasa en los fardeles de paños mayores, así ypres como londres y brujas y velartes y cestres y contrays y de los otros paños y en la pieza de paño menor, por consiguiente en cada vara de los dichos paños y en las lanas y lienzos y cera y herraje y en las otras cosas que menester fueren y que se guarde así en vuestra Corte y en las ciudades y villas de vuestros reinos, lo que se haga so grandes penas, las cuales sean ejecutadas en aquellos que lo no guardaren y contra ello fueren, por que así cumple a vuestro servicio y a bien de vuestros reinos.

$\mathrm{Y}$ yo viendo que lo contenido en la dicha petición era cumplidero a mi servicio y a pro y bien común de los dichos mis reinos y queriendo proveer y proveyendo en ello, con consejo de los señores dichos, hice y ordené cierta ordenanza tasando y poniendo precio a los paños y mercaderías y otras cosas contenidas en la dicha ordenanza, la cual yo mandé publicar y guardar en la mi Corte y en las ciudades y villas y lugares de los mis reinos y mandeles dar sobre ello ciertas mis cartas firmadas de mi nombre y selladas con mi sello que fueron enviadas a algunas ciudades y villas de mis reinos, después de lo cual algunos mercaderes y oficiales y otras personas, así de Corte como de fuera de ella, se me quejaron diciendo que los precios tasados en dicha mi ordenanza eran bajos, según los precios a que ellos habían comprado y valían los dichos paños y otras mercaderías y que si por aquellos precios los hubiesen a dar que se perderian y que así mismo que los dichos oficiales y menestrales no podrían mantener en los oficios y menesteres en que trataban si hubiesen a pasar en los precios tasados en la dicha mi ordenanza, por lo cual habían de cesar de trocar las dichas mercaderías y oficios y me pidieron por merced que mandase sobre ello proveer, mandando revocar los dichos precios y tasas contenidas en la dicha mi ordenanza y los moderar y acrecentar por tal manera que ellos pudiesen tratar las dichas mercaderías y oficios y no se perdiesen en ellas. 
Lo cual todo yo mandé ver y visto y habida información con algunos mercaderes, asi naturales de mis reinos, como extranjeros y otras personas y oficiales de los oficios y menesteres que en esta mi ordenanza adelante se hizo mención, sobre juramento que sobre ello hicieron, así de lo que costaban las dichas mercaderías en Flandes y en otras partes fuera de mis reinos y en los dichos mis reinos y de los derechos que pagaban y cosas que sobre ello hacían, como de los precios que en los tiempos pasados valian y habido respeto y consideración a lo que se abajó el valor del dicho oro y plata y moneda de blancas que yo así mandé labrar y queriendo remediar y proveer al bien propio de los dichos mis reinos y a los dichos mercaderes y oficiales, con consejo de los dichos reina, mi mujer y rey don Juan de Navarra, mi primo y de los prelados y caballeros y doctores de el mi Consejo que conmigo estaban, mandé moderar y abajar algunos de los precios y cosas en la dicha ordenanza contenidas y añadí de acrecentar otras cosas y precios de ellas que en la dicha mi ordenanza no se contenían, por manera que los mercaderes, así los que traen las mercaderías fuera de mis reinos, como los que de ellos compraren y los otros que tratan en mis reinos las dichas mercaderías y otras cosas, hayan en ellas ganancia convenible y los oficiales y otras personas que en la dicha ordenanza se hace mención se puedan mantener razonablemente en sus oficios y menesteres en que tratan y por cuanto en las ferias que se hacen en la villa de Medina del Campo en cada año se compran y venden paños de oro y de seda y de lana y plata y joyas y lienzos y especieria y mercería y pelletería y otras muchas mercaderias y cosas que son necesarias para provisión y mantenimiento de las gentes y de las dichas ferias se reparten las dichas mercaderías para las más de las ciudades $y$ villas y lugares de mis reinos y de los precios y valor que en las dichas ferias se venden y compran las dichas mercaderias se toma regla y orden en los precios de las mercaderías y otras cosas que se venden y compran en las dichas ciudades y villas y lugares de los dichos mis reinos, por ende habida la dicha consideración, es mi merced y mando y ordeno, lo cual quiero que haya fuerza y vigor de ley, que los paños de seda y de lana y mercaderías y otras cosas que en esta mi ordenanza serán contenidas, valgan y se vendan y compren y traten en la feria de la dicha villa de Medina primera que vendrá, que será en el mes de octubre primero que viene de este año presente, $y$ dende adelante en la dicha villa de Medina y en las otras ferias y en todas las ciudades y villas y lugares de los mis reinos y señoríos con los precios y cuantías en esta mi ordenanza declaradas y especificadas y no más ni allende, salvo en la muy noble ciudad de Sevilla y en los lugares de los puertos de la costa de la mar y en otros lugares donde se labran y hacen los dichos paños, que es mi merced que se abajen de los dichos precios las costas que se pueden hacer en traer las mercaderías a la dicha villa de Medina y los diezmos y almojarifazgos y portazgos y otras cosas y derechos que se 
hacen y pagan en las sacar de los dichos lugares puertos hasta ser puestas en la dicha villa de Medina, lo cual mando y es mi merced que sea moderado y tasado por los que fueren diputados en las dichas ciudades, villas y lugares para tasar y moderar las mercaderías que en esta mi ordenanza van tasadas y que se descarguen de ellas los derechos y almojarifazgos y portazgos y costas a vista y ordenanza de los dichos tasadores, los cuales dichos precios en que yo así mandé moderar y tasar las dichas mercaderías y otras cosas son estas que se siguen:

A la pieza de la escarlata de Florencia de grana colorada, por once mil maravedis y cada vara del dicho paño a trescientos y sesenta maravedís.

La pieza de la escarlata de Mellinas, el más fino por diez mil maravedís y cada vara del dicho paño a trescientos y cincuenta maravedís.

La pieza de la escarlata de Londres de esta ciudad, la más fina por doce mil maravedís y cada vara del dicho paño a cuatrocientos maravedis.

La pieza de escarlata de Ypre , la más fina por cinco mil y quinientos maravedís y cada vara del dicho paño a doscientos y veinte maravedís.

La pieza de la escarlata de Mostrebiller, el más fino por doce mil maravedís y cada vara del dicho paño a cuatrocientos maravedís.

La pieza del velarte de Melinas, el más fino seis mil maravedis y cada vara del dicho paño por doscientos y cuarenta maravedís.

La pieza del clusequín de Mellinas, el más fino a tres mil y cuatrocientos maravedis y la vara del dicho paño a ciento y treinta y dos maravedís.

La pieza del velarte del verrio mayor, el más fino cinco mil maravedis y la vara del dicho paño a doscientos y cuatro maravedís.

La pieza del velarte del contray mayor, el más fino por cuatro mil y quinientos maravedís y cada vara del dicho paño a doscientos y ochenta maravedís.

La pieza del paño de florentín, lo más fino por siete mil maravedís y cada vara del dicho paño a doscientos y noventa maravedís y otro florentín que no fuere de la suerte mayor, la vara de él a ciento y cincuenta maravedís.

La pieza del mostreviller negro y pardillo, el más fino a cinco mil maravedís y la vara del dicho paño a doscientos maravedís.

La pieza de mellinas mediano, el más fino a tres mil maravedis y la vara del dicho paño a ciento y veinte maravedís.

La pieza de verria clusequín entrefino por tres mil y trescientos maravedís y cada vara del dicho paño a ciento y treinta y cinco maravedis.

La pieza de la verria menor fina, por dos mil y seiscientos y cincuenta maravedis y cada vara del dicho paño a ciento y diez maravedís.

El fardel de Brujas de abantaja en que haya dos pardillos gutuses y los otros dos paños ferreles o verdes o de otras colores, catorce mil maravedís y la vara de las dichas brujas pardillas a ciento y cincuenta maravedis y de los otros colores a ciento y veinte maravedís. 
La pieza de las dichas brujas pardillas, a tres mil y ochocientos maravedís y la pieza de las otras colores a tres mil y trescientos maravedís.

El fardel de ypres mayores finos que no sean retarados ni desorejados, que haya en ellos dos prietos y otros dos de colores, por precio de doce mil maravedís.

La pieza del ypre negro, a tres mil y ciento y cincuenta maravedís y la pieza del ypre de otra color a dos mil y ochocientos y cincuenta maravedís y cada vara del dicho paño de ypre mayor prieto a ciento y treinta maravedís y cada vara de ypre de otra color a ciento y veinte maravedís.

Brujas de suelte, el más fino la pieza a dos mil maravedís y la vara de él a ochenta maravedís.

Fardel de ypres menores que haya un presado y dos violetes y un colorado, por diez mil maravedis y cada vara del presado a noventa y cinco maravedís y de los violetes a ochenta maravedis y de lo colorado a sesenta y seis maravedis.

La pieza del contray, por dos mil maravedís y cada vara del dicho paño por ochenta maravedís.

La pieza del celestre fino, por dos mil y ochocientos y cincuenta maravedis y cada vara del dicho paño a ciento y doce maravedis y que el vendedor que los tales paños vendiere no sea tenido de demandar en florines ni el comprador de se los dar.

La pieza del bervi de Flandes de tres sellos, por dos mil maravedís y cada vara del dicho paño a ochenta maravedís.

Londres de la ciudad, lo más fino cada vara del dicho paño a doscientos maravedís y dende abajo sea tasado por los fieles, cada uno según merece.

La pieza del paño fino de Londres, por tres mil y quinientos maravedís y cada vara del dicho paño por ciento y cuarenta maravedís.

La pieza de san Juan deciocheno, por mil y novecientos y sesenta maravedis y cada vara del dicho paño a setenta maravedís y que el vendedor no sea tenido de demandar los dichos florines ni el comprador de se los dar, como dicho es.

La pieza de san Juan dioceceno, por mil y seiscientos y sesenta maravedís y cada vara del dicho paño a sesenta y cinco maravedís.

La pieza del urebi de Valencia, el más fino enrosado o pardillo, por mil y quinientos y sesenta maravedís y cada vara del dicho paño a sesenta y dos maravedís.

Paños pardillos de Zaragoza y de otros semejantes que sean de la dicha ciudad, cada pieza por mil maravedís y la vara del dicho paño a cuarenta y dos maravedis.

La pieza de paño pardillo o mezcla o verde o azul, salido de Segovia, por novecientos maravedís y la vara del dicho paño por treinta y siete maravedis.

La pieza del pardillo fino de Valladolid, por mil maravedis y cada vara del dicho paño por treinta maravedís. 
La pieza de otros pardillos de Valladolid que no sean tan finos, por setecientos maravedis y cada vara del dicho paño por treinta maravedís.

La vara del paño de Palencia, lo más fino blanco ocho leguas fuera de la dicha ciudad de Palencia a cuarenta y cinco maravedís y lo otro que no es tan fino a treinta y cinco maravedís.

Otrosí es mi merced y mando que en la mi Corte y en todas las ciudades y villas y lugares de los mis reinos, sean puestas dos personas buenas y de buena fama para tasar y ver todas las dichas cosas y les sean tomado juramento que guardarán, cumplirán y harán guardar y cumplir esta mi ordenanza y todo lo que en ella se contiene, bien y fiel y lealmente y que los tales fieles y tasadores no cohecharán ni llevarán por causa de la dicha tasa cosa alguna, salvo el salario que les fuere señalado por las ciudades y villas y los que lo contrario hicieren pierdan los bienes y sean por el mismo hecho confiscados y aplicados para la mi Cámara y demás que le sea dada pena, la cual en tal caso se requiere por derecho y las ciudades y villas y lugares que las cosas contenidas en esta mi ordenanza suelen valer más barato y a menor precios de los que suso en esta mi ordenanza se contiene, que los dichos fieles y tasadores puedan poner y tasar y pongan y tasen a los precios convenibles que entiendan que se deban poner y tasar, no embargante los precios en esta mi ordenanza contenidos, pero que los mayores precios que pasaren no puedan pasar ni pasen de más ni allende de los contenidos en esta mi ordenanza.

Lo cual todo susodicho y cada cosa y parte de ello es mi merced y mando y ordeno que se use y haga guardar y cumplir, así en la mi Corte y en todas las otras ciudades y villas y lugares de los dichos mis reinos y señoríos, asi realengos como abadengos y órdenes y behetrias y señoríos y otros cualesquier como susodicho es y que desde el día que esta mi carta y ordenanza fuere mostrada y publicada en la dicha mi Corte y en estas dichas ciudades y villas y lugares hasta diez días primeros siguientes en adelante use y guarde y cumpla todo y cada parte de ello, así según y por la forma y manera que susodicho es.

Por que vos mando a todos y a cada uno de vos en vuestros lugares y jurisdicciones que lo guardades y cumplades y ejecutades y hagades guardar y cumplir y ejecutar, según y como dicho es y que lo hagades así pregonar por las plazas y mercados y otros lugares acostumbrados de la dicha mi Corte y de todas las dichas ciudades y villas y lugares de los dichos mis reinos y señoríos por pregonero y ante nosotros por que venga a noticia de todos y de ello no puedan pretender ignorancia. $Y$ que ninguna ni algunas personas de cualquier estado o condición, preeminencia, dignidad que sean no vayan ni pasen ni consientan ir ni pasar contra ello ni contra cosa 
alguna ni parte en algún tiempo ni por alguna manera, causa o razón que sea o pueda ser, porque asi es cumplidero a mi servicio y a provecho y bien común de los dichos mis reinos y señoríos. Y si alguna o algunas personas fueren o pasaren contra ello o cosa alguna o parte de ello que aquellos que pasaren contra ello o contra algo de lo susodicho fueren o vinieren, paguen la estimación de la cosa que asi vendieren y por la segunda vez el dos tanto y por la tercera el tres tanto y dende en adelante, por cada vez que suba en esta misma forma en cuatro tanto y cinco tanto y dende arriba, que las tales penas sean las dos tercias partes para la mi Cámara y la otra tercia para el acusador que lo acusare y que las otras dos tercias partes que son para la mi Cámara que sean arrendadas y se arrienden para mi y que yo no pueda hacer ni haga merced de ellas a persona alguna y si hiciere la tal merced que haya sido y sea por el mismo hecho y por ese mismo derecho ninguna y de ningún valor y habida por obrreticia y ganada por importunidad, no embargante que diga procede de mi cierta ciencia y propio motu y poderío real absoluto, aunque contenga cualesquier cláusulas derogatorias y otras firmezas. Y demás que el que la impetrare, por el mismo hecho allende de lo susodicho, pague otro tanto en pena para la mi Cámara y no pueda ser ni sea habido por parte ni recibido en juicio ni fuera de juicio para la demandar ni recurrir ni litigar sobre ello, aunque haga mención especial de esta mi ordenanza. $Y$ que el arrendador que así arrendare las dos tercias partes de la dicha mi Cámara sea tenido de los acusar dentro en tercero dia y si no lo acusare o hiciere en ello algún fraude que dende en adelante cualquier del pueblo lo pueda acusar y haya para sí la dicha tercia parte y las otras dos tercias partes que queden para la dicha mi Cámara. Y por cuanto en esta mi ordenanza no van declaradas y especificadas todas las otras cosas en que deben ser puestos precios de más y allende de las aquí contenidas, por ende es mi merced y mando que en cada una ciudad o villa o lugar de los dichos mis reinos se ponga precio convenible a cada una cosa de las que son especificadas, tasándolo todo razonablemente, habiendo respeto y acatamiento a las tierras y lugares y comarcas y al valor que el oro solía valer antes que se labrare la dicha moneda nueva que yo mandé labrar en los dichos mis reinos, acrecentando el tal precio y al respecto del cuarto más, según que acrecenté y mandé acrecentar en el valor del oro este dicho año de la data de esta mi carta. $Y$ esto en aquellas cosas que razonablemente se deben acrecentar. $Y$ que en la dicha mi Corte los dichos mis alcaldes de ella y en cada una de las dichas ciudades y villas y lugares, los concejos y justicias y oficiales por ellas pongan fieles y buenas personas juramentadas, las cuales sean tenidas de nombrar y nombren desde el dicho día de la publicación de esta mi ordenanza hasta diez días primeros siguientes. $Y$ que los tales fieles asi nombrados hagan juramento en forma debida de lo hacer y tasar $y$ tasen bien y leal y conveniblemente, pospuesta 
toda afición y odio e interés y toda otra cosa que embargar pueda al bien común. $Y$ que los tales dichos oficiales pongan y tasen los dichos precios y todas las otras dichas cosas que en esta dicha mi ordenanza se hace mención. Y aquello se guarde y cumpla so las penas susodichas y que las justicias de la dicha mi Corte y así mismo de las ciudades y villas y lugares de los dichos mis reinos y señoríos lo hagan guardar y cumplir y ejecutar, cada uno en su jurisdicción, según y por la forma y manera y so las penas que en esta dicha mi ordenanza se contiene. $Y$ asi mismo según que los dichos fieles lo hicieren y tasaren y moderaren en las cosas que suso en esta mi ordenanza no va tasado ni moderado. $Y$ que conozcan de todo ello y lo libren y determinen y ejecuten todos simplemente y de plano, sin estrépito y figura de juicio, solamente sabida la verdad, no dando lugar a luengas de malicia, más abreviando lo más que ser pueda. Y que el arrendador que así arrendare las dichas penas ni pueda permitir ni dar lugar que persona ni personas vayan contra esta dicha mi ordenanza ni contra alguna cosa de lo en ella contenido ni contra parte de ello. $Y$ que si lo hiciere que sin embargo de ello cualquier del pueblo lo pueda acusar como susodicho es y haya para sí la tercia parte de las dichas penas y las otras dos tercias partes que las pierda el arrendador en el caso que hiciere o consintiere cualquier fraude contra lo contenido en esta mi ordenanza. $Y$ que las dichas justicias de los dichos lugares sean tenidos de me enviar y envien notificar las penas que de esto juzgaren para la mi Cámara y fisco porque las yo mande cobrar y mejor sean ejecutadas. Y que yo no haga merced de ellas ni puedan ser dadas a persona alguna como susodicho es, más que todavia se cobren para mí. Y que las justicias de la dicha mi Corte, así mismo las de las dichas ciudades y villas y lugares, cada uno en su jurisdicción, diputen personas llanas y abonadas que reciban y tengan de manifiesto para mi y para los arrendadores en mi nombre, las penas que fueren juzgadas para la mi Cámara contra los que no guardaren esta dicha mi ordenanza. $Y$ otrosi que las dichas ciudades y justicias de ellas apremien y constriñan a los mercaderes y oficiales y otras personas que acostumbran vender las tales cosas que las vendan a los precios susodichos.

Concuerda con igual copia que comprende seis hojas útiles del mismo papel de marca y libro citado de esta iglesia catedral de Córdoba, sacado de un archivo a este fin con las propias solemnidades de que certifico en ella a 27 de febrero de 1753 años. Licenciado don José Vázquez Verregas. 